Portland State University

PDXScholar

Spring 5-24-2016

\title{
An Investigation of Invasion: Boater Knowledge Concerning Aquatic Invasive Species and the Influence of the New Zealand Mud Snail on Benthic Food Webs
}

Samuel Anthony Cimino

Portland State University

Follow this and additional works at: https://pdxscholar.library.pdx.edu/open_access_etds

Part of the Environmental Sciences Commons

Let us know how access to this document benefits you.

\section{Recommended Citation}

Cimino, Samuel Anthony, "An Investigation of Invasion: Boater Knowledge Concerning Aquatic Invasive Species and the Influence of the New Zealand Mud Snail on Benthic Food Webs" (2016). Dissertations and Theses. Paper 2992.

https://doi.org/10.15760/etd.2993

This Thesis is brought to you for free and open access. It has been accepted for inclusion in Dissertations and Theses by an authorized administrator of PDXScholar. Please contact us if we can make this document more accessible: pdxscholar@pdx.edu. 
An Investigation of Invasion: Boater Knowledge Concerning Aquatic Invasive Species and the Influence of the New Zealand Mud Snail On Benthic Food Webs

by

Samuel Anthony Cimino

A thesis submitted in partial fulfillment of the requirements for the degree of

Master of Science

in

Environmental Science and Management

Thesis Committee:

Angela Strecker, Chair

Valance Brenneis

Ian Waite

Portland State University

2016 
C 2016 Samuel Anthony Cimino 


\begin{abstract}
Invasive species are second only to habitat loss as a leading cause of native species displacement and the management of invasive species costs hundreds of billions annually. Invasion is often conceptualized as a series of stages (Transport, Introduction, Establishment, and Spread), which encourages ecologists to isolate factors that might enable a species to pass from one stage to another and therefore guide prevention or impact management. This thesis addresses each stage of invasion and attempts to determine where management might succeed in preventing invasion or minimizing impacts. The transport and introduction of aquatic invasive species (AIS) was analyzed by conducting a three tier human subjects survey at Tenmile Lake, Oregon over a two year period in which a public boat wash station was built and installed. Assessing boater knowledge of AIS and understanding proper boat cleaning procedure is useful in determining the threat of transport and introduction as overland boater movements is a major vector of AIS. The comparison between pre- and post- boat wash surveys indicate that there is a disconnect between what boaters say they will do and how they actually behave. While $75.9 \%$ of boaters from the pre-survey claimed they would use a boat wash station at Tenmile Lake, only $38.5 \%$ of post-survey boaters were observed using the station. Furthermore, the surveys identified knowledge gaps of boater's awareness of AIS. More than $20.0 \%$ of boaters surveyed could not verbally name any AIS. To better understand the establishment and spread stages of invasion, I examined the influence of a specific AIS, the New Zealand mud snail (Potamopyrgus antipodarum; NZMS), on benthic food webs throughout three very different aquatic ecosystems (lakes, rivers, and
\end{abstract}


estuaries). Samples of benthic lake, river, and estuarine invertebrates were collected, identified, and counted, and stable isotope analyses (SIA) were conducted on several components of the food web. NZMS densities were found to be dynamic, with population densities fluctuating over time and between locations. A significant negative relationship between NZMS density and community diversity across all ecosystems was found. However, the densities of specific feeding groups had varying positive (omnivores) and negative (herbivores) correlations with NZMS densities. Furthermore, SIA indicated that NZMS don't appear to be competing with native macroinvertebrates for the same food source. NZMS were found to have different influences on each invaded ecosystem, thus management of this particular AIS is difficult once established and spreading. The results of this thesis suggest that prevention of the transport and introduction of NZMS needs to be the focus for future management. Preventative management should include public outreach regarding AIS and proper boat cleaning procedure, and management should also emphasize the need for regional policies and regulations on the transport of AIS rather than site or state specific policies and regulations. 


\section{Acknowledgements}

None of this work would have been possible without the help and support of the Strecker Aquatic Ecology Lab: Angela Strecker, Jeff Brittain, Meredith Jordan, Tim Elder, Ari Chiapella, Amelia Johnson, and Brian McGann at Portland State University; my lab and field assistants Jared Anderson, Katrina Dunn, and Kristine Hopkins for all of their hours of hard work. Feedback from Ian Waite and Valance Brenneis as well as data shared by Valance Brenneis and her quantitative sampling methods were extremely beneficial and essential to the execution of this research. Statistical feedback and guidance from Pat Edwards and Yangdong Pan was also essential to this study. A huge thank you to Mike Mader, Richard Litts, and the City of Lakeside for assisting me in my research and letting me use their facilities. Also, a big thank you to Glenn Dolphin of the OSMB and Sam Chan of OSU for providing me with the statistics of a similar boater survey to compare with my survey results. A thank you to the UC Davis Stable Isotope Facility for processing my samples for stable isotope analysis. This study was made possible with funding from the Oregon State Marine Board, Portland State University, and the Center for Lakes and Reservoirs. Samples were taken under NOAA Scientific Taking Permit \#17879. Finally, I would like to thank my friends and family for all of their support, love, and room and board. 


\section{Table of Contents}

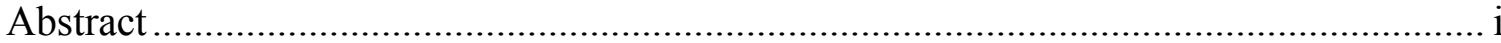

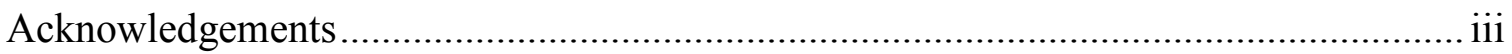

List of Tables ................................................................................................... vii

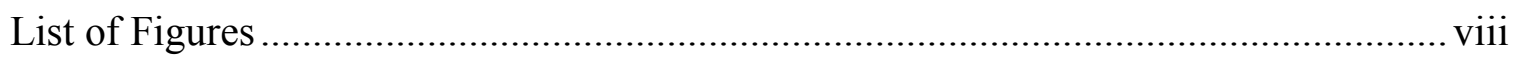

Chapter 1: Background on vectors, establishment, effects, and prevention of aquatic

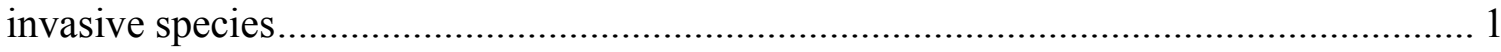

Transport and Introduction of Aquatic Invasive Species (AIS) ............................. 1

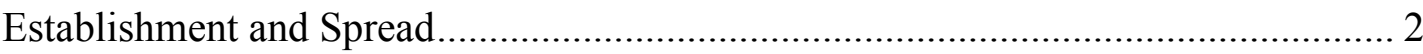

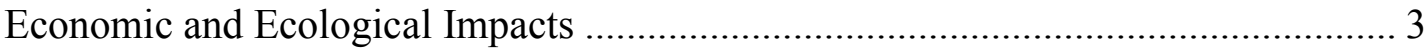

Methods for Studying Introductions and Impacts ........................................... 5

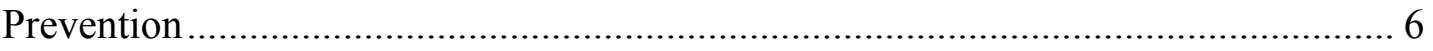

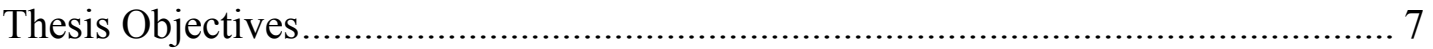

Chapter 2: Developing an understanding of boater's knowledge concerning aquatic invasive species and proper boat cleaning procedure ............................................... 9

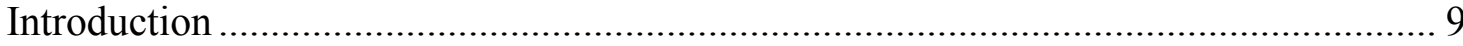

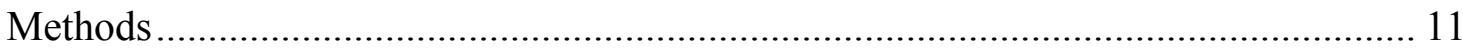

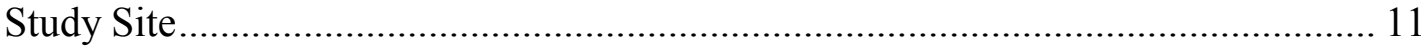

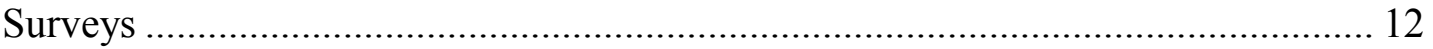

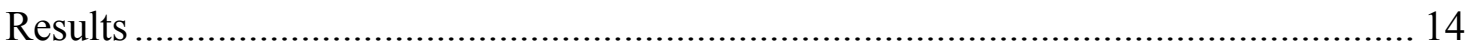

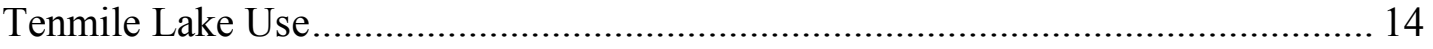

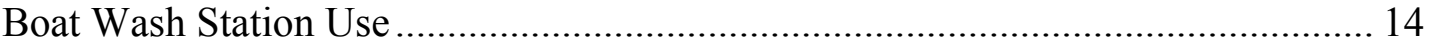

Knowledge of Aquatic Invasive Species and Relevant Regulations ....................... 15

Awareness of Educational Outreach................................................................. 16

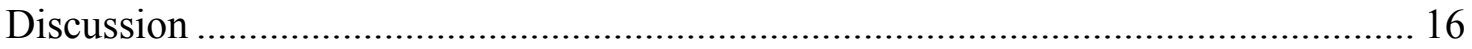

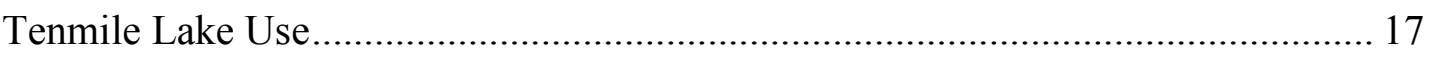

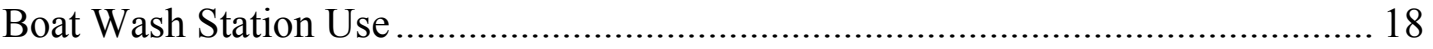

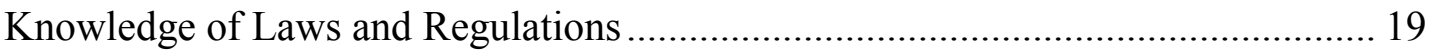

Awareness of Educational Outreach................................................................... 20

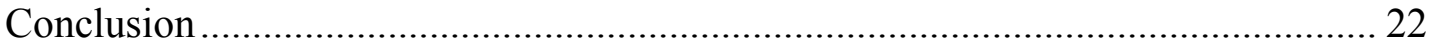

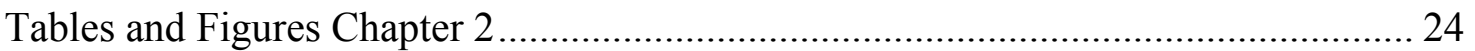


Chapter 3: The influence of New Zealand mud snail in benthic freshwater and brackish water ecosystems in the Pacific Northwest................................................................. 29

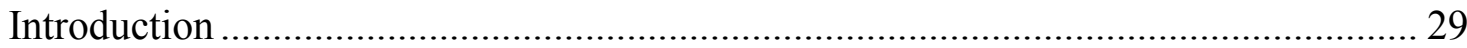

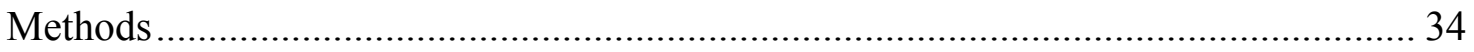

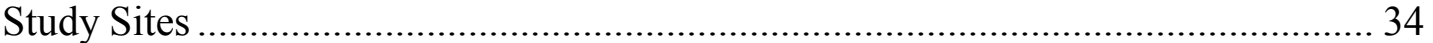

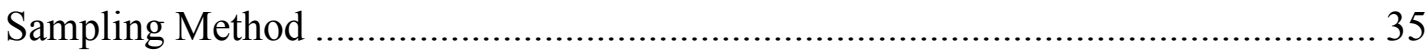

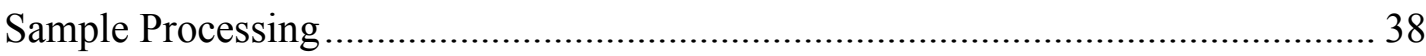

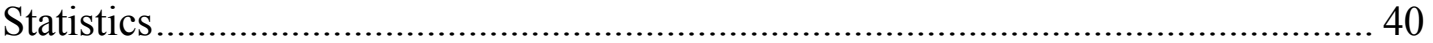

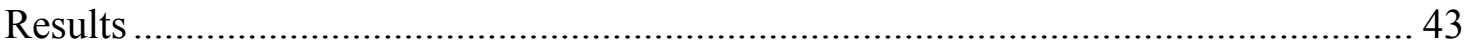

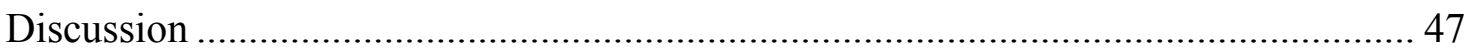

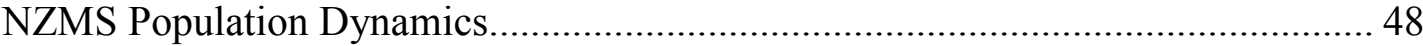

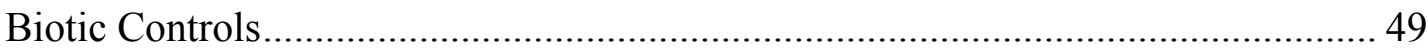

Abiotic and Human-Mediated Controls ............................................................ 50

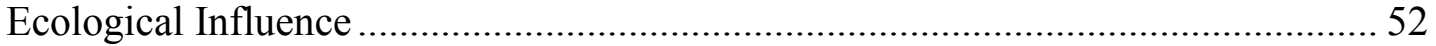

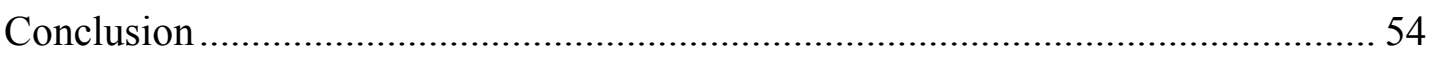

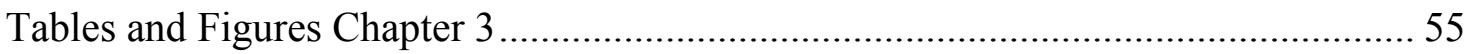

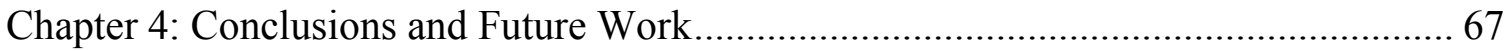

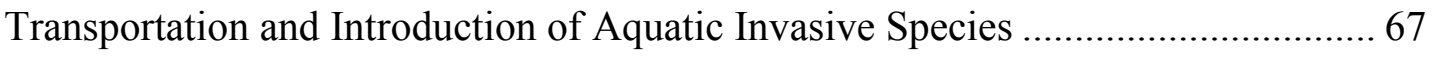

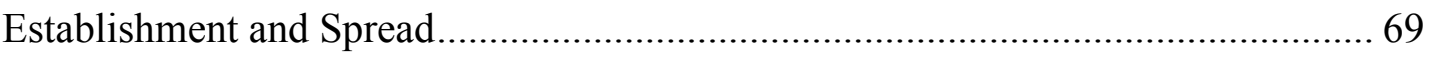

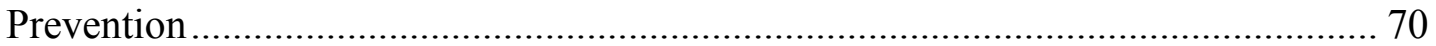

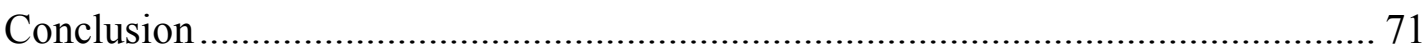

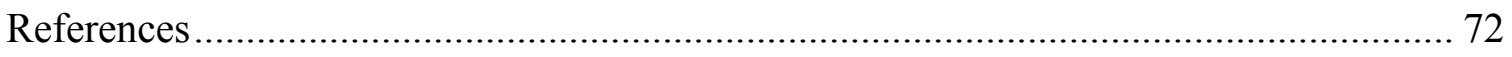

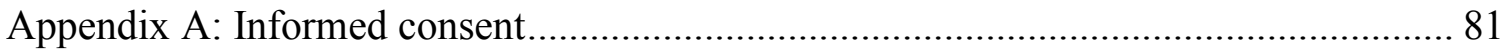

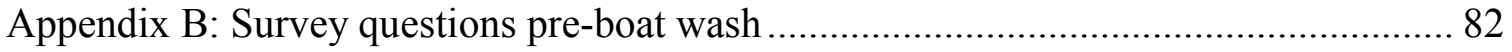

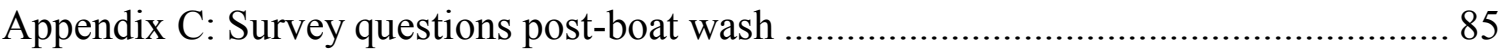

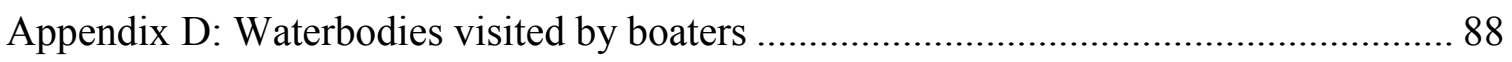

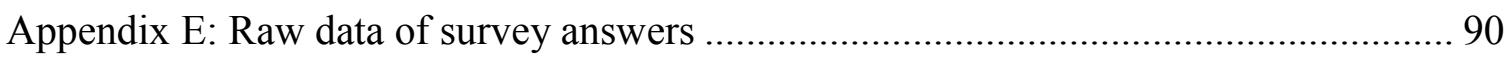

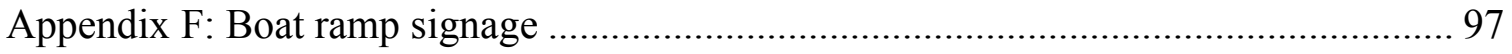

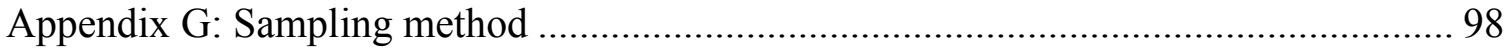

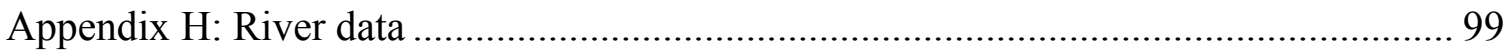

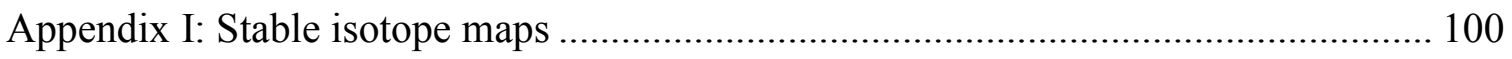


Appendix J: Convex hulls depicting feeding ranges............................................... 105

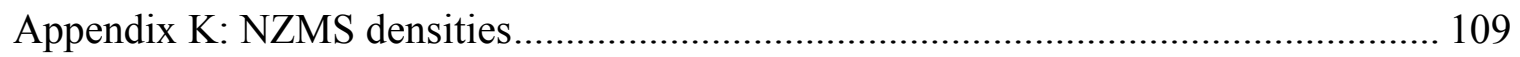




\section{List of Tables}

Chapter 2:

Table 2.1: The percentage of boaters surveyed aware of Oregon State laws and regulations regarding aquatic invasive species.

Chapter 3:

Table 3.1. Sampling design for New Zealand mud snails (NZMS) and benthic invertebrate surveys from 2006 to 2013.

Table 3.2. The median, minimum, maximum, and standard deviation of abiotic variables in the freshwater coastal lakes, freshwater rivers, and brackish estuaries sampled through the extent of the research. 


\section{List of Figures}

Chapter 2:

Figure 2.1: The number of days since the surveyed participant last put their boat in a waterbody from the pre-boat wash data collected in $2012(\mathrm{n}=199)$ and post-boat wash data collected in $2013(\mathrm{n}=200)$.

Figure 2.2: The road distance of water bodies (kilometers) surveyed boaters last came from. Symbols as in Figure 2.1.

Figure 2.3: The percentage of boaters claiming they would use a boat wash station in the pre-boat wash survey, and the percentage of boaters who were observed using the boat wash station in the post-boat wash survey.

Figure 2.4: The percentage of boaters surveyed who named specific aquatic invasive species when asked what aquatic invasive species they were aware of. Symbols as in Figure

2.1 . 28

\section{Chapter 3:}

Figure 3.1. A relief map of Oregon, USA depicting the New Zealand mud snail sampling locations and the type of waterbody for each location.

Figure 3.2. The average $\log _{10}$ New Zealand mud snail (NZMS) density (individuals $\cdot \mathrm{m}^{-2}$ ) at each of the sites tested from 2006-2013 ( \pm 1 standard error). Only the Umpqua downstream and Siuslaw downstream river sites were sampled in the winter of 2013. Deschutes downstream, Umpqua upstream, Siuslaw upstream, and the John Day River upstream and downstream were not included in this graph due to absence or near absence of NZMS at every sampling period.

Figure 3.3. Boxplots depicting the range of $\log _{10}$ New Zealand mud snail (NZMS) density (individuals $\cdot \mathrm{m}^{-2}$ ) in estuaries $(\mathrm{n}=7)$, lakes $(\mathrm{n}=4)$, and rivers $(\mathrm{n}=7)$ including all samples and all sampling periods. Only sites with NZMS present were included in the boxplots. The center line of each box represents the median NZMS density in that ecosystem. The lower reach of the box represents the lower quartile and the upper reach of the box represents the upper quartile. The whiskers of the boxplots represent variability outside the upper and lower quartile within the $5^{\text {th }}$ and $95^{\text {th }}$ percentile range, with the black symbol representing an outlier $\left(>95^{\text {th }}\right.$ percentile). Letters represent the results of Tukey HSD post hoc tests, where different letters are significantly different from each other $(\mathrm{p}<0.05)$.

Figure 3.4. A correlation $(r=-0.476)$ of the average log-transformed New Zealand mud 
snails (NZMS) density and average Shannon-Weiner diversity index (H') of every system, at all sampling sites, and throughout the extent of the sampling effort. Rivers are represented by triangles, estuaries are represented by squares, and lakes are represented by circles. Only sites with NZMS present were included.

Figure 3.5. Correlation analyses representing the relationships of average $\log _{10^{-}}$ transformed and scaled to the maximum value (max-scaled) New Zealand mud snails (NZMS) densities and log-transformed, max-scaled densities of specific macroinvertebrate feeding groups: (a) herbivore, (b) detritivore, (c) predator, and (d) omnivore. All sites were included in this analysis. Densities were scaled to the maximum value to visually compare between ecosystems (each site scaled within ecosystem type between $0-1)$.

Figure 3.6. PCA biplot of the (a) all sampling locations and (b) freshwater sampling locations depicting environmental factors recorded at each site PCA biplot of the and $\log _{10}$-transformed New Zealand mud snails (NZMS) densities (individuals $\cdot \mathrm{m}^{-2}$ ) represented by shape size. The size of the shape is related to the density of the NZMS in the system and solid shapes were absent of NZMS in the system. DO = dissolved oxygen, Temp $=$ surface water temperature.

Figure 3.7. Regression trees predicting which variables in all sampling sites influence (a) New Zealand mud snails (NZMS) density and (b) Shannon-Weiner diversity (H') and which variables in just freshwater sites influence (c) New Zealand mud snails (NZMS) density and (d) Shannon-Weiner diversity $\left(H^{\prime}\right) . \quad D O=$ dissolved oxygen, Temp $=$ surface water temperature. Less than $(<)$ independent variable values - the response variables are to the right branch. Greater than $(>)$ independent variable values - the response variables are to the left branch.

Figure 3.8. Box plots depicting the percentage of trophic overlap between New Zealand mud snails (NZMS) feeding range and specific feeding group feeding ranges. The thick, bold line of each box represents the median percentage of overlap between NZMS feeding ranges and the particular feeding group's feeding range. The lower reach of the box represents the lower quartile and the upper reach of the box represents the upper quartile of the overlap. The whiskers of the boxplots represent variability outside the upper and lower quartile within the $5^{\text {th }}$ and $95^{\text {th }}$ percentile range, with the black dots representing outliers $\left(>95^{\text {th }}\right.$ percentile). A y-axis break was created between $\sim 20$ and $\sim 40$ percent overlap.

Figure 3.9. Correlations between feeding range overlap (percentage of NZMS range overlapping other feeding group's range) of specific macroinvertebrate feeding groups (a. herbivores, b. detritivores, c. omnivores, d. predators) and log-transformed New Zealand mud snails (NZMS) densities. Convex hulls were created to measure feeding range using the stable isotope signatures $\left(\delta^{15} \mathrm{~N}\right.$ and $\left.\delta^{13} \mathrm{C}\right)$ of taxon and then the hulls were measured for total area. Each point represents the amount of overlap of convex hulls between 
NZMS feeding range and another feeding group's feeding range at the same sampling location. The location's ecosystem is represented by a circle (lake), triangle (river), and square (estuary). No herbivores were sampled from the estuaries thus only feeding range overlaps and NZMS densities from lakes and rivers are present in the correlation.

Figure 3.10. Correlation between feeding range (total area of convex hulls, max-scaled) of New Zealand mud snails (NZMS) and $\log _{10}$-transformed NZMS densities. Convex hulls were created to measure feeding range using the stable isotope signatures $\left(\delta^{15} \mathrm{~N}\right.$ and $\delta^{13} \mathrm{C}$ ) of NZMS and then the hulls were measured for total area. Each point represents an individual convex hull area from a certain location in an identified ecosystem represented by a circle (lake), triangle (river), and square (estuary). 


\section{Chapter 1: Background on vectors, establishment, effects, and prevention of aquatic invasive species}

Since humans have had the ability to travel across continents and over oceans, they have facilitated the expansion of species' geographic boundaries via introductions for sport and fishing, the domestication of animals and plants, and accidental transport (Lodge et al. 2006, Loo et al. 2007a). The introduction of species that are not native to a region can lead to novel selection pressures that have not previously been observed (Mooney and Cleland 2001). Some systems are more vulnerable to invasion as the result of anthropogenic influences like land use change, as well as the invasibility of the introduced species and the resilience of the native species. Risk analysis for an ecosystem requires information on the invading species, vulnerability of habitats to invasion, modeled information on current and potential distributions, and the costs (ecological and economic) associated with containing (or failing to contain) harmful species (Stohlgren and Schnase 2006, Lodge et al. 2006). Invasion is often conceptualized as a series of stages, which encourages ecologists to conceive factors that might enable a species to pass from one stage to another and therefore guide management (Catford et al. 2009).

\section{Transport and Introduction of Aquatic Invasive Species (AIS)}

Aquatic systems are especially vulnerable to invasion as a result of rapid invasive species spread by means of highly-connected lake and river ecosystems (Kinlan and Gaines 2003, Bobeldyk et al. 2005, Peters and Lodge 2009). Non-native species introductions and rapid dispersal are often exacerbated by a variety of human-influenced drivers of global change, all of which are increasing in frequency including: globalization of commerce, engineering of waterways, land-use changes, climatic changes, and 
fisheries management (Kolar and Lodge 2002). There are multiple vectors with varying degrees of intensity for the introduction of aquatic invasive species. It has been recognized that ballast water from commercial ships is a well-established vector for invasive species introductions (Grigorovich et al. 2003, Endresen et al. 2004). A significant source of aquatic invasions is also likely through the ornamental pet and plant trade by aquarists (Padilla and Williams 2004, Strecker et al. 2011). Chapter 2 of my thesis focuses on overland movement of boaters between waterbodies, which is potentially the greatest pathway for dispersal for most aquatic species (Buchan and Padilla 1999, Johnson et al. 2001, Leung et al. 2006).

\section{Establishment and Spread}

Invasions are dependent both on the receiving environment (the invasibility of the environment and the community) and on the ability of species to reach these new systems (Leung and Mandrak 2007). The probability of establishment of an introduced species increases as the frequency of introduction events and the number of individuals released (propagule pressure) increases (Kolar and Lodge 2001). Propagule pressure also increases with the condition or health of the individuals released and the resiliency of their released life stage (Smith et al. 1999, Lodge et al. 2006). The receiving environment may also facilitate establishment by providing empty niche space or an opportunity window after a disturbance event where the invaders can utilize spare resources (Leppäkoski and Olenin 2000, Paavola et al. 2005, Catford et al. 2009). Once established in a novel ecosystem, invasive species may spread freely without the constraint of their natural predators, competitors, parasites, and diseases that limit their population in its home range (Catford et al. 2009). Interactions like enemy release can facilitate invasions, 
but it is still important for invasive species to be able to adapt quickly to their new environment and be reproductively flexible for successful spread (Kolar and Lodge 2001, Dybdahl and Kane 2005). If an invasive species has established and spread, the only stage managers and ecologists can now address is the harmful impact of the invasive species to the economy and the ecosystem.

\section{Economic and Ecological Impacts}

The expected economic damages associated with non-native invasive species and their control has been estimated at approximately $\$ 120$ billion annually (Pimentel et al. 2005). Much of this sum is attributed to the cost of controlling the density and the spread of these species due to the expectation that economic and ecological damages incurred from inaction are far more costly than preventative measures (Pimentel et al. 2005, Stohlgren and Schnase 2006). The establishment of invasive species is a leading cause of native species endangerment and extinction (Wilcove et al. 1998) and can lead to homogenized genetic and/or functional variation jeopardizing future resilience of biological communities by altering evolutionary trajectories (Olden et al. 2004). Without management, the populations of these invasive species grow and spread so that ecological and economic damages accelerate over time (Lodge et al. 2006).

The influence of invasive species is often variable and dependent on the recipient community. Aquatic invasive predators have been observed to cause significant reductions in specific species as well as significant reductions in community richness, diversity, and abundance (Strecker et al. 2006, Herbst et al. 2009, Dick et al. 2012). Invasive predators not only reduce native populations within a community but they can also lead to extinctions (Rodda et al. 1997, Mooney and Cleland 2001). The influence of 
invasive herbivores on native communities may be less direct but can also be substantial, altering the control of plant resources, thereby exerting bottom-up control on the flows of energy through invaded food webs (Carlsson et al. 2004, Moore et al. 2012). Invasive herbivores have the potential of inserting themselves into ecosystems and causing farreaching consequences.

Although much research focuses on the negative effects of non-native invasions, not all impacts caused by invasive species introduction and establishment are negative. Facilitation of native species by non-native species is common, can occur in a wide range of habitats, and can strengthen native communities (Rodriguez 2006). Facilitative interactions of invasive species on native species can be both direct (habitat modification or trophic subsidy) or indirect (competitive release or predatory release) interactions (Rodriguez 2006). For example, invasive zebra mussel (Dressena polymorpha) colonies have been observed to enhance soft-sediment habitats creating refuge and food for native invertebrates resulting in $700 \%$ more settlement in these mussel colonies than neighboring mussel-free habitats (Bially and Macisaac 2000, Beekey et al. 2004). Similarly, the invasive New Zealand mud snail (Potamopyrgus antipodarum) may facilitate native young instar invertebrates that rely heavily on detritus as a food source, the New Zealand mud snail can improve the quality of available detritus by feeding on it and excreting it in a more digestible form (Schreiber et al. 2002). Thus, the influence of invasive species is often subtle and highly dependent on the invaded community and habitat. 


\section{Methods for Studying Introductions and Impacts}

Studying human behavior can be a valuable tool for determining the risk of an invasion. Understanding the common practices of the communities most likely to disperse AIS (i.e., boaters), as well as their knowledge gaps pertaining to invasive species characteristics and dispersal, is essential for building more comprehensive management plans. Surveys have been valuable in identifying the vectors for invasive species dispersal and the knowledge gaps of the community regarding ecosystem health (Pergams and Zaradic 2008, Rothlisberger et al. 2010).

In addition to understanding the propagule pressure of an invasive species, there are various methods to better understand the impacts invasive species can have on an ecosystem. Recently, stable carbon and nitrogen isotope ratios have been used to provide a better understanding of the effects of invasive species on aquatic food-webs.

The ratio of the rarer and heavy less abundant stable carbon isotope $\left({ }^{13} \mathrm{C}\right)$ to the more common carbon isotope $\left({ }^{12} \mathrm{C}\right)$ in a given sample compared to the standard (limestone for carbon) is denoted as $\delta^{13} \mathrm{C}$ (Fry 2006). Different types of primary producers $\left(\mathrm{C}_{3}, \mathrm{C}_{4}\right.$, and $\left.\mathrm{CAM}\right)$ have different photosynthetic pathways that influence unique $\delta^{13} \mathrm{C}$ signatures. The $\delta^{13} \mathrm{C}$ value can be useful in determining the primary production source responsible for energy flow in the ecosystem as there is little or no enrichment in ${ }^{13} \mathrm{C}$ between trophic levels $(<1 \%$ ) (Vander Zanden and Rasmussen 1999, Fry 2006). In simpler terms, in regards to carbon isotopes, 'you are what you eat' (Fry 2006). Conversely, the stable nitrogen isotope ratio $\delta^{15} \mathrm{~N}$ can be used to estimate trophic position due to an enrichment of ${ }^{15} \mathrm{~N}$ (at $\sim 3.4 \%$ ) in consumers relative to their prey (Vander Zanden and Rasmussen 1999, Fry 2006). The $\delta^{15} \mathrm{~N}$ signature is the ratio of the rare and heavier stable isotope ${ }^{15} \mathrm{~N}$ to the more common ${ }^{14} \mathrm{~N}$ in a given sample compared 
to the standard (atmospheric $\mathrm{N}_{2}$ for nitrogen). Different consumers will have different $\delta^{13} \mathrm{C}$ signatures due to variances in diet and digestion during assimilation and metabolic processes, but these consumers may have very similar $\delta^{15} \mathrm{~N}$ if they are at the same trophic level (Vander Zanden and Rasmussen 1999, McCutchan et al. 2003, Fry 2006).

Using stable isotopes to determine trophic position and the energy flow of carbon (what is eating what) through the food web can show impacts that abiotic or biotic disturbance (like the establishment of an invasive species) may have on the food webs (Fry 2006). Stable isotope analyses along with quantitative analyses and understanding of the ecosystem can help provide a better understanding of the influence AIS can have on the invaded food web.

\section{Prevention}

To reduce establishment and spread of aquatic invasive species, multiple preventative measures need to be addressed including: better management of transportation pathways, more quantitative procedures for risk analysis, increased active surveillance and information sharing, and more funding for programs reducing the spread of existing invasive species (Lodge et al. 2006). It is important to understand that there are multiple steps and approaches to preventing biological invasions. Understanding the influence of distinct invasive species is important for reactive mitigation, but managing vectors rather than specific invasive species has shown to be a more effective proactive approach to controlling the spread of invasive species (Leung et al. 2006, Peters and Lodge 2009, Rothlisberger et al. 2010). Management also needs to be adaptive depending on the stage and severity of the invasion (Drury and Rothlisberger 2008, Stewart-Koster et al. 2015). Furthermore, providing the public information on the threat of invasive 
species, how they can contribute to the control of invasive species spread, and pertinent laws and regulations regarding invasive species should be among the first steps in any management plan.

The cost of reacting to an invasion and controlling spread is more expensive, not to mention more ecologically degrading, than preventative measures (Stohlgren and Schnase 2006, Lodge et al. 2006). Laws and regulations can be a highly effective tool preventing invasive species dispersal. However, effective local-scale prevention measures can be weakened by the lack of action at neighboring source habitats (Peters and Lodge 2009, Stewart-Koster et al. 2015). For aquatic invasive species that can easily travel (naturally or with human assistance) across political boundaries like state lines or management districts, regional policies are necessary (Peters and Lodge 2009). Shifting management from individual species to vectors and using a regional council to guide proactive regulations as well as educational outreach is essential for controlling the dispersal and spread of aquatic invasive species.

\section{Thesis Objectives}

My thesis aims to provide new details on the effects of invasive species on native invertebrate communities, increase public awareness of AIS and proper boat cleaning procedure, and contribute to future conservation and management of native and novel ecosystems. More specifically, my thesis addresses: the information known about AIS dispersal and spread from one of their most common vectors, boaters (Chapter 2); and the influence of a particular AIS, the New Zealand mud snail, on native competitors like herbivores and detritivores, and how this invasive species may be influencing changes in native benthic food webs (Chapter 3). To determine overland AIS transport and 
introduction by boaters and their knowledge surrounding AIS and boat cleaning procedure, I conducted human subjects surveys at Tenmile Lake in Lakeside, Oregon. To complement the boater surveys and investigate the influence of an invasive species that has been introduced and is at various phases of establishment and spread, I conducted field sampling to define the influence of New Zealand mud snail invasion on benthic lake, river, and estuarine food webs. This research will provide valuable information for the science and management of AIS. 


\section{Chapter 2: Developing an understanding of boater's knowledge concerning aquatic invasive species and proper boat cleaning procedure}

\section{Introduction}

The introduction and establishment of invasive species is second only to habitat loss as the leading cause of species endangerment and extinction (Wilcove et al. 1998). The successful management of aquatic invasive species (AIS) necessitates continual adaptation depending on the species, transportation vectors, and the stage at which the invasive species has spread. Models indicate that early in the invasion process the best way to protect uninvaded areas is to allocate resources to containing already invaded sites (Drury and Rothlisberger 2008). As an invasion progresses however, containment at the invaded sites should give way to the protection of uninvaded sites (Drury and Rothlisberger 2008). Determining the type of management needed involves estimating the suitability of the receiving habitat given the ecological niche of the invader and having an understanding of the connectivity of the managed habitat with other at risk or invaded habitats (Stewart-Koster et al. 2015). Studies on AIS spread have shown that the movement of recreational boaters between waterbodies is potentially the most important pathway of overland dispersal for the majority of aquatic organisms (Buchan and Padilla 1999, Johnson et al. 2001, Leung et al. 2006, Vander Zanden and Olden 2008).

In addition to using an adaptive management strategy, creating more public awareness of AIS and proper boat cleaning procedures may prove to be highly beneficial in reducing the transport and establishment of AIS. Recent studies suggest that managing vectors rather than focusing on specific invasive species is a more effective approach to controlling the spread of invasive species (Leung et al. 2006, Peters and Lodge 2009, 
Rothlisberger et al. 2010). Visual inspection and hand removal can reduce the amount of invasive macrophytes on boats by $88 \%$ and high-pressure washing can remove smallbodied organisms at an efficiency of 91\% (Rothlisberger 2010). However, surveys have indicated that these simple boat cleaning procedures are only being performed by about one-third of the boating community (Rothlisberger et al. 2010), suggesting that there is a knowledge gap in proper boat cleaning procedure and potentially the harmful effects of AIS.

Educational campaigns for the public are an increasingly important tool for creating awareness of AIS and how individuals can help control the spread of invasive species. Outreach can come in many forms including through laws and regulations, newsletters, signage at boat launches, as well as from investing in infrastructure, such as a public boat wash station. Educational campaigns aimed to motivate boaters to take responsibility for their own boat hygiene would likely be a relatively inexpensive way to save the public the expense of equipment and employees required to clean boats at check stations and boat ramps. However, self-reported data on cleaning rates and boater observations suggest that existing and previous education campaigns that have not been augmented with staff cleaning stations, enforcement, or fines have resulted in consistently low cleaning rates by boaters (Rothlisberger et al. 2010). Therefore, determining the effectiveness of educational outreach tools is important for future management. My study used interviews with boaters to determine the vulnerability of the system and the effectiveness of a new management tool, a free public boat wash station. With this knowledge, I aim to guide future educational outreach and management plans for AIS. 
This study draws on data from the results of human subjects surveys conducted both prior and following the installation of a public boat wash station. The objectives for this project were: 1) to determine the frequency in which boaters visited waterbodies and the traffic patterns of boater movement; 2) to ascertain boaters' general knowledge of aquatic invasive species and proper boat cleaning procedure, as well as how they acquired their knowledge; 3 ) to measure the utilization and effectiveness of a public boat wash station; and 4) to establish an understanding of boaters' knowledge on local laws and regulations.

\section{Methods}

Study Site

Tenmile Lake is a large, shallow, and eutrophic freshwater lake on the Oregon Coast in Coos County. It is a popular spot for bass fishing and other recreation with nearly weekly fishing tournaments throughout the summer. Tenmile Lake is surrounded by many other popular recreational freshwater lakes and rivers as well as large estuarine bays (e.g., Winchester Bay, Coos Bay). The lake's proximity to the ocean makes it a convenient destination for boaters wishing to back-flush, the process of running a boat's motor in freshwater in order to wash out the salt or brackish water in the engine from the saline waterbody most recently boated. Tenmile Lake is a prime spot to passively observe and actively survey boaters traveling from within Oregon and those who are visiting from out of state because of the lake's accessibility, recreational aspects, and its proximity to other waterbodies. Additionally, Tenmile Lake was chosen as the site for this research because a boat wash station was installed in the summer of 2013 at the primary public boat ramp of the lake. 


\section{Surveys}

In order to obtain a better understanding of boat traffic patterns and public awareness of invasive species, as well as proper boat-cleaning procedure, a human subjects survey at Tenmile Lake was conducted over the summers of 2012 and 2013. Boaters were surveyed prior to the installation of the boat-wash station in summer 2012 (pre-boat wash survey, $n=199$ ), as well as following the installation of the boat wash station in summer 2013 (post-boat wash survey, $n=200$ ). The purpose of this management tool (the boat wash station) is to: 1) prevent invasive species from entering a waterbody; 2) contain invasive species already present in the waterbody from being transported elsewhere; 3) provide a free and efficient tool for cleaning motors after boating in salt water and before entering freshwater; and 4) increase public awareness of invasive species and proper boat cleaning procedure. These surveys were also useful in identifying knowledge of AIS and the willingness of boaters to use a free, voluntary boat wash station.

The surveys were voluntarily submitted and all boaters received contact information verbally and through an informed consent form (Appendix A). The pre-boat wash installation surveys were collected on boaters' knowledge of invasive species, their familiarity with proper boat cleaning procedure like the slogan "Clean, Drain, Dry", and the patterns in boater movement to determine areas of frequent visit and common transportation routes (Appendix B). Post-boat wash installation surveys conducted (Appendix C) were similar to the pre-boat wash installation surveys, but also included observations on the pattern of boat wash station use. Both surveys were approved for human subject research by the Portland State University Institutional Review Board 
(\#122208). A three-tiered survey was implemented at Tenmile Lake, which included an observational survey, a short form boater survey, and an in-depth boater survey. The observational survey consisted of passive visual observations of the boater and their use of aquatic invasive species prevention techniques before entering Tenmile Lake and again while exiting Tenmile Lake. The observational portion of the survey was done prior to questioning in order to avoid biasing the behavior of the individuals participating in the survey.

The short form boater survey consisted of quick, simple questions asked to the boater while exiting Tenmile Lake. Of the boaters observed and approached to partake in the survey, $67.3 \%$ participated in the short form boater survey. Short form boater survey questions included where and when the boater last boated, whether the boater was aware of state regulations and permits, whether the boater was aware of proper boat cleaning procedures, and their knowledge of aquatic invasive species (Appendix B, C). The short form boater surveys consisted of twelve questions and took approximately ten to fifteen minutes to complete.

Of the boaters who completed the short form boater survey, $31.6 \%$ agreed to participate in a more in-depth boater survey, for an overall response rate of $21.3 \%$. The in-depth boater survey asked the boater to elaborate on how aquatic invasive species (AIS) affect their on and off lake activities and where they learned about AIS. The indepth boater survey consisted of six questions and took an additional five to ten minutes to complete. All surveys were completed by the same researcher (S. Cimino). All survey answers were confidential. All questions and their responses can be found in Appendices 
B-E; however, due to the great volume of questions only a select few that best represented the overarching themes of the paper were addressed below.

\section{Results}

\section{Tenmile Lake Use}

The boaters at Tenmile Lake reported using the lake primarily for fishing and other recreational activities. Most boaters that use Tenmile Lake reported that they are frequent recreationalists, the majority boating more than twice a month (Figure 2.1). As would be expected, most of the boaters surveyed (pre-boat wash $=75.9 \%$, post-boat wash $=69.0 \%$ ) stated that they last came from waterbodies (freshwater and saltwater) that were within 50 kilometers traveling by road to Tenmile Lake (Figure 2.2); however, 3.0\% of boaters who were surveyed also indicated that the last waterbody they boated at was beyond the Oregon state lines in places such as Shasta Lake, California, Snake River, Idaho, and Flathead Lake, Montana (Appendix D). Additionally, 9.5\% of boaters surveyed at Tenmile Lake were observed to have boats registered to states other than Oregon (Appendix D).

\section{Boat Wash Station Use}

Of the pre-boat wash boaters surveyed, $75.9 \%$ of boaters claimed they would use a boat wash station at Tenmile Lake (Figure 2.3). After the boat wash station was installed, an amendment to the survey was made to include observations of whether or not boaters were using the boat wash station. The actual use of the boat wash station based on my observations during the post-boat wash survey was only $38.5 \%$ (Figure 2.3 ). Reasons reported for not planning to use or not using the boat wash station at Tenmile 
Lake included: boaters would like better equipment at the station (pre-boat wash $=45.8 \%$, post-boat wash $=39.7 \%$ ), the station was inconvenient (pre-boat wash $=16.7 \%$, post-boat wash $=27.8 \%$ ), or boaters didn't deem washing at a boat wash station necessary for their boating frequency or activities (pre-boat wash $=33.3 \%$, post-boat wash $=30.2 \%$; Appendix E). Only boaters who claimed they would not use the boat wash station in the pre-boat wash survey $(n=48)$ and do not use the boat wash station in the post-boat wash survey ( $n=123$ ) are represented in the survey questions regarding to the reasons why they would not or do not use the boat wash station.

\section{Knowledge of Aquatic Invasive Species and Relevant Regulations}

The aquatic invasive species (AIS) that surveyed boaters most frequently named was the zebra mussel (Dreissena polymorpha), where $44.7 \%$ of boaters in the pre-boat wash survey and $59.0 \%$ of boaters in the post-boat wash survey named this invasive species (Figure 2.4). Other commonly identified AIS included the New Zealand mud snail (Potamopyrgus antipodarum), hydrilla (Hydrilla verticallata), and rusty crayfish (Orconectes rusticus; Figure 2.4). However, the second most common answer to whether or not a surveyed boater could name an AIS was that they could not name any particular invasive species (Figure 2.4). In the pre-boat wash field season, $25.6 \%$ of boaters could not name an invasive species and in the post-boat wash field season $23.0 \%$ of boaters could not name an invasive species (Figure 2.4).

Surveyed boaters were less informed in the post-boat wash survey (55.0\%) compared to the pre-boat wash survey $(69.0 \%)$ about the Oregon state law prohibiting the launching of a boat with invasive species attachment (Table 2.1). Conversely, surveyed boaters were more aware of the state regulations regarding the use and movement of bait 
fish in the post-boat wash survey $(82.0 \%)$ versus the pre-boat wash survey $(63.0 \%$; Table 2.1). The awareness of the state regulation regarding the use and movement of crayfish changed only slightly from pre-boat wash survey (60.0\%) to post-boat wash survey $(62.0 \%$; Table 2.1).

\section{Awareness of Educational Outreach}

A minority of surveyed boaters arriving at Tenmile Lake saw signage regarding aquatic invasive species (AIS) in both the pre-boat wash field season $(25.1 \%)$ and the post-boat wash field season (31.5\%). Even fewer boaters saw signage regarding AIS when leaving Tenmile Lake in both the pre-boat wash field season $(5.5 \%)$ and post-boat wash field season (4.5\%). However, the majority of boaters surveyed in both the pre-boat wash (63.3\%) and post-boat wash $(66.0 \%)$ field seasons were aware of the phrase "Clean, Drain, Dry" as an appropriate method to mitigate for AIS. Moreover, $44.7 \%$ of pre-boat wash boaters and $59.0 \%$ of the post boat wash boaters reported always practicing the "Clean, Drain, Dry" method. The majority of boaters unaware of the phrase "Clean, Drain, Dry" in the pre-boat wash season and post-boat wash season still reported practicing this cleaning method at least some of the time. See Appendix E for responses to additional survey questions.

\section{Discussion}

The pre-boat wash surveys and the post-boat wash surveys conducted at Tenmile Lake identified the type of recreationalists boating at Tenmile and their knowledge of AIS, proper boat cleaning procedures, and relevant boating and fishing laws and regulations. Most of the boaters' surveyed had boats licensed in Oregon and primarily 
boat locally within the state. However, numerous boaters surveyed boated in waterbodies outside of the state of Oregon immediately prior to boating at Tenmile Lake. Although most of the boaters' surveyed report following the "Clean, Drain, and Dry" approach to wash their boats after use, they did not actually use the boat wash station at Tenmile Lake. This result is unique because most boaters indicated during the pre-boat wash survey that they would use the boat wash station once installed. The surveyed boaters revealed gaps in their knowledge of AIS as well as inconsistencies in their knowledge of proper boat cleaning procedure and state laws and regulations. Furthermore, signage regarding AIS at Tenmile Lake is being largely overlooked when arriving at the lake and even more so upon exiting the lake. More efforts need to focus on public outreach concerning the threats of current and future AIS to lake health and biodiversity as well as establishing more regional level laws and policies.

\section{Tenmile Lake Use}

The majority of boaters visited Tenmile Lake after boating in freshwater and saltwater waterbodies within $50 \mathrm{~km}$ of the lake (using road distance). In addition, the majority of these boaters are boating multiple times a month. Fishing is the most common activity of boaters surveyed at Tenmile Lake and it is becoming increasingly essential that fishermen are well educated on AIS identification and proper boat cleaning procedures. A greater investment in the environment and the protection of the environment will require a shift from current recreationalists' choices and significant changes in these human behaviors (Kareiva 2008). Fishermen, who often participate in multiple different tournaments throughout the nation during peak fishing season, are likely the greatest vector of AIS spread (Buchan and Padilla 1999, Leung et al. 2006, 
Vander Zanden and Olden 2008). Therefore, fishermen and other recreationalists' behavior and choices must shift toward a greater investment in the environment, which may result in shorter fishing seasons and/or limited access to sites vulnerable to invasion and establishment. This shift towards environmental protection will likely result in shortterm economic costs but may be essential for long-term environmental benefits.

\section{Boat Wash Station Use}

Understanding the use of the boat wash station at Tenmile Lake should also provide a better understanding of recreationalists use and views of Tenmile Lake itself. Results from the two seasons of field surveys indicate that there was a disconnect between boater responses to the survey and boater behavior. In the pre-boat wash surveys, boaters were asked if they would be willing to use a boat wash station and $75.9 \%$ said they would; however, in the post-boat wash surveys only $38.5 \%$ of surveyed boaters were actually observed using the washing station. Boaters appear to like the idea and the benefits of a healthy lake ecosystem, but they may not be inclined to change their daily routines. Pergams and Zaradic (2008) found that there has been a downtrend in nature-based recreation since the late 1980s, and a decline in wilderness and nature experience can lead to lower value being placed on nature (Kareiva 2008). Responses to why boaters are not using the Tenmile Lake boat wash station indicate that they support maintaining or promoting a healthy lake ecosystem, but their behavior may indicate they are not interested in actions that require more individual preparation and involvement that might limit access to parts of the lake. Similarly, mail-in boater surveys conducted by the Oregon State Marine Board indicate that in-state boaters support more education and 
information regarding the maintenance of a healthy waterbody but are concerned with over-regulation and increased taxes and fines (Chan et al. 2014).

It is worth considering that the post-boat wash surveys were administered within a month of the completion of the boat wash station and before the official opening. Perhaps with time, boaters will become more aware of the station's existence and its efficacy for de-fouling boats. The plan for volunteers to work the station was also not put into effect by the time the post-boat wash surveys were completed. Observing the station's use with volunteers present might provide an even greater understanding of boaters' willingness to use the boat wash station. Furthermore, boat wash station use was only recorded from surveyed boaters, and thus may not fully represent the boat wash station usage. My presence may have encouraged the surveyed boaters to use the boat wash station more than non-surveyed boaters, and therefore my estimates of boat wash station usage may be inflated.

\section{Knowledge of Laws and Regulations}

Despite boaters' awareness of proper boat cleaning procedure, AIS have been spreading quickly and effectively in the United States (Loo et al. 2007a, McMahon 2011). In 2001, in response to the growing threat of invasive species to the state, the Oregon Invasive Species Council was created by the Oregon State Legislature (Reesman et al. 2012). Similarly, many other states have created their own councils to address the growing need of invasive species prevention. These councils have been effective at providing educational outreach and developing watercraft inspection programs. In 2015, the Washington Invasive Species Council reached more than 3,000 people through direct communication regarding the impacts of invasive species (Washington Invasive Species 
Council 2015). Furthermore, Idaho's "Invasive Species Watercraft Inspection Program" intercepted 105 vessels transporting zebra and/or quagga mussels from 2009-2013 (Idaho State Department of Agriculture 2014). However, Peters and Lodge (2009) found that inconsistencies among states concerning laws and regulations confuse consumers (in this case, boaters) and reduce the credibility of management agencies. A focus toward more regional and national regulations as well as international agreements need to be developed to govern the movement of potentially invasive species (Lodge et al. 2006, Drury and Rothlisberger 2008, Vander Zanden and Olden 2008).

The majority of boaters surveyed were aware of Oregon's state law that prohibits a boat from launching with an attached invasive species. However, awareness of this state law decreased by 14\% from 2012 to 2013. The law passed by Oregon Legislature House Bill 2220 created an Aquatic Invasive Species Prevention Program and established a new user fee for boaters in 2009, the "Aquatic Invasive Species Prevention Permit" (Reesman et al. 2012). All licensed boats are paying this user fee, but since the law passed, boaters have appeared to become less aware of what this fee actually represents. However, boaters have shown continued awareness of the state regulations regarding the use and movement of bait fish and crayfish (Reesman et al. 2012) throughout the two year boater survey period.

\section{Awareness of Educational Outreach}

Through the information gathered from the boater surveys, a better understanding of recreationalists' knowledge of AIS was developed. Case studies have shown that recreationalists have concerns for the environment but may not understand the vast range of ecosystem services provided by a healthy environment, such as clean water (Ryan 
2005, Tilt et al. 2007, Kareiva 2008). Similarly, at Tenmile Lake most recreationalists were concerned with the health of the lake and especially the lakes' fish populations. However, boaters were unaware of some of the major pressures threatening the health of the lake. The most noticeable lack of boater knowledge was in the verbal identification of AIS (Figure 2.4). After the zebra mussel (which has currently not been detected in Oregon), the second most common answer when asked to verbally identify AIS was that they could not name a single aquatic invasive species (Figure 2.4).

At public boat ramps across the state of Oregon, signs have been posted with pictures of common AIS and information on how they can be transported via attachment to trailers and boats (Appendix F), as well as transportation of AIS by the process of back-flushing (Appendix F). The visibility of these signs at Tenmile Lake was low. Location of the signage being a substantial distance (approximately $30 \mathrm{~m}$ ) from the boat ramp (Appendix F) may be a leading contributor to such a small percentage of surveyed boaters claiming to have seen a sign entering or leaving the lake. In 2013, new signs were put up along the edges of the Tenmile Lake boat ramp warning boaters about the illegality of back-flushing their motors (Appendix F), but this sign only mentions the risk of transporting invasive species in small print. Better use of signage at boat docks and marinas may have considerable ecological benefits. In a 2014 mail-in survey, 55.0\% of boaters in Oregon indicated that they prefer getting information about boating issues through posters or signs, which was the second most common answer given after the preference of getting information from the internet at 70.0\% (Chan et al. 2014). Signs can be an effective educational outreach tool but they need to be more visible and easier to read. 


\section{Conclusion}

By obtaining recreationalists' knowledge of AIS, laws and regulations, and proper boat cleaning procedures through human subjects surveys, local, state, and federal managers can collaborate to adapt the current AIS policies and move forward in future management plans. However, the survey administered provides only a snapshot of boater knowledge and only reflects a subset of the community's awareness of AIS, laws and regulations, and proper boat cleaning practices. Moreover, visual representations through the use of pictures of common AIS while interviewing boaters may prove to be a more useful technique to gage local and recreational knowledge of invasive species.

The majority of boaters were familiar with state laws and regulations regarding AIS, but as boaters continue to venture across state borders, more specific regional or federal laws and regulations are necessary to prevent invasion and control spread. Without regional laws concerning AIS transport, the current lack of usage of the free boat wash station at Tenmile Lake is a concern. Adding volunteers to the boat wash station to assist boaters and provide information on the spread of AIS and specific species of concern could be an effective method to encourage more boat wash station use while increasing boater knowledge. Additionally, AIS signage at Tenmile Lake needs to be bigger and closer to the boat ramp.

The Tenmile Lake boat wash station aims to prevent outside AIS from entering the lake, contain present invasive species, provide a safe and effective tool for boat flushing, and increase public awareness. These goals are not unique to Tenmile Lake, but a free public boat wash station is unique to Oregon. Innovative techniques or tools like the boat wash station to reduce AIS introductions and increase public knowledge of AIS 
threats may be essential to future management. Much of the estimated cost associated with the economic and ecological damages inflicted by invasive species is controlling the density and spread of already established invasive species (Pimentel et al. 2005, Stohlgren and Schnase 2006). Thus, the successful management of AIS necessitates a focus on the transportation and introduction of AIS using tools like boat wash stations, educational outreach, and regional laws and regulations. 


\section{Tables and Figures Chapter 2}

Table 2.1: The percentage of boaters surveyed aware of Oregon State laws and regulations regarding aquatic invasive species.

\begin{tabular}{lrrrr}
\hline Survey Questions & $\begin{array}{c}\text { Pre-boat wash } \\
(\mathrm{n}=199)\end{array}$ & $\begin{array}{c}\text { Post-boat wash } \\
(\mathrm{n}=200)\end{array}$ \\
\hline & Yes & No & Yes & No \\
$\begin{array}{l}\text { Aware of state law that prohibits launching a boat } \\
\text { with invasive species on it? }\end{array}$ & $69 \%$ & $31 \%$ & $55 \%$ & $45 \%$ \\
$\begin{array}{l}\text { Aware of state regulations regarding the use and } \\
\text { movement of bait fish? }\end{array}$ & $63 \%$ & $37 \%$ & $82 \%$ & $18 \%$ \\
$\begin{array}{l}\text { Aware of state regulations regarding crayfish use } \\
\text { and movement? }\end{array}$ & $60 \%$ & $40 \%$ & $62 \%$ & $38 \%$ \\
\hline
\end{tabular}




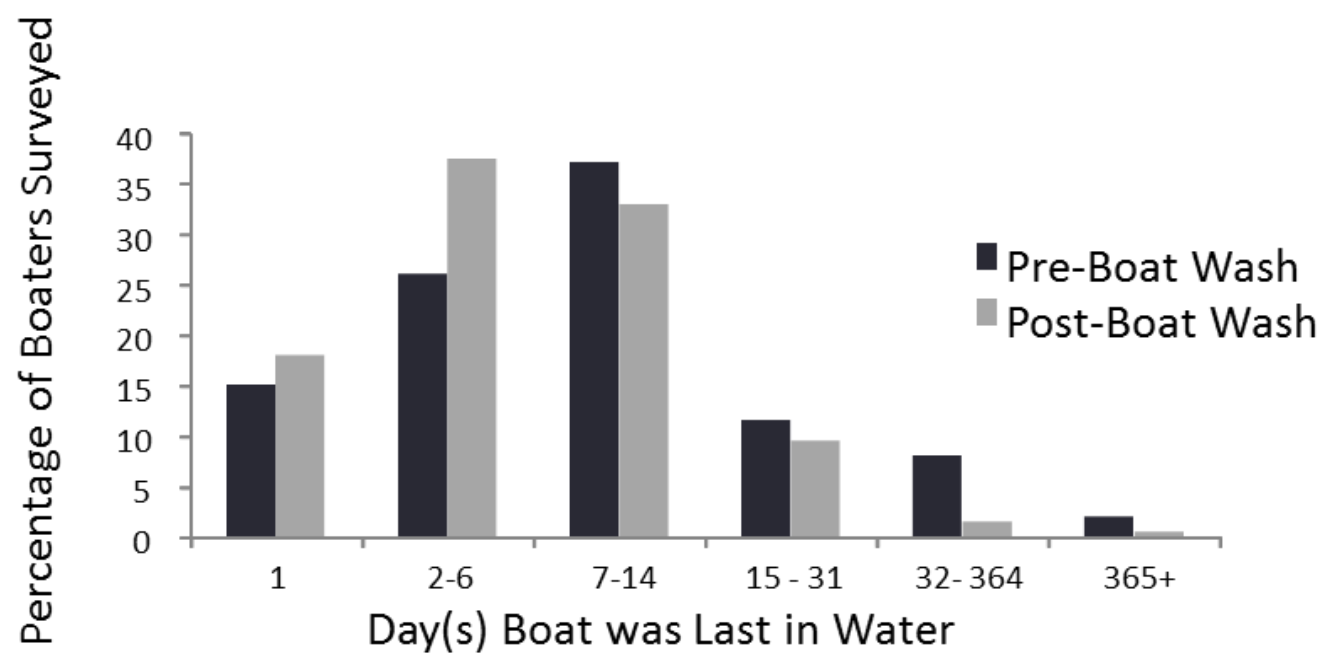

Figure 2.1: The number of days since the surveyed participant last put their boat in a waterbody from the pre-boat wash data collected in $2012(\mathrm{n}=199)$ and post-boat wash data collected in $2013(\mathrm{n}=200)$. 


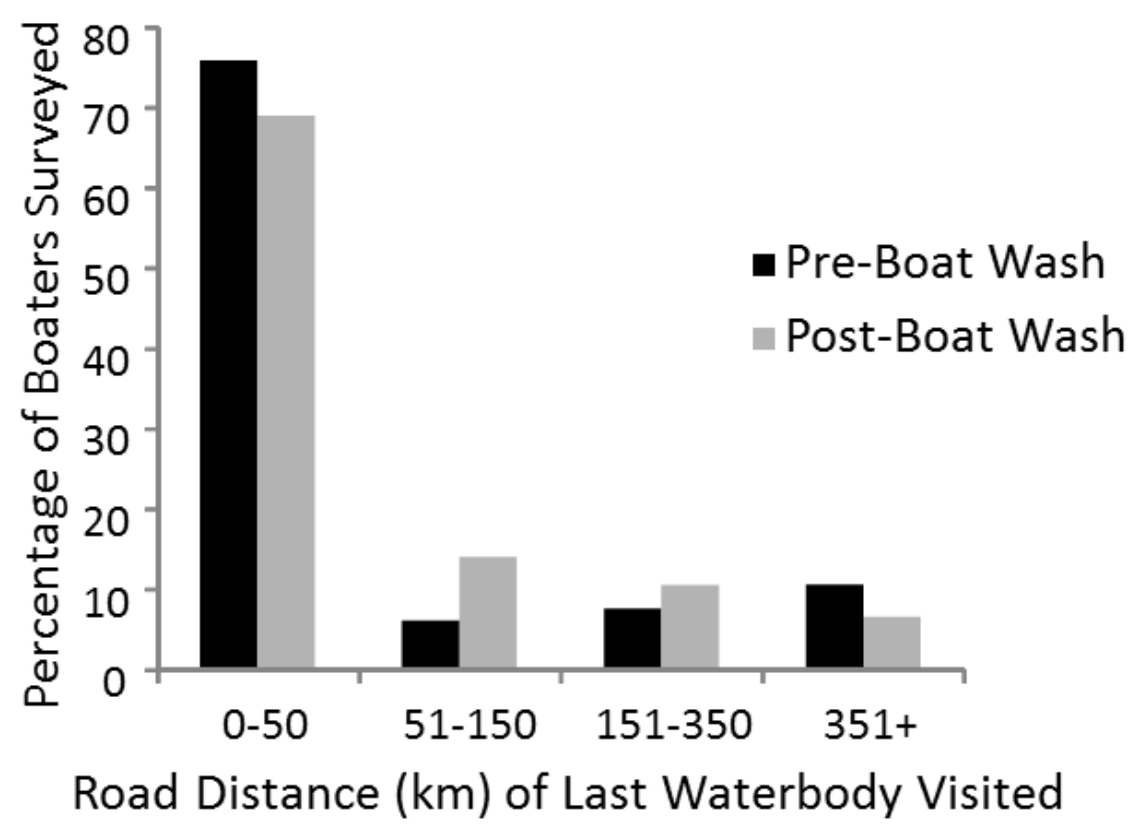

Figure 2.2: The road distance of water bodies (kilometers) surveyed boaters last came from. Symbols as in Figure 2.1. 


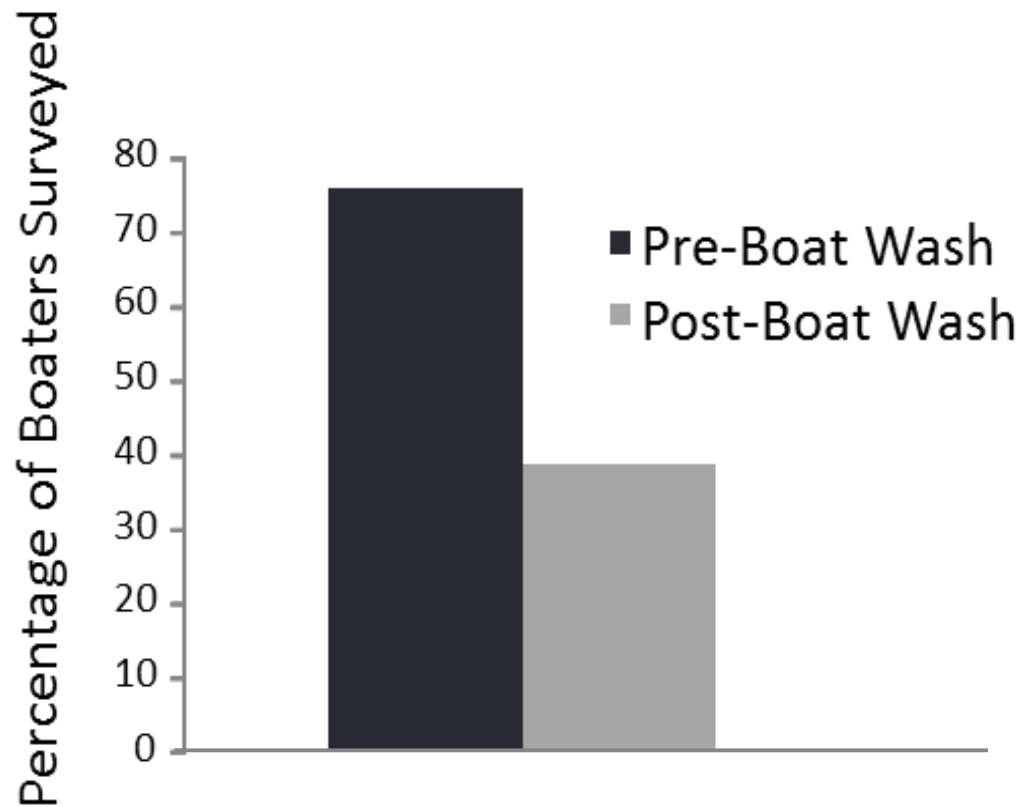

Figure 2.3: The percentage of boaters claiming they would use a boat wash station in the pre-boat wash survey, and the percentage of boaters who were observed using the boat wash station in the post-boat wash survey. 


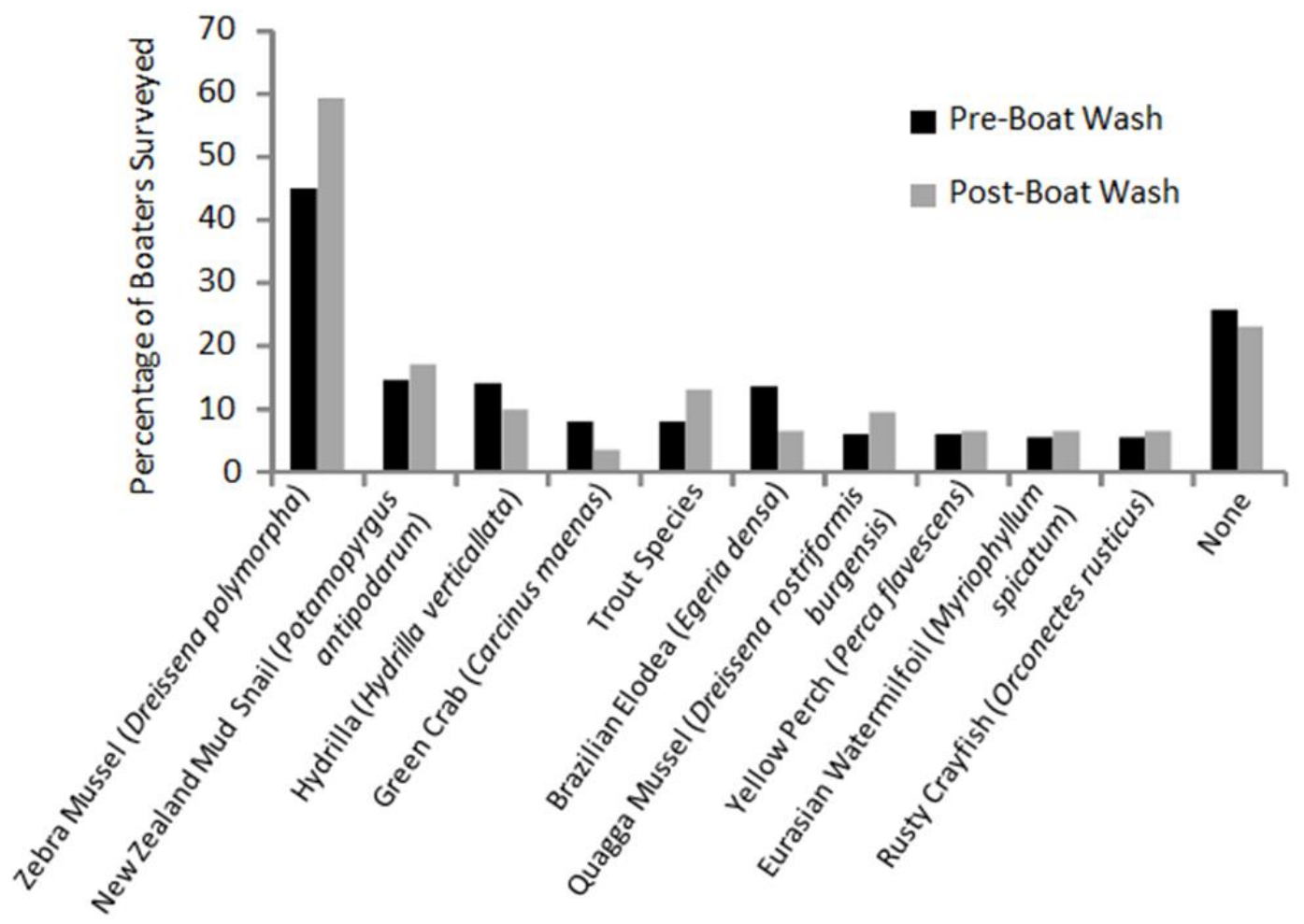

Figure 2.4: The percentage of boaters surveyed who named specific aquatic invasive species when asked what aquatic invasive species they were aware of. Symbols as in Figure 2.1. 


\section{Chapter 3: The influence of New Zealand mud snail in benthic freshwater and brackish water ecosystems in the Pacific Northwest}

\section{Introduction}

Invasive species can compete with native taxa to drive ecological changes such as niche displacement or even extinction (Mooney and Cleland 2001, Schreiber et al. 2002, Carlsson et al. 2004). These ecological changes may include alterations in the distribution and abundance of native species and changes in the feeding habit or diet of native species (Byers 2000, Carlsson et al. 2004, Brenneis et al. 2010, Moore et al. 2012). However, many studies have also shown invasive species to facilitate native species by providing food, shelter, and in some instances predator release (Schreiber et al. 2002, Beekey et al. 2004, Rodriguez 2006). The influence of an invasive species on a community is highly variable and dependent both on the vulnerability of the native community and the invasibility of the ecosystem (Leung and Mandrak 2007).

The New Zealand mud snail (Potamopyrgus antipodarum; NZMS) is an invasive grazing herbivore and detritivore (i.e., generalist feeder) that utilizes the same food source as many native macroinvertebrates (Zaranko et al. 1997, Kerans et al. 2005). New Zealand mud snails are an aquatic invasive species (AIS) of concern because once established, they may out-compete native invertebrate grazers such as insect larvae that provide an important food source for salmon and trout species, whereas the NZMS themselves provide little nutritional value (McCarter 1986, Hall et al. 2006). However, Brenneis et al (2010) concluded that even at high densities in estuaries there was minimal competition and no obvious negative impacts between the NZMS and a native foraging isopod. The long-term ecological effects of the NZMS on invaded aquatic communities is 
expected to be significant (Kerans et al. 2005) because NZMS can reach high densities, reducing niche space for native competitors (Dorgelo 1987, Richards et al. 2004). In general snails are important links between primary producers and higher order consumers in aquatic ecosystems (Hawkins and Furnish 1987, Feminella and Hawkins 1995). Furthermore, the NZMS is found in a variety of different aquatic ecosystems and thus their influence on native communities may vary greatly depending on the system. A more thorough investigation on the invasion of NZMS on these varying ecosystems is necessary to gain a better understanding of their influence on benthic food webs.

The New Zealand mud snail has been known to invade brackish estuaries, freshwater rivers, and freshwater lakes. These ecosystems, though very different, are all popular among boaters and anglers who are likely the most important vectors of AIS spread (Buchan and Padilla 1999, Leung et al. 2006, Loo et al. 2007b, Vander Zanden and Olden 2008). NZMS were first discovered in the United States in the Snake River, Idaho in 1987 (Bowler 1991). Within the first ten years, they colonized more than 640 $\mathrm{km}$ of the Snake River and spread across the North American continental divide (Zaranko et al. 1997). NZMS can spread actively upstream up to $1 \mathrm{~km} \cdot \mathrm{year}^{-1}$ (Loo et al. 2007b) and float passively downstream independently or attached to vegetation (Kerans et al. 2005). Additionally, they can be transported by fish species, passing live through the fish's digestive tract (McCarter 1986, Vinson and Baker 2008, Brenneis et al. 2011).

The ability to establish in a new system is equally as important as the ability to spread. The term invasibility is used to describe the necessary environmental conditions suitable for the persistence (i.e., survival and reproduction) of an invasive species (Leung and Mandrak 2007, Crooks et al. 2011). NZMS are tolerant of a wide range of abiotic 
conditions (Jacobsen and Forbes 1997, Zaranko et al. 1997, Dybdahl and Kane 2005). Their densities do not show evidence of declining until temperatures exceed $28^{\circ} \mathrm{C}$, and they have been known to reproduce at temperatures $>24^{\circ} \mathrm{C}$ in an environment without limiting factors such as a lack of food or space (Dybdahl and Kane 2005). Furthermore, the presence of an operculum allows the NZMS to resist desiccation, which is beneficial for overland dispersal, but the operculum also allows the typically freshwater NZMS to tolerate and even thrive in brackish environments with salinity levels as high as $15 \mathrm{psu}$ (Alonso and Castro-Díez 2008). Along with a high tolerance of abiotic factors, NZMS are unique in that they reproduce primarily by parthenogenesis (Wallace 1992). Sexual reproduction can occur but is very rare, especially outside of New Zealand (Dybdahl and Lively 1995). Instead, asexual females develop eggs that can grow without fertilization; therefore, one female is sufficient to initiate a new population (Wallace 1992). This reproductive characteristic allows NZMS to establish quickly.

Densities of NZMS in invaded communities have been measured at levels as high as 800,000 individuals $\cdot \mathrm{m}^{-2}$ (Dorgelo 1987, Kerans et al. 2005). Densities have typically been greatest in systems with high primary productivity, constant temperatures, and constant flow rates, with peak densities in the summer (Richards et al. 2001). At these high densities, NZMS are capable of consuming large volumes of algae and detritus, potentially competing with native benthic freshwater herbivores and detritivores, reducing their biomass production (Hall et al. 2006). Moore et al. (2012) observed that benthic invertebrates competing with a high density NZMS population changed their diets from their preferred food source of periphyton to detritus as a result of competitive exclusion, switching from a specialized feeding habit to a more generalized feeding habit. 
My study is unique in addressing both applied and basic ecological questions related to the influence of the NZMS throughout three aquatic ecosystems that vary greatly in biological and environmental characteristics. Studies have examined NZMS population dynamics and their influence on food webs in different freshwater and brackish ecosystems (Hall et al. 2006, Bersine et al. 2008, Brenneis et al. 2011, Moore et al. 2012); however, no one has looked at NZMS population dynamics and their influence on native food webs simultaneously across multiple ecosystem types (rivers, lakes, and estuaries). Critically, NZMS may have unique impacts in different ecosystems, as well as responding differently to environmental variables. Further, studies of NZMS population dynamic have typically observed only one site over an extended time period or compared very similar sites of differing NZMS densities within the same ecosystem and thus did not compare the effects of a NZMS invasion in different systems. Studying NZMS simultaneously across these diverse aquatic ecosystems may also broaden the gradient of densities and environmental conditions, allowing observation of effects that may only be noticeable at the extremes of the gradients. A better understanding of NZMS population dynamics in these three different ecosystems may be critical in determining where management and mitigation efforts are most needed especially in areas like the Oregon coast where the NZMS is easily transported between all of these ecosystems. The specific objectives of this study include: (1) Describing how the density of NZMS differs across invaded sites in estuaries, rivers, and lakes, how these densities vary over time, and what factors control density; and (2) Investigating the influence of NZMS density and establishment on community diversity, macroinvertebrate feeding groups (i.e., herbivores, omnivores, etc.), and benthic food webs using stable isotope analyses. 
I hypothesized that NZMS densities would have a negative relationship with the benthic invertebrate community's diversity and with densities of competing benthic invertebrate feeding groups when environmental conditions are suitable for introduction and establishment. Diversity is predicted to be lower where NZMS density is higher because systems with available niche space (potentially due to degradation or harsh environmental conditions) accumulate more invaders than less-impacted systems with limited niche space (Paavola et al. 2005). Additionally, biological invasions have been shown to alter the properties of invaded habitats, decrease biodiversity, and induce biotic homogenization (Kolar and Lodge 2001, Alonso and Castro-Díez 2008, Crooks et al. 2011). I also hypothesized that an increase in NZMS density will be negatively correlated with native competitors' densities. Invasive herbivores have been observed to diminish, and in some cases eliminate, native species through competitive exclusion (Byers 2000, Mooney and Cleland 2001, Hall et al. 2006). Furthermore, I hypothesized that at high densities, NZMS would out-compete native invertebrates of the same feeding niche, thus forcing the native competitors into more generalized diets. Moore et al. (2012) observed such niche shifts of competing native invertebrates in freshwater streams when NZMS were at high densities, but not in streams with low or absent NZMS densities. Lastly, I hypothesized that NZMS will fill different feeding niches (i.e., detritivore or herbivore) when at high densities compared to low densities. New Zealand mud snails can significantly alter community dynamics when present at high densities by altering the competing invertebrates' biotic interactions within the community and their resourceconsumer dynamics, thus creating an Eltonian niche shift (Elton 1927, Soberón 2007, Larson et al. 2010). 


\section{Methods}

Study Sites

To address the first objective, a long-term monitoring study was performed at upstream and downstream reaches of four rivers (John Day River, Umpqua River, Siuslaw River, and Deschutes River) and one estuary (Columbia River Estuary at Youngs Bay) in Oregon at various times from the summer 2006 to winter 2008 (Figure 3.1). Two of these rivers had documented NZMS presence as of 2006 (Table 3.1). Rivers in adjacent watersheds without reported NZMS were selected for comparison of community structure and abiotic variables. The estuary and river sites were again re-sampled in summer 2012 to look for changes in population densities, as well as the potential spread of NZMS (Figure 3.1). Further investigations were performed at some sites in winter 2013 to conclude the temporal sampling (Table 3.1). The long-term monitoring project on NZMS was designed by Dr. Valance Brenneis, and data collection and analysis during this period were also performed by Dr. Brenneis. Within each river reach, four sub-sites were selected based on accessibility. When access sites (e.g., boat ramps or campgrounds) were abundant, sampling sub-sites were spread out (one site per access point). When access was sparse, multiple sub-sites were located at one access point; efforts were made to locate the sampling sub-sites as far apart as possible.

To complement the long-term monitoring study and to investigate specific aspects of NZMS invasion in a variety of ecosystems, five new brackish estuaries and six new freshwater coastal lakes were sampled in the summer of 2013, as well as a repeat sampling of the Columbia River Estuary at Youngs Bay (Figure 3.1; Table 3.1). All coastal freshwater lakes in Oregon with reported NZMS sightings (as of summer 2013; 
USGS 2015) were selected for this study: Coffenbury Lake, Lake Lytle, Devils Lake (Lincoln County), and Garrison Lake. Three other brackish water estuaries with reported NZMS sightings were also sampled: Tillamook River Estuary, Yaquina River Estuary, and the Lower Rogue River Estuary. In addition, two freshwater coastal lakes and two estuaries without known NZMS presence were sampled as controls: Cullaby Lake, Mercer Lake, Nestucca River Estuary, and Coquille River Estuary (Figure 3.1).

At each estuarine site, exposed shoreline locations were selected adjacent to boat access ramps. Within each site, six sub-sites were sampled. Five of the estuarine subsites were in exposed mudflats or rocky shoreline and one sub-site was pelagic (watercolumn) and deep-water benthic (Table 3.1). Within each lake there were also six sampling sub-sites. One benthic sampling sub-site was selected near a public boat ramp and then the lake perimeter was divided into four more sections and one benthic sub-site was chosen in each section to best characterize the lake along with one pelagic sub-site (Table 3.1). When diverse habitats were present in estuaries and lakes (macrophyte stands, bedrock, cobble, riffle, run) an effort was made to sample across all habitat types to incorporate the maximum amount of diversity present at each site. Sampling protocols remained the same from 2006-2013.

\section{Sampling Method}

The quantitative sampling method used for the lake and river sites was modified from the Oregon Department of Environmental Quality protocols for wadeable streams (ODEQ 2004a). Benthic invertebrates were sampled in littoral lake and riverine sub-sites by disturbing a fixed area $\left(0.743 \mathrm{~m}^{2}\right)$ of substrate with a D-net $(250-\mu \mathrm{m}$ mesh size $)$ (Appendix G). When large rocks were present in the sample grid, they were scraped to 
remove invertebrates. When aquatic vegetation was present, the D-net was swept over the grid area several times. The spacing between grids within a sub-site ranged between 5 and $20 \mathrm{~m}$. All grids per sub-site were pooled into a bucket and then poured through a $250-\mu \mathrm{m}$ sieve, and preserved at a final concentration of $70 \%$ ethanol.

Sampling of the exposed mudflats and rocky shoreline of the estuarine sites was performed using a circular PVC ring $\left(0.073 \mathrm{~m}^{2}\right.$ in area, $30.5-\mathrm{cm}$ diameter, created by sawing off the top of a 5-gallon bucket). The sampling ring was placed at 5 different subsites within the accessible and exposed intertidal zone at low tide $\left(0.365-\mathrm{m}^{2}\right.$ total area sampled), incorporating cobble and mud substrate at each estuary. The distance between sampling sub-sites was determined using a random number generator between 1 and 10 and pacing out the distance of the number generated. A spade was used to dig to 2-cm depth within the $30.5-\mathrm{cm}$ core benthic ring. Any large rocks within the core ring were scraped and cleaned for invertebrates and the entire sub-site sample was then pooled in a 5-gallon bucket. All material collected was then sifted through using a $250-\mu \mathrm{m}$ sieve. Macroinvertebrates captured were preserved at a final concentration of $70 \%$ ethanol. Samples for stable isotope analyses (described below) were collected using the same methods as the quantitative sampling methods described above with the addition of using an Ekman grab to collect a benthic profundal sample for stable isotope analysis at each coastal lake and estuary.

Samples of aquatic vegetation from the lake, river, and estuary sites were collected from each sub-site and placed in Ziploc bags and frozen for subsequent stable isotope analysis. Periphyton and phytoplankton samples were also collected for stable isotope analysis at each sub-site by brushing periphyton off rocks and other smooth surfaces and 
using a Van Dorn to collect phytoplankton in the pelagic water column. The periphyton slurry was filtered on to $25-\mathrm{mm}$ Whatman glass microfiber filter papers with $0.7-\mu \mathrm{m}$ pore size (Whatman International Ltd., Maidstone, England) using a BD 60-mL syringe (BD, Franklin Lakes, NJ). Phytoplankton was filtered on to $47-\mathrm{mm}$ glass microfiber filter papers with $0.7-\mu \mathrm{m}$ pore size (Whatman International Ltd., Maidstone, England) and filtered using a Nalgene filter and pump. Both periphyton and phytoplankton samples were wrapped in tinfoil, put in Ziploc bags, and flash frozen using dry ice. Zooplankton sampled at the pelagic site were collected with a horizontally towed $250-\mu \mathrm{m}$ plankton net $($ diameter $=30 \mathrm{~cm})$ and preserved at a final concentration of $70 \%$ ethanol. Baited minnow traps were used at each sub-site to catch secondary invertebrate consumers like crayfish, which were then preserved at a final concentration of $70 \%$ ethanol. In the estuaries, minnow traps were used during higher tide and at depths that were still submerged during low tide for collection of secondary consumers.

In situ measurements of abiotic conditions using a YSI ProPlus (Yellow Springs, $\mathrm{OH})$ included measurements at $1-\mathrm{m}$ intervals for specific conductance $\left(\mu \mathrm{S} \cdot \mathrm{cm}^{-1}\right)$, dissolved oxygen $\left(\mathrm{mg} \cdot \mathrm{L}^{-1}\right), \mathrm{pH}$, and temperature $\left({ }^{\circ} \mathrm{C}\right)$ in lakes, and surface measurements in rivers and estuaries (Table 3.2). A Secchi disc was used to determine water clarity. Rapid observational environmental assessments were also conducted at each site and subsite including relative wind and sky clarity assessment, shoreline/bank assessment, substrate, types of riparian vegetation and emergent macrophytes, and any key environmental or anthropogenic characteristics. Research was conducted on NOAA Scientific Permit \#17879. 


\section{Sample Processing}

For quantitative macroinvertebrate samples, I used the Caton subsampling

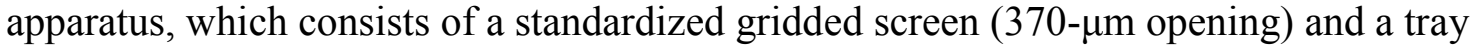
(Caton 1991). Each sample from a sub-site was emptied and washed onto the Caton gridded screen making sure to spread the sample contents evenly across the screen (Blackwood 2007). Macroinvertebrates $\geq 1.3 \mathrm{~cm}$ in length that occur in four or fewer grids were noted and included in the subsample (Blackwood 2007). A random number generator was used to select at least $12.5 \%$ of the gridded screen (with 24 grids, 3 grids were chosen) for subsampling. At least 300 and no more than 500 organisms had to be present within the three grids; if less than 300 specimens were counted, another grid was randomly selected for sampling (Blackwood 2007). There was never a case where more than 500 organisms were present in the three randomly selected Caton tray grids. After subsampling, counts for each taxa were multiplied by the fraction of sample not contained in the chosen grids to provide an approximate count of the entire sample and scaled to the sampled area.

A Leica MI65C microscope and IC80HD camera (Leica Microsystems Inc., Buffalo Grove, IL) was used to identify macroinvertebrate, mosses, and macrophyte samples with the following taxonomic identification guides (Smith 2001, Voshell and Reese 2002, Merritt et al. 2008, Thorp and Covich 2010). Once taxonomically identified (usually to family or genus), macroinvertebrates were grouped into functional feeding groups (herbivores, detritivores, predators, omnivores, collector-filterers, and collectorgatherers) based on the classification of Barbour et al. (1999), Voshell and Reese (2002), Poff et al. (2006), and Bob Wisseman (personal communication 2015). Macrophytes and mosses were also categorized into groups primarily by how they photosynthesize $\left(\mathrm{C}_{3}\right.$ 
plants, $\mathrm{C}_{4}$ plants, CAM plants) and location of photosynthesis (pelagic, littoral, and terrestrial leaf litter). Primary producer groups were determined using various published keys and reports (Van et al. 1976, Anton Hough and Wetzel 1977, Degroote and Kennedy 1977, Aiken et al. 1979, Keeley 1981, Longstreth 1989, Curtis et al. 1990, Frost-Christensen and Sand-Jensen 1995, Stribling and Cornwell 1997, Pagano and Titus 2004, Liu and Wang 2006, Bruhl and Wilson 2007, Minckley et al. 2009, Sage et al. 2011, Xu et al. 2013).

Stable carbon $(\mathrm{C})$ and nitrogen $(\mathrm{N})$ isotope ratios can be used to provide a better understanding of the effects of invasive species on aquatic food-webs. The stable carbon isotope ratio $\left(\delta^{13} \mathrm{C}\right)$ can be useful in determining the primary production source responsible for energy flow in the ecosystem, and the stable nitrogen isotope ratio $\left(\delta^{15} \mathrm{~N}\right)$ can be used to estimate trophic position (Fry 2006). Stable isotope analyses of nitrogen and carbon were performed on preserved invertebrate, macrophyte, algal, and terrestrial leaf litter samples. Leaf litter can be an important pathway for macroinvertebrates like detritivores to get nutrients. Collected SIA samples were dried at $60^{\circ} \mathrm{C}$ for 24 to 48 hours until a constant dry weight was achieved and homogenized with a mortar and pestle. A total of $1 \mathrm{mg}( \pm 0.2 \mathrm{mg})$ of dry weight for individual invertebrate samples and a total of 3$5 \mathrm{mg}$ of dry weight for individual primary producer samples were enclosed in tin capsules, placed in a 96-well tray, and kept dry in a desiccator (UC Davis Stable Isotope Facility 2013). All samples were then analyzed for $\delta^{15} \mathrm{~N}$ and $\delta^{13} \mathrm{C}$ using a PDZ Europa ANCA-GSL elemental analyzer interfaced to a PDZ Europa 20-20 isotope ratio mass spectrometer (Sercon Ltd., Cheshire, UK) at the UC Davis Stable Isotope Facility. The facility expresses measuring error as the long-term standard deviation of $0.2 \% \delta^{13} \mathrm{C}$ and 
$0.3 \% \delta^{15} \mathrm{~N}$. All benthic invertebrate samples were preserved in $70 \%$ ethanol and this preservation process can alter isotopic signatures. To correct for alteration of isotopic signatures, a constant adjustment factor was used, subtracting $0.39 \%$ from $\delta^{15} \mathrm{~N}$ and $1.18 \%$ from $\delta^{13} \mathrm{C}$ (Ventura and Jeppesen 2009).

\section{Statistics}

The densities of NZMS and macroinvertebrate feeding groups from each sampling site were calculated to obtain average density. Densities were $\log$ transformed $\left(\log _{10}(\mathrm{x})\right.$ $+1)$ to achieve normality. The assumption of normality was tested using the Shapiro-Wilk test and histograms and boxplots were used to visually observe normality. A one-way ANOVA with Tukey HSD post hoc test was conducted to test for differences between densities of NZMS between different systems (lake, river, and estuary).

For all sites and sampling dates, a Pearson's correlation was used to determine the relationship between the average NZMS density and average alpha diversity using the Shannon-Weiner diversity index $H^{\prime}=-\sum_{i=1}^{R} \rho_{i} \ln \rho_{i}$, where $\rho_{i}=$ is the fraction of individuals in a random sample that represent species $i$ (Gotelli and Ellison 2004). All sites were used to help determine if the presence and density of NZMS influenced diversity. Thus, both upstream and downstream sites of river systems were treated as independent replicates based on spatial distance of sampling sites, elevation differences, and substrate differences (Appendix H). Samples taken from 2006-2008 and from 20122013 (averaged within time period) were also treated as independent based on the time gap between sampling events (summer 2008 - summer 2012). I also analyzed the correlation between the density of NZMS and the density of individuals in specific feeding groups (herbivores, detritivores, omnivores, and predators) in the recipient 
community using Pearson's correlation. Herbivores, detritivores, and omnivores were deemed to be the most likely to compete for food sources with NZMS (Zaranko et al. 1997, Kerans et al. 2005) and predators were included because invasive species have been observed to facilitate predator densities (Rodriguez 2006). Analyses were performed using the basic R package version 3.0.1 (R Core Team 2013).

Correlations between NZMS densities and environmental variables (specific conductance, dissolved oxygen, $\mathrm{pH}$, and temperature) and variables representing propagule pressure (boat use days and trips) were examined using principal component analysis (PCA). Boat use days is a count of the number of boaters on a particular waterbody in a year (Oregon State Marine Board 2009). Trips is defined as leaving a residence to go boating at a waterbody; therefore, boaters living at a particular waterbody are not included in the trips count when boating at their home waterbody (Oregon State Marine Board 2009). Like the correlation analyses described above, both upstream and downstream sites, as well as both time periods were treated as independent replicates and used for PCA analysis.

Understanding the variables that influence macroinvertebrate diversity as well as NZMS density may indicate which ecosystems are most susceptible to the establishment of invasive species (Paavola et al. 2005). Regression trees are an appropriate tool for testing the variables that best describe NZMS density and community diversity because they are able to detect and reveal interactions in the data set, they are not affected by outliers, and regression trees can identify a reduced set of important variables from a large number of submitted variables (Olden et al. 2008). Regression trees used the same set of variables as PCA to predict which variables best define NZMS density and 
macroinvertebrate community diversity $\left(\mathrm{H}^{\prime}\right)$. A regression tree was run using $\mathrm{R}$ version 3.0.1 (R Core Team 2013) with the "tree" library, and PCA was run using the "MASS" and "vegan" libraries in R version 3.0.1 (R Core Team 2013).

To obtain a better understanding of how NZMS may be influencing or altering feeding habits in the benthic food web, the $\delta^{13} \mathrm{C}$ and $\delta^{15} \mathrm{~N}$ signatures of sampled benthic taxa at each site were examined (Appendix I). When comparing from ecosystem to ecosystem, the $\delta^{13} \mathrm{C}$ and $\delta^{15} \mathrm{~N}$ of an organism alone provides little information about its absolute trophic position or ultimate source of carbon because there is considerable variation among ecosystems (Post 2002); therefore, I obtained an isotopic baseline to estimate trophic position in each ecosystem. I used an equation derived from Post (2002) to determine an isotopic baseline that allowed for comparison between ecosystems where consumers acquire nitrogen from benthic food webs without pelagic influence: trophic position $=\lambda+\left(\delta^{15} \mathrm{~N}\right.$ secondary consumer $-\delta^{15} \mathrm{~N}$ base $) / \Delta_{\mathrm{n}}$, where $\lambda$ is the trophic position of the organism used to estimate $\delta^{15} \mathrm{~N}$ base (e.g., $\lambda=1$ for primary producers), $\delta^{15} \mathrm{~N}$ secondary consumer $\left(\delta^{15} \mathrm{~N}_{\mathrm{sc}}\right.$, or any higher consumer) is measured directly, and $\Delta_{\mathrm{n}}$ is the enrichment in $\delta^{15} \mathrm{~N}$ per trophic level or 3.4\%o. Organisms used as baselines for most sites were bivalve collector-filterers, which are typically long-lived primary consumers with tissue that is not very sensitive to short-term seasonal fluctuations in nutrients (Cabana and Rasmussen 1996, Post 2002). For sites absent of collector-filterers, other collector-gatherer taxa were used as the baseline organisms.

In order to examine potential competition between NZMS and native macroinvertebrates, I determined the amount of overlap in the feeding ranges of feeding groups (detritivore, herbivore, and omnivore) and NZMS using stable isotope analyses. I 
also examined the amount of overlap in the feeding ranges of predators and NZMS. Convex hulls can be used to represent the total extent of a feeding group's trait space or niche space (Cornwell et al. 2006, Layman et al. 2007). Convex hulls were created within each feeding group's scatter plot depicting the feeding range of individuals from a certain sampling location (at least 3 individuals were required to create the convex hull). Separate convex hulls of NZMS feeding range were also created for each site in which NZMS were present, which were overlaid with feeding group convex hulls (Appendix J), allowing measurement of the percent of overlap between the feeding ranges. The area of the hull was measured using the program ImageJ and scaled to the maximum feeding range value. These percentages were related to log-transformed NZMS densities of the same sampling location with Pearson's correlation. A one-way ANOVA with Tukey HSD post hoc test was conducted to test for significant differences in the amount of trophic overlap shared between NZMS the different feeding groups. The ranges created by the convex hulls were produced in the "basic" R library version 3.0.1 (R Core Team 2013) and correlation analyses were performed with the libraries "ggplot2" in R version 3.0.1 (R Core Team 2013).

\section{Results}

This study revealed some dramatic changes in NZMS densities over time as well as new detections at previously undetected sites. Notably, NZMS were detected for the first time in the lower Siuslaw River at the Tiernan boat ramp in summer 2012 and in the Nestucca River Estuary in summer 2013 (Figure 3.2). Conversely, the densities of NZMS at the Umpqua River downstream sites appeared to have declined over the seven year sampling period from $\sim 3,200 \mathrm{NZMS} \cdot \mathrm{m}^{-2}$ to $\sim 30 \mathrm{NZMS} \cdot \mathrm{m}^{-2}$ (Figure 3.2). The Deschutes 
River upstream sites had consistently low NZMS densities with a slight upward trend over the study period (Figure 3.2). NZMS densities remained high in Youngs Bay throughout the sampling period, with values averaging around 10,000 NZMS $\cdot \mathrm{m}^{-2}$ (Figure 3.2). There were no or few detections of NZMS at the upstream and downstream reaches of the John Day River, Siuslaw River upstream, Umpqua River upstream, and the Deschutes River downstream (average $<2 \mathrm{NZMS} \cdot \mathrm{m}^{-2}$ ) sites during every sampling period (see Appendix K for densities).

NZMS densities varied greatly across lakes, rivers, and estuaries (Figure 3.3). Estuaries on average had the greatest densities of NZMS followed by lakes, and then rivers (Figure 3.3). There was a significant difference in NZMS densities between ecosystems $(F=10.16, p=0.002)$ : a Tukey HSD test determined that the main difference occurred between river and estuary sites $(p=0.001$; Figure 3.3$)$. No significant differences in NZMS densities were found between lake and estuary sites $(p=0.332)$. River and lake sites had nearly significantly different NZMS densities $(p=0.079)$.

There was a wide range of macroinvertebrate species diversity among the sites: the lowest diversity averaged over time was $\mathrm{H}^{\prime}=0.46$ (Siuslaw River downstream 20062008), whereas the highest alpha diversity was $H^{\prime}=2.40$ (John Day River downstream 2012; Figure 3.4). Within each system (lakes, rivers, or estuaries), there was no significant correlation between NZMS densities and the macroinvertebrate diversity (lakes $r=-0.422, n=6, p=0.404$; estuaries $r=-0.396, n=7, p=0.379$; rivers $r=-0.273, n=16$, $p=0.307$; Figure 3.4). However, across all sites, systems, and sampling periods there was a significant negative correlation between NZMS density and the diversity of the benthic invertebrate community ( $r=-0.476, n=29, p=0.009$; Figure 3.4$)$. 
At all sampled sites, there was a modestly significant negative correlation between NZMS densities and the densities of herbivores $(r=-0.366, n=29, p=0.051)$ (Figure 3.5a). Conversely, there was a significant positive correlation between NZMS densities and the densities of omnivores $(r=0.393, n=29, p=0.035$; Figure 3.5d). However, detritivore densities $(r=0.205, n=29, p=0.286)$ and predator densities $(r=0.279, n=29$, $p=0.144$ ) had no significant correlations with NZMS densities (Figure 3.5b, c).

A Principal Components Analysis (PCA) was performed for all sampling sites to indicate which environmental factors and propagule pressures correlate with NZMS densities in each of these distinct ecosystem types (lake, river, and estuary; Figure 3.6a). Trips to a waterbody and boat use days at a waterbody were correlated with principal component I (PC I), which explained 52.8\% of the variance between sites (Figure 3.6a). Principal component II (PC II) explained $41.0 \%$ of the variance between the sampling sites and was influenced primarily by specific conductance (Figure 3.6a), which was highest in estuaries. PC I and PC II explained $93.8 \%$ of the total variance between sampling sites. An additional PCA was performed for just the freshwater sampling sites to indicate which environmental factors and propagule pressures correlate with NZMS densities in lakes and rivers without the amplified variance of the high specific conductance in estuaries (Figure 3.6b). Trips to a waterbody and boat use days at a waterbody were the most influential variables driving principal component I (PC I), which explained $81.6 \%$ of the variance between sites (Figure 3.6b). Principal component II (PC II) explained $10.8 \%$ of the variance between the sampling sites and was influenced primarily by specific conductance and $\mathrm{pH}$ (Figure 3.6b). PC I and PC II explained 92.4\% of the total variance between freshwater sampling sites. 
A regression tree was run to help determine which abiotic and propagule pressure (i.e., boat use days and trips) variables at all sites best predicted NZMS densities as well as native macroinvertebrate diversity (Figure 3.7a,b). Higher specific conductance $\left(>2,029 \mu \mathrm{S} \cdot \mathrm{cm}^{-1}\right)$ predicted the highest NZMS densities at an average of 703.1 individuals $\cdot \mathrm{m}^{-2}$ (Figure $\left.3.7 \mathrm{a}\right)$. The lowest NZMS densities $\left(1.04\right.$ individuals $\cdot \mathrm{m}^{-2}$ ) were predicted by lower specific conductance $\left(<2,029 \mu \mathrm{S} \cdot \mathrm{cm}^{-1}\right)$, high dissolved oxygen $(>9.13$ $\left.\mathrm{mg} \cdot \mathrm{L}^{-1}\right)$, and high $\mathrm{pH}(>8.09$; Figure $3.7 \mathrm{a})$. Low native macroinvertebrate diversity $\left(\mathrm{H}^{\prime}=0.915\right)$ was found in sites with moderate specific conductance $\left(>317.4 \mu \mathrm{S} \cdot \mathrm{cm}^{-1}\right)$, whereas the highest diversity was predicted to occur at lower specific conductance $\left(<317.4 \mu \mathrm{S} \cdot \mathrm{cm}^{-1}\right)$ and lower temperatures $\left(<18.12^{\circ} \mathrm{C}\right)$ (Figure 3.7b). An additional regression tree was also run without estuaries to help determine which variables best predicted NZMS densities as well as native macroinvertebrate diversity in the freshwater sampling sites (Figure 3.7c,d). Lower dissolved oxygen $\left(<9.13 \mathrm{mg} \cdot \mathrm{L}^{-1}\right)$ predicted the highest NZMS densities at an average of 395.4 individuals $\cdot \mathrm{m}^{-2}$ (Figure $3.7 \mathrm{c}$ ). The lowest NZMS densities $\left(1.04\right.$ individuals $\left.\cdot \mathrm{m}^{-2}\right)$ were predicted by higher dissolved oxygen $(>9.13$ $\left.\mathrm{mg} \cdot \mathrm{L}^{-1}\right)$ and high $\mathrm{pH}(>8.09$; Figure $3.7 \mathrm{c})$. Low native macroinvertebrate diversity $\left(H^{\prime}=1.11\right)$ was found in sites with higher boat use days $(>4753)$, whereas the highest diversity $\left(H^{\prime}=1.97\right)$ was predicted to occur at freshwater waterbodies with lower boat use days $(<4753)$ and lower average surface water temperatures $\left(<18.12^{\circ} \mathrm{C}\right.$; Figure $\left.3.7 \mathrm{~d}\right)$. Differences in variables between the NZMS density trees and the diversity trees indicate that NZMS aren't simply responding to the sites that are good for native taxa.

The degree of feeding similarity between NZMS and its competitors was evaluated using the amount of overlap between trophic niches as observed with stable isotope 
analyses. The amount of overlap between NZMS feeding ranges and each particular feeding group's (herbivore, detritivore, omnivore, or predator) feeding range was not significantly different $(F=1.711, p=0.182$; Figure 3.8$)$. A Tukey HSD test identified herbivore-NZMS trophic overlap and detritivore-NZMS trophic overlap were the most dissimilar but not significantly different ( $p=0.198$; Figure 3.8 ). Additionally, though there was a tendency for high density NZMS sites to show a greater degree of feeding overlap between NZMS and a specific feeding group (herbivore, detritivore, omnivore, or predator), none of the correlations were significant (herbivores $r=0.438, n=7, p=0.326$; detritivores $r=0.366, n=10, p=0.298$; omnivores $r=-0.552, n=11, p=0.078$; predators $r=$ $0.472, n=12, p=0.121$; Figure 3.9 ). For NZMS feeding range, there is a nearly significant positive correlation between the size of the feeding range and NZMS density ( $r=0.570$, $n=10, p=0.086$; Figure 3.10 ) suggesting that as NZMS densities increased their feeding range also increased.

\section{Discussion}

New Zealand mud snails are unique in their ability to successfully establish in a variety of very different aquatic environments, and range widely in the densities at which they occur in aquatic environments. My research objectives were spurred by the unique ecology of NZMS. I sought to describe how NZMS densities differ across invaded sites and over time in specific sites and what factors control the density differences, and to describe the influence NZMS might have at these varying densities on diversity and benthic food web feeding ranges. This study is unique in that it observes NZMS population dynamics and their influence on native food webs simultaneously across multiple ecosystem types (rivers, lakes, and estuaries), in contrast to previous studies that 
examined NZMS population dynamics and their influence on specific food webs in either freshwater or brackish ecosystems (Hall et al. 2006, Bersine et al. 2008, Moore et al. 2012). As expected, this study observed varying densities of NZMS throughout all ecosystems and sites. Additionally, variations were observed on how NZMS may be influencing invaded communities. There are three major mechanisms that could have driven these changes in NZMS densities as well as their influence on benthic communities: NZMS population dynamics, biotic controls (competition/predation), and abiotic and human-mediated (propagule pressure) controls.

\section{NZMS Population Dynamics}

There was significant variation in the population dynamics of NZMS, which may be the result of boom and bust cycles. NZMS densities tend to boom and bust seasonally and even more dramatically on longer time scales (Kerans et al. 2005, Moore et al. 2012). Although the three ecosystems surveyed are uniquely different from each other, NZMS densities were only significantly different in estuaries compared to rivers, with estuaries having $\sim 92.5 \%$ larger populations than rivers, on average (Figure 3.3). This result does not come as a great surprise considering NZMS have been known to thrive in a variety of lake, river, and estuarine ecosystems (Zaranko et al. 1997, Richards et al. 2001, Hoy et al. 2012). However, I believe the variation in NZMS densities between estuaries and rivers is more likely due to abiotic and biotic conditions. Biodiversity in estuaries is typically controlled more by the ability to tolerate disturbance rather than being controlled by competition (Kittelson and Boyd 1997, Chabrerie et al. 2001), whereas environmental conditions tend to be comparatively less harsh in rivers. It is well known that invasions can be promoted by disturbance through the creation of available 
niche space (Hobbs and Huenneke 1992, Mack and D'Antonio 1998). Because of these variations in population dynamics, it is important to understand the influence of NZMS at varying densities on benthic communities in a range of different ecosystems.

\section{Biotic Controls}

Biotic variables like predation and competition may influence NZMS densities, as well as the impact of NZMS on native communities. Comparing the density of an invasive population and the diversity of the native community may provide a better understanding of what type of community is most vulnerable to establishment and higher densities of invaders. In fact, isolated, young, and species-poor communities have been shown to be more vulnerable to invasion (Elton 1958). The results of this study showed a trend of higher NZMS density in communities with lower diversity when comparing across all ecosystems, which supports my hypothesis that there is a negative relationship between NZMS density and community diversity. There are two possible interpretations of this result: first, NZMS may be having a negative effect on the biodiversity of the invaded communities via competition, and second, NZMS have more establishment success and spread in systems with already low native diversity. Other studies of invasive species have found this same pattern and determined that low species richness and diversity provided less competition for establishing species and a wider range of unoccupied niches (Wolff 1998, Leppäkoski and Olenin 2000, Paavola et al. 2005). In this study I contend that it is more likely that NZMS densities thrive in systems with low biodiversity and ample niche space rather than NZMS outcompeting native competitors, and this is supported by the lack of feeding range overlap of NZMS and other benthic feeding groups (Figure 3.8). 
Stable isotopes can be used to examine competition for feeding resources (Post 2002, Moore et al. 2012, Hill et al. 2015). I observed very little overlap between NZMS feeding range and that of benthic competitor's and predator's feeding ranges (average overlap across all feeding groups $=5.3 \%$ ) and no relationship with NZMS density (Figure 3.9; Appendix J), which would indicate that NZMS are not currently competing with these other feeding groups for food. A possible explanation for this trend could be that NZMS at high densities have already forced competitors to change their diets (e.g., Hall et al. 2006, Moore et al. 2012). However, I also observed a nearly significant trend that at higher NZMS density sites the feeding range of NZMS was comparatively larger than at sites with low NZMS densities, which did not support my hypothesis that the NZMS feeding range would become more specialized at higher densities (Figure 3.9). A larger feeding range would indicate a more generalized diet and thus would not be likely to force competing feeding groups to change their diets. Therefore, this study did not observe Eltonian niche shifts among any surveyed feeding group. Biotic components like community diversity may be a good indicator of where establishment and high NZMS densities may be most successful, but the competition of specific feeding groups does not appear to influence or be influenced by NZMS densities in these sites.

\section{Abiotic and Human-Mediated Controls}

Abiotic and human-mediated controls may have a more apparent influence on NZMS establishment and densities. Although NZMS can tolerate a wide range of abiotic conditions due to the presence of an operculum (Zaranko et al. 1997, Dybdahl and Kane 2005, Alonso and Castro-Díez 2008), it is reasonable to expect that densities may be controlled by abiotic and human-mediated factors, such as those that increase propagule 
pressure. Across all of my sampling sites, the sites with higher specific conductance (mainly estuaries) had higher NZMS densities (Figure 3.7a). Conversely when looking across all of my sites, I found that higher specific conductance was associated with lower community diversity, which may again suggest NZMS thrive in systems with unoccupied niche space and that increased niche availability may be due in part by relatively harsh abiotic conditions (Figure 3.7b). Additionally, analysis on just my freshwater sites indicated sites with lower dissolved oxygen had higher NZMS densities (Figure 3.7c). However, I found that dissolved oxygen was not a predicting factor for invertebrate community diversity in my freshwater sites. The lowest community diversities were associated with freshwater sites that had the greatest boat use days, which may suggest that boaters are decreasing diversity by introducing non-native species that out-compete native species or boaters may be disturbing these waterbodies creating conditions not favorable to diversity (Figure 3.7d). Relatively harsh abiotic conditions like low dissolved oxygen (freshwater sites) and higher specific conductance (estuarine sites) have been observed to make a system vulnerable to NZMS establishment (Herbst et al. 2008). In contrast, systems with very low disturbance like freshwater streams with constant temperatures and flow rates have also shown to be conducive to NZMS establishment and can promote high densities (Hall et al. 2003, Kerans et al. 2005, Alonso and CastroDíez 2008). NZMS densities thriving at low disturbance (other studies) and high disturbance (this study) may be explained by the intermediate disturbance hypothesis.

In the intermediate disturbance hypothesis, diversity forms a bell shaped curve in relation to disturbance where low disturbance and high disturbance both result in lower diversity (Connell 1978, Townsend et al. 1997). As previously mentioned, this study 
found that diversity and NZMS densities were negatively correlated, thus more disturbed systems may be creating available niche space for NZMS due to a lack of diversity. Furthermore, establishment of NZMS may be greatly dependent on human-mediated controls like boater trips to a waterbody, particularly considering the spread of NZMS is likely exacerbated by overland dispersal by boaters (Buchan and Padilla 1999, Leung et al. 2006, Vander Zanden and Olden 2008). Although the boat use day variable was not a predictor of NZMS densities in this study, it was a predictor of freshwater invertebrate community diversity (Figure 3.7). It is possible boat use days and trips were not significant variables at predicting NZMS densities in this study because there can be a lag time between the establishment of an invasive species and when the species spreads and increases in population density (Sakai et al. 2001). A more predictive variable might be the date at which NZMS were first introduced or how long they have been established, but I did not have enough reliable information to include these variables. Regardless of how NZMS were introduced, once they become established in a community due to a combination of favorable biotic and abiotic controls it is essential to measure their ecological effect on the system.

\section{Ecological Influence}

The relationship between NZMS populations and specific feeding groups may provide a good understanding of how invasive species affect native communities. My study indicated that there was a significant negative correlation between NZMS densities and the density of herbivores (Figure 3.5a). This negative relationship supports my hypothesis that NZMS densities would be inversely related to competitor herbivore densities and supports other studies' findings of competitive exclusion at high invasive 
herbivore densities (Byers 2000, Mooney and Cleland 2001, Hall et al. 2006). However, this result may be skewed due to the absence of herbivores in estuarine systems in which many NZMS densities were high. These estuaries may not actually be absent of herbivores, instead a taxa like oligochaetes (classified as detritivores or collectorgatherers; Appendix I) may be functioning as herbivores in these estuaries to help fill the empty niche. In my estuarine stable isotope plots there is some overlap between NZMS feeding range and the feeding range of collector-gatherers (like the oligochaete) and sometimes collector-filterers (Appendix I). Common collector-filterers captured in my estuaries include the Asian clam (Corbicula fluminea) and the fingernail clam (Sphaeriidae). Neither of these taxa have shown evidence as acting as an herbivore grazer. In contrast, omnivores were abundant at all my sites and were positively correlated to NZMS densities (Figure 3.5d). This positive correlation may indicate that NZMS are facilitating omnivore feeding groups. Another potential explanation is that the systems that are suitable for NZMS are also suitable for omnivores. Studies have observed that factors promoting native species richness and density, such as propagule pressure, can also promote the establishment and population density of invasive species (Levine 2000, Schreiber et al. 2002, Brenneis et al. 2010). Furthermore, NZMS have the ability to break down large organic matter making it available for native fauna and can also provide high nutrient waste, potentially facilitating native taxa (Schreiber et al. 2002). Yet, detritivores were not correlated with NZMS in my study. My analysis of feeding groups may provide more accurate information about the ecological role of NZMS and whether their effect is feeding group dependent. The ecological effects of NZMS on their invaded systems was varied in my study, and further investigation of their 
influence on these three highly diverse ecosystems is necessary for future management efforts.

\section{Conclusion}

Overall, this study found that estuarine systems were the most conducive to high densities of NZMS possibly due to the available niche space in a disturbance controlled estuary as opposed to the lack of niche space in the more competition-controlled rivers and lakes. However, even at high NZMS densities in estuaries and some of the freshwater systems, this study did not support the conventional wisdom that the invasive NZMS will out-compete native taxa or markedly influence a change in competitors' diets. In fact, some competitors may even be facilitated by NZMS densities in this study. It is tempting to make generalizations about invasive species and their influence on communities, but this study echoes the findings of multiple other studies illustrating that the influence of invasive species is often subtle and dependent on the composition of the recipient community. NZMS at higher densities than what were found in this study may have a greater influence on native competitors. Thus, management should focus on proactive approaches to minimize NZMS densities and keep NZMS from spreading to systems with available niche space. Therefore, the focus of this management should be on systems potentially controlled by disturbance rather than competition in which NZMS populations can reach extremely high densities. 


\section{Tables and Figures Chapter 3}

Table 3.1. Sampling design for New Zealand mud snails (NZMS) and benthic invertebrate surveys from 2006 to 2013.

\begin{tabular}{|c|c|c|c|c|c|c|}
\hline Ecosystem & Ecoregion & Site & $\begin{array}{l}\text { Sample } \\
\text { Years }\end{array}$ & $\begin{array}{l}\text { Sample Size \& Site } \\
\text { Description }\end{array}$ & Location & $\begin{array}{l}\text { Year: } \\
\text { NZMS? }\end{array}$ \\
\hline \multirow[t]{15}{*}{ River } & \multirow[t]{7}{*}{ Coastal Rivers } & Siuslaw & 2006 & Rocky substrate & $44.031 \mathrm{~N}$ & 2006: No \\
\hline & & Upstream & $2012-2013$ & $(\mathrm{n}=4)$ & $-123.858 \mathrm{~W}$ & 2013: No \\
\hline & & Siuslaw & 2006 & Tidally influenced, & $43.967 \mathrm{~N}$ & 2006: No \\
\hline & & Downstream & $2012-2013$ & mudflats (4) & $-124.102 \mathrm{~W}$ & 2013: Yes \\
\hline & & Umpqua & 2006-2008 & Rocky substrate, & $43.650 \mathrm{~N}$ & 2006: No \\
\hline & & Upstream & 2012-2013 & bedrock (4) & $-123.839 \mathrm{~W}$ & 2013: Yes \\
\hline & & $\begin{array}{l}\text { Umpqua } \\
\text { Downstream }\end{array}$ & $2006-2013$ & $\begin{array}{l}\text { Tidally influenced, } \\
\text { silt/sand (4) }\end{array}$ & $\begin{array}{l}43.710 \mathrm{~N} \\
-124.095 \mathrm{~W}\end{array}$ & $\begin{array}{l}\text { 2006: Yes } \\
\text { 2013: Yes }\end{array}$ \\
\hline & \multirow{8}{*}{$\begin{array}{l}\text { Columbia } \\
\text { Plateau Rivers }\end{array}$} & John Day & \multirow{2}{*}{$2006-2012$} & \multirow{2}{*}{$\begin{array}{l}\text { Rocky and gravel } \\
\text { substrate (4) }\end{array}$} & $45.858 \mathrm{~N}$ & 2006: No \\
\hline & & Upstream & & & $-120.409 \mathrm{~W}$ & 2012: No \\
\hline & & John Day & \multirow[t]{2}{*}{$2006-2012$} & \multirow{2}{*}{$\begin{array}{l}\text { Rocky and gravel } \\
\text { substrate (4) }\end{array}$} & $45.706 \mathrm{~N}$ & 2006: No \\
\hline & & Downstream & & & $-120.602 \mathrm{~W}$ & 2012: No \\
\hline & & Deschutes & \multirow{2}{*}{ 2006-2012 } & \multirow{2}{*}{$\begin{array}{l}\text { Gravel and } \\
\text { bedrock(5) }\end{array}$} & $45.388 \mathrm{~N}$ & 2006: Yes \\
\hline & & Upstream & & & $-120.871 \mathrm{~W}$ & 2012: Yes \\
\hline & & Deschutes & \multirow[t]{2}{*}{$2006-2012$} & \multirow[t]{2}{*}{ Silt and bedrock (4) } & $45.633 \mathrm{~N}$ & 2006: Yes \\
\hline & & Downstream & & & $-120.913 \mathrm{~W}$ & 2012: Yes \\
\hline \multirow[t]{10}{*}{ Estuary } & \multirow{10}{*}{$\begin{array}{l}\text { Brackish } \\
\text { Estuaries }\end{array}$} & Columbia: & \multirow[t]{2}{*}{$2006-2013$} & \multirow{2}{*}{$\begin{array}{l}\text { Mudflats(3), Rocky } \\
\text { shore(2), Pelagic(1) }\end{array}$} & $46.170 \mathrm{~N}$ & 2006: Yes \\
\hline & & Youngs Bay & & & $-123.834 \mathrm{~W}$ & 2012: Yes \\
\hline & & Tillamook & 2013 & Mudflats(2), & $45.472 \mathrm{~N}$ & 2013: Yes \\
\hline & & & & Rocky(3), Pelagic(1) & $-123.891 \mathrm{~W}$ & \\
\hline & & Nestucca & 2013 & Mudflats/Organic(3), & $45.207 \mathrm{~N}$ & 2013: Yes \\
\hline & & Yaquina & 2013 & Mudflats/Organic (5), & $44.591 \mathrm{~N}$ & 2013: Yes \\
\hline & & & & Pelagic (1) & $-123.943 \mathrm{~W}$ & \\
\hline & & Coquille & 2013 & Mudflats/Rocky(3), & $43.148 \mathrm{~N}$ & 2013: No \\
\hline & & & & Rocky(2), Pelagic(1) & $-124.401 \mathrm{~W}$ & \\
\hline & & Rogue & 2013 & Mudflats/Rock(2), & $\begin{array}{l}42.420 \mathrm{~N} \\
-124423 \mathrm{~W}\end{array}$ & 2013: Yes \\
\hline \multirow[t]{8}{*}{ Lake } & \multirow{8}{*}{ Coastal Lakes } & Coffenbury & 2013 & Littoral (5): Muddy/ & $46.173 \mathrm{~N}$ & 2013: Yes \\
\hline & & & & organic; Pelagic (1) & $-123.963 \mathrm{~W}$ & \\
\hline & & Cullaby & 2013 & $\begin{array}{l}\text { Littoral (5): Sandy/ } \\
\text { silty; Pelagic (1) }\end{array}$ & $\begin{array}{l}46.087 \mathrm{~N} \\
-123.906 \mathrm{~W}\end{array}$ & 2013: No \\
\hline & & Lytle & 2013 & Littoral (5): Muddy/ & $45.624 \mathrm{~N}$ & 2013: Yes \\
\hline & & & & organic; Pelagic (1) & $-123.940 \mathrm{~W}$ & \\
\hline & & Devils & 2013 & $\begin{array}{l}\text { Littoral (5): Sandy/ } \\
\text { rock; Pelagic (1) }\end{array}$ & $\begin{array}{l}44.979 \mathrm{~N} \\
-123.991 \mathrm{~W}\end{array}$ & 2013: Yes \\
\hline & & Mercer & 2013 & $\begin{array}{l}\text { Littoral (5): Organic/ } \\
\text { sandy; Pelagic (1) }\end{array}$ & $\begin{array}{l}44.048 \mathrm{~N} \\
-124.075 \mathrm{~W}\end{array}$ & 2013: No \\
\hline & & Garrison & 2013 & $\begin{array}{l}\text { Littoral (5): Organic/ } \\
\text { sandy; Pelagic (1) }\end{array}$ & $\begin{array}{l}42.754 \mathrm{~N} \\
-124.506 \mathrm{~W}\end{array}$ & 2013: Yes \\
\hline
\end{tabular}


Table 3.2. The median, minimum, maximum, and standard deviation of abiotic variables in the freshwater coastal lakes, freshwater rivers, and brackish estuaries sampled through the extent of the research.

\begin{tabular}{llrrr}
\hline & & Rivers & \multicolumn{1}{c}{ Lakes } & \multicolumn{1}{c}{ Estuaries } \\
\hline Temperature & Median & 13.5 & 21.6 & 19.1 \\
$\left({ }^{\circ} \mathbf{C}\right)$ & Min & 12.2 & 19.7 & 17.3 \\
& Max & 24.2 & 22.6 & 22.2 \\
& Standard Deviation & 4.09 & 1.01 & 1.49 \\
Dissolved & Median & 10.7 & 8.14 & 8.21 \\
Oxygen & Min & 7.75 & 7.54 & 7.01 \\
$\left(\mathbf{m g} \cdot \mathbf{L}^{-1}\right)$ & Max & 11.4 & 8.63 & 9.03 \\
& Standard Deviation & 1.30 & 0.41 & 0.73 \\
Specific & Median & 131.7 & 119.5 & 6900 \\
Conductance & Min & 53.5 & 74.5 & 2710 \\
$\left(\boldsymbol{\mu S} \cdot \mathbf{c m}^{-1}\right)$ & Max & 449.9 & 202 & 19650 \\
& Standard Deviation & 127.1 & 40.5 & 6824 \\
$\mathbf{p H}$ & Median & 7.92 & 7.68 & 7.57 \\
& Min & 7.08 & 6.7 & 6.81 \\
& Max & 8.40 & 8.25 & 8.37 \\
& Standard Deviation & 0.46 & 0.48 & 0.51 \\
\hline
\end{tabular}




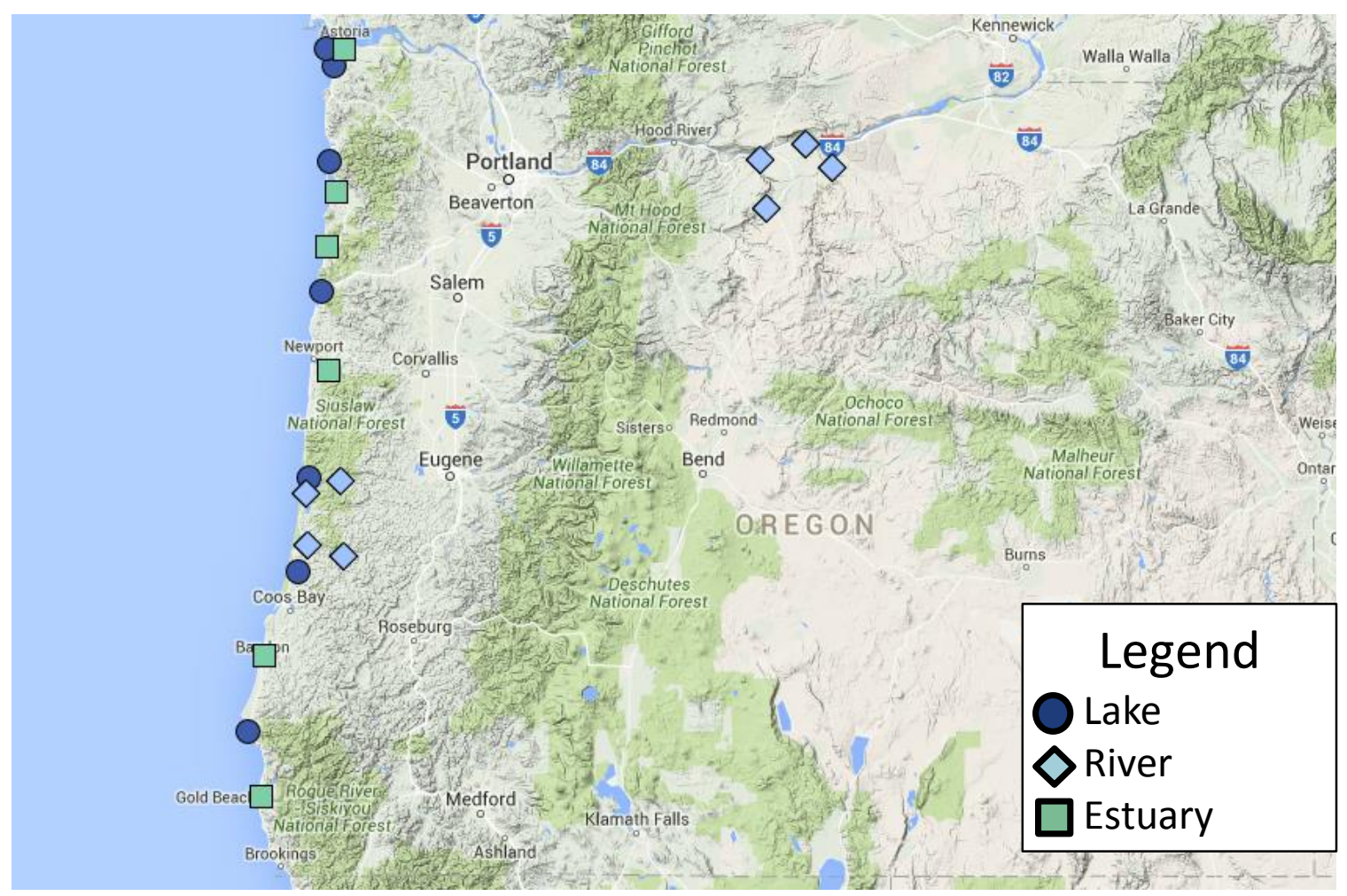

Figure 3.1. A relief map of Oregon, USA depicting the New Zealand mud snail sampling locations and the type of waterbody for each location. 


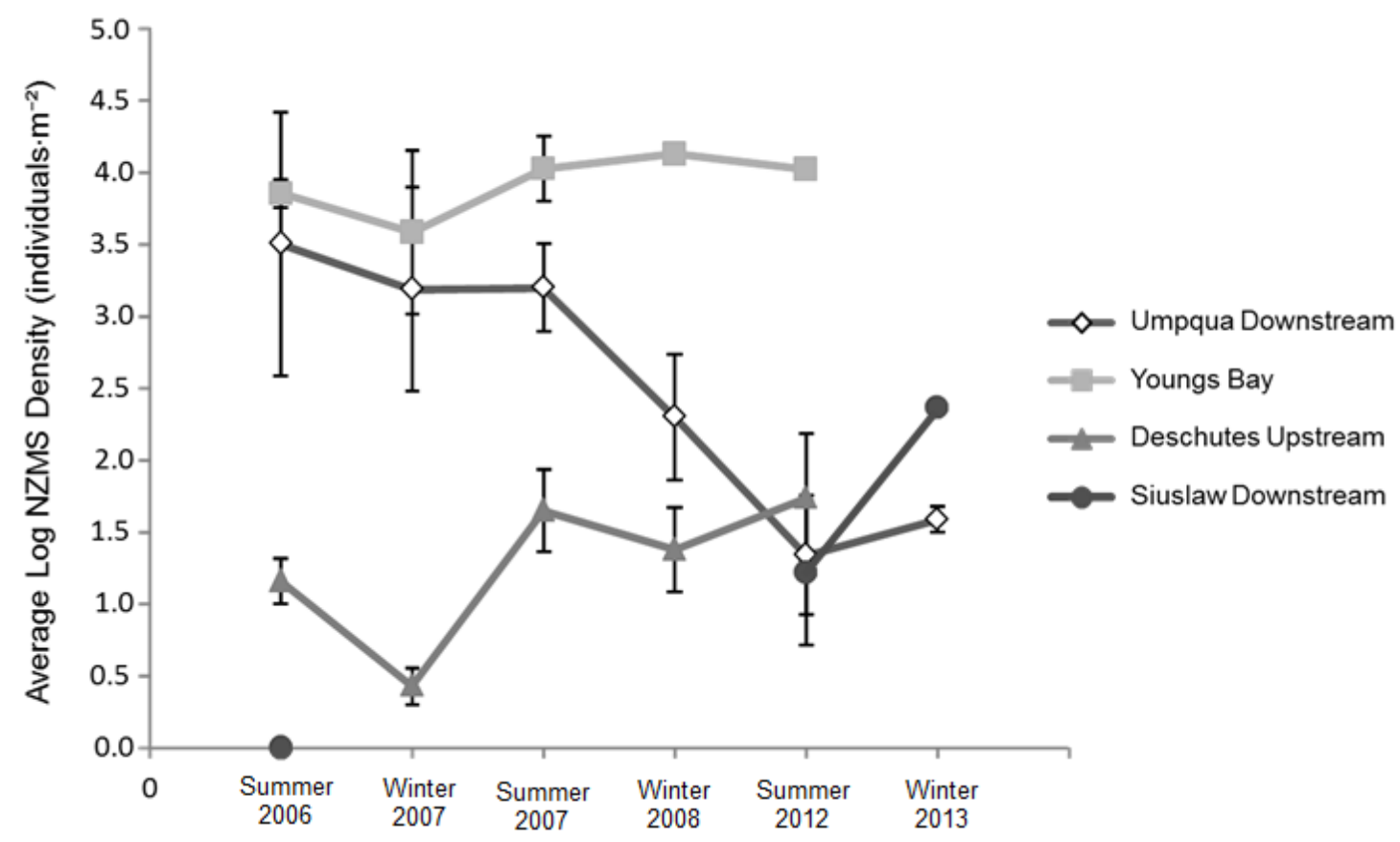

Figure 3.2. The average $\log _{10}$ New Zealand mud snail (NZMS) density (individuals $\cdot \mathrm{m}^{-2}$ ) at each of the sites tested from 2006-2013 ( \pm 1 standard error). Only the Umpqua downstream and Siuslaw downstream river sites were sampled in the winter of 2013. Deschutes downstream, Umpqua upstream, Siuslaw upstream, and the John Day River upstream and downstream were not included in this graph due to absence or near absence of NZMS at every sampling period. 


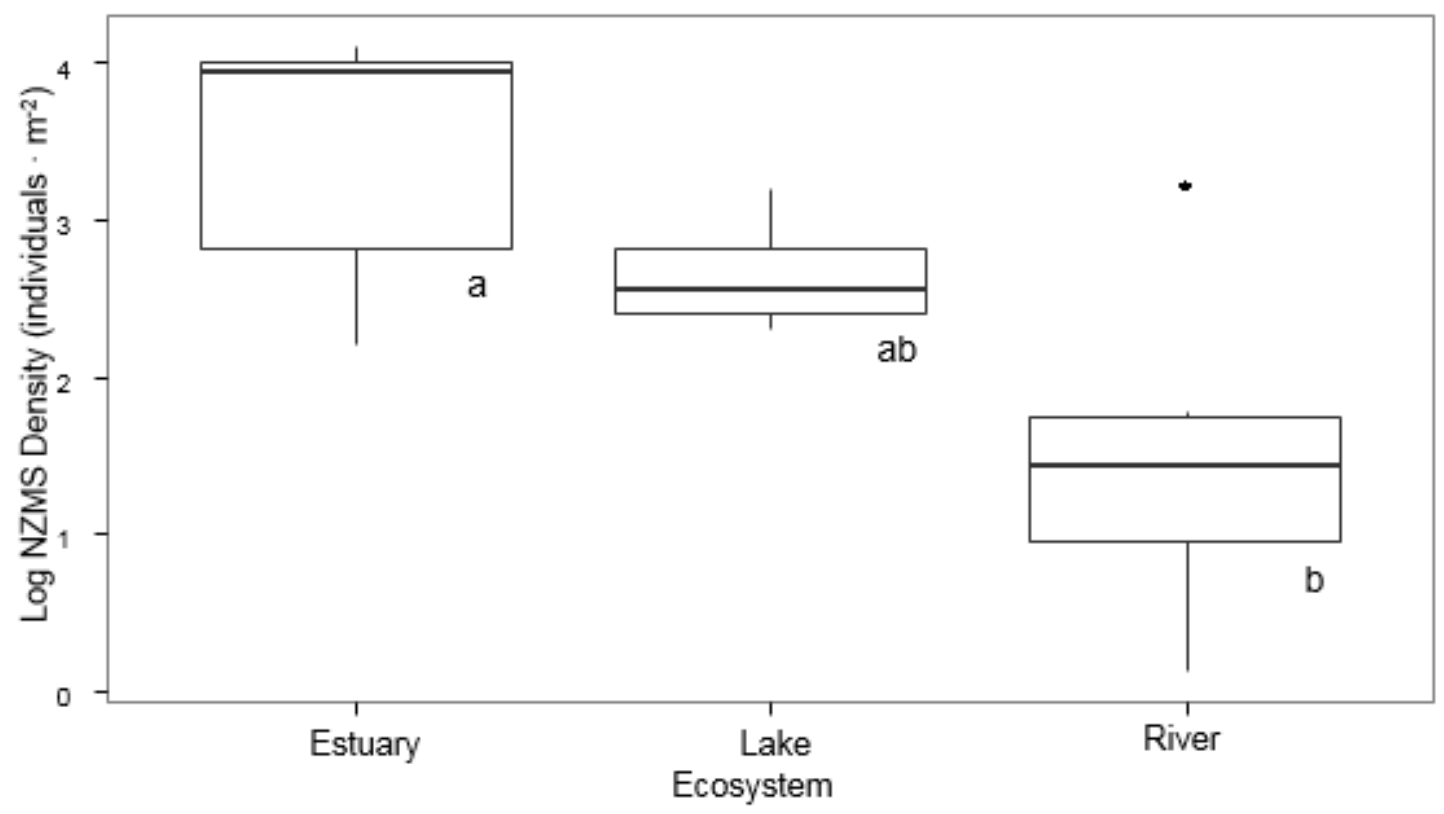

Figure 3.3. Boxplots depicting the range of $\log _{10}$ New Zealand mud snail (NZMS) density (individuals $\cdot \mathrm{m}^{-2}$ ) in estuaries $(\mathrm{n}=7)$, lakes $(\mathrm{n}=4)$, and rivers $(\mathrm{n}=7)$ including all samples and all sampling periods. Only sites with NZMS present were included in the boxplots. The center line of each box represents the median NZMS density in that ecosystem. The lower reach of the box represents the lower quartile and the upper reach of the box represents the upper quartile. The whiskers of the boxplots represent variability outside the upper and lower quartile within the $5^{\text {th }}$ and $95^{\text {th }}$ percentile range, with the black symbol representing an outlier $\left(>95^{\text {th }}\right.$ percentile). Letters represent the results of Tukey HSD post hoc tests, where different letters are significantly different from each other $(\mathrm{p}<0.05)$. 


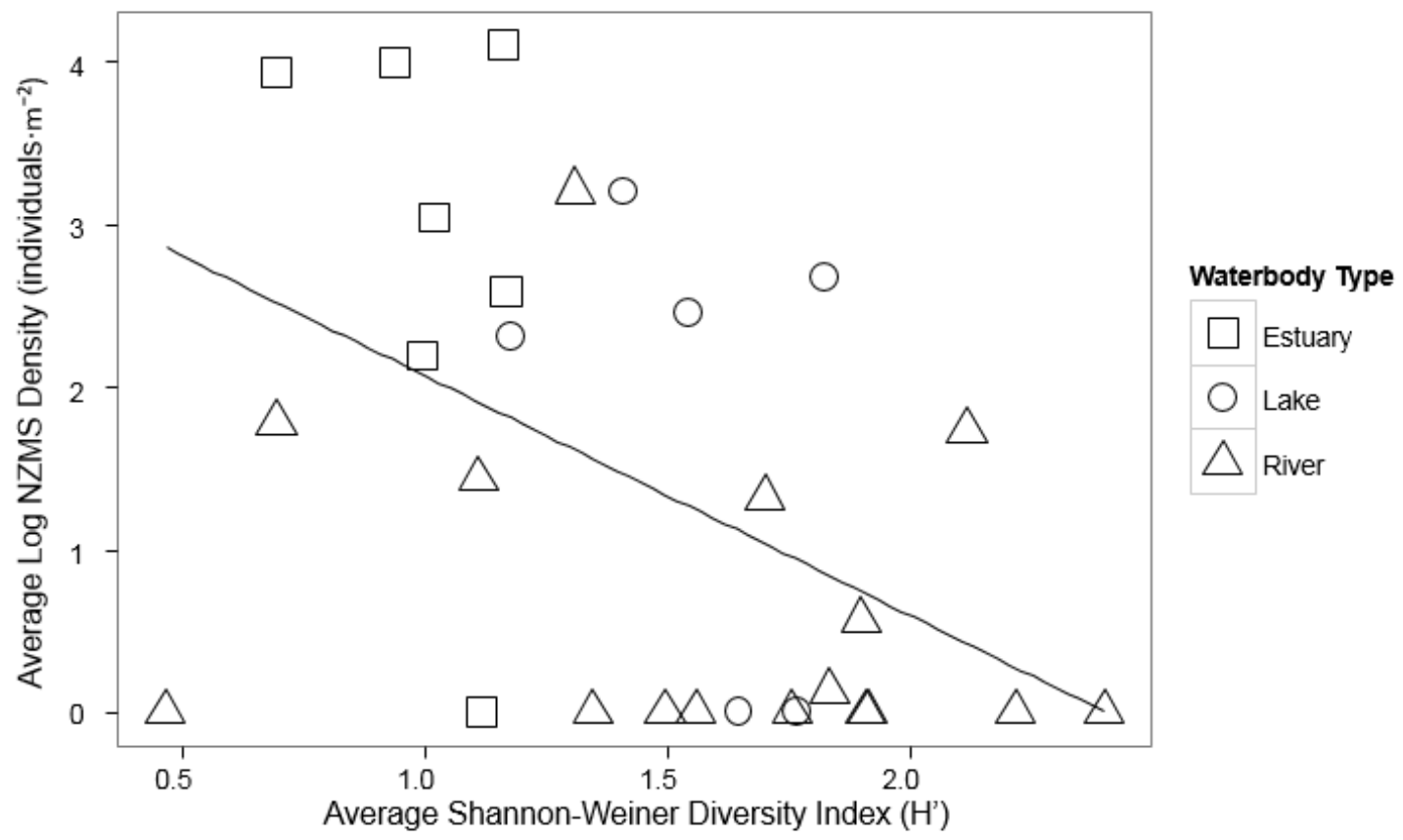

Figure 3.4. A correlation $(r=-0.476)$ of the average log-transformed New Zealand mud snails (NZMS) density and average Shannon-Weiner diversity index $\left(\mathrm{H}^{\prime}\right)$ of every system, at all sampling sites, and throughout the extent of the sampling effort. Rivers are represented by triangles, estuaries are represented by squares, and lakes are represented by circles. Only sites with NZMS present were included. 

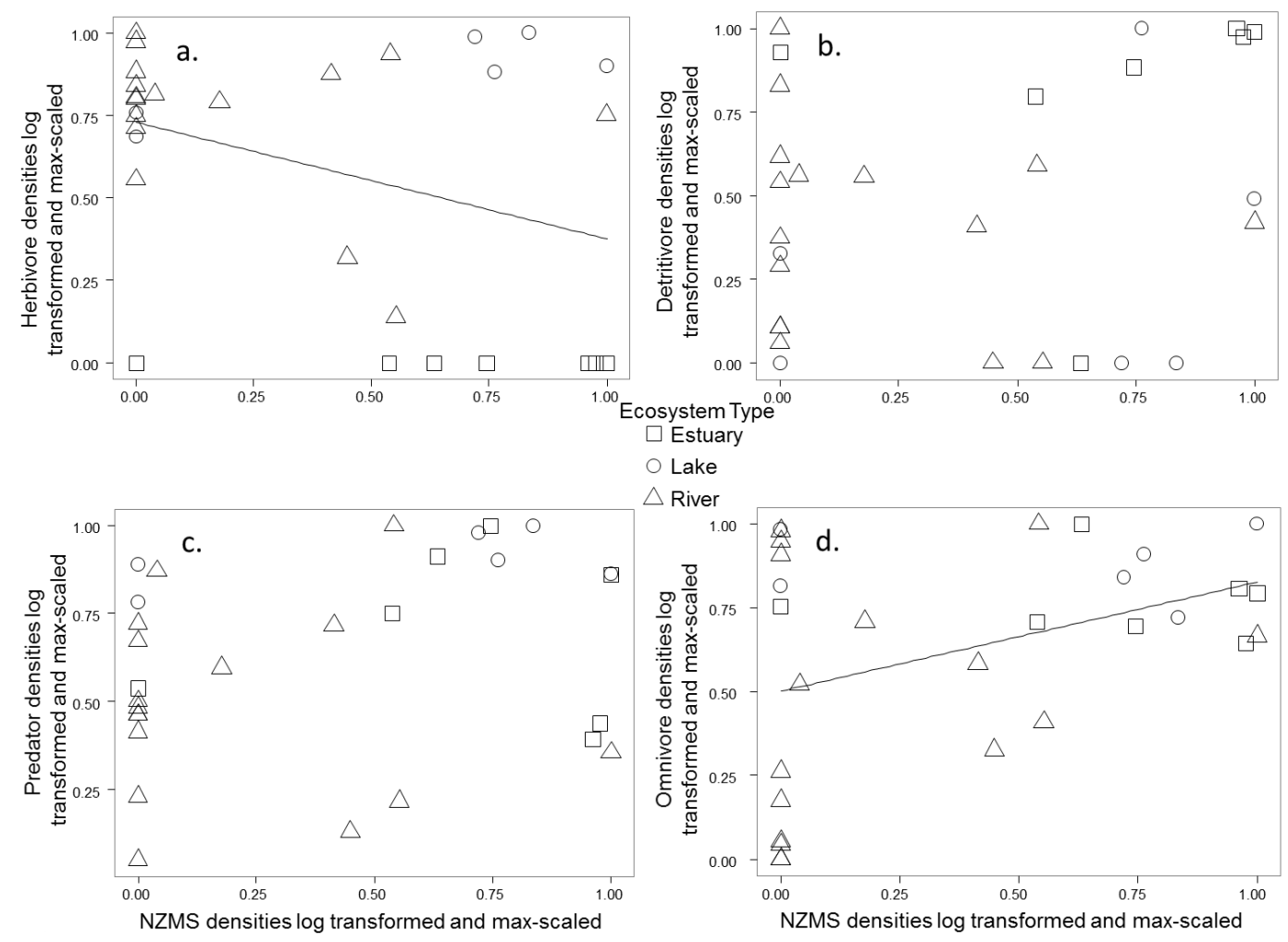

Figure 3.5. Correlation analyses representing the relationships of average $\log _{10^{-}}$ transformed and scaled to the maximum value (max-scaled) New Zealand mud snails (NZMS) densities and log-transformed, max-scaled densities of specific macroinvertebrate feeding groups: (a) herbivore, (b) detritivore, (c) predator, and (d) omnivore. All sites were included in this analysis. Densities were scaled to the maximum value to visually compare between ecosystems (each site scaled within ecosystem type between $0-1)$. 

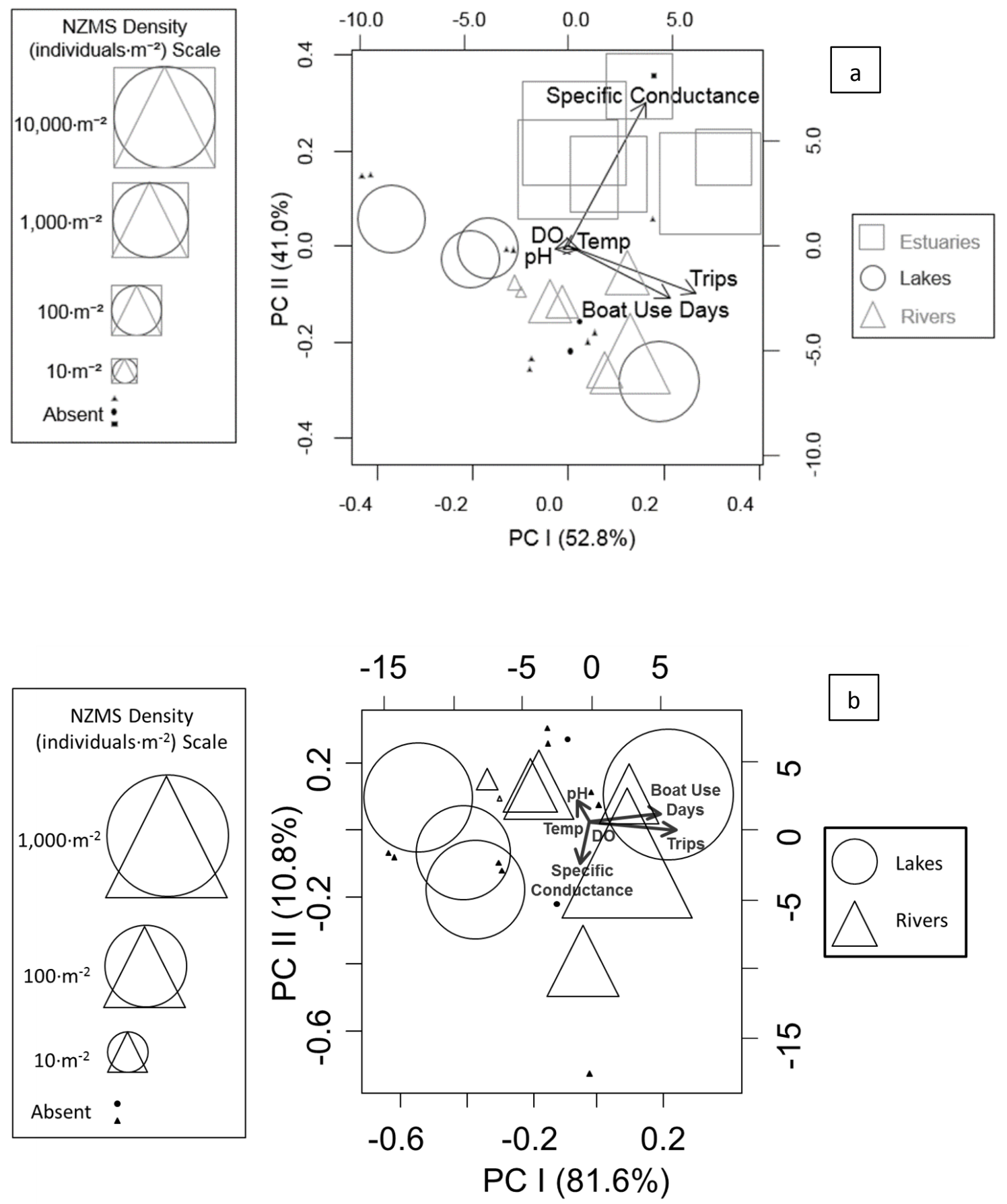

Figure 3.6. PCA biplot of the (a) all sampling locations and (b) freshwater sampling locations depicting environmental factors recorded at each site PCA biplot of the and $\log _{10}$-transformed New Zealand mud snails (NZMS) densities (individuals $\cdot \mathrm{m}^{-2}$ ) represented by shape size. The size of the shape is related to the density of the NZMS in the system and solid shapes were absent of NZMS in the system. DO = dissolved oxygen, Temp $=$ surface water temperature. 

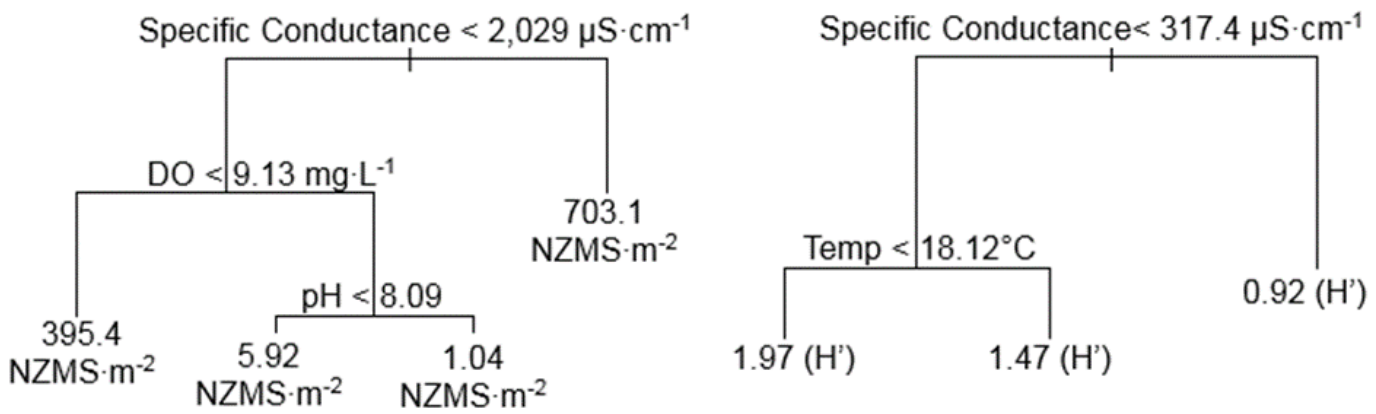

C

d

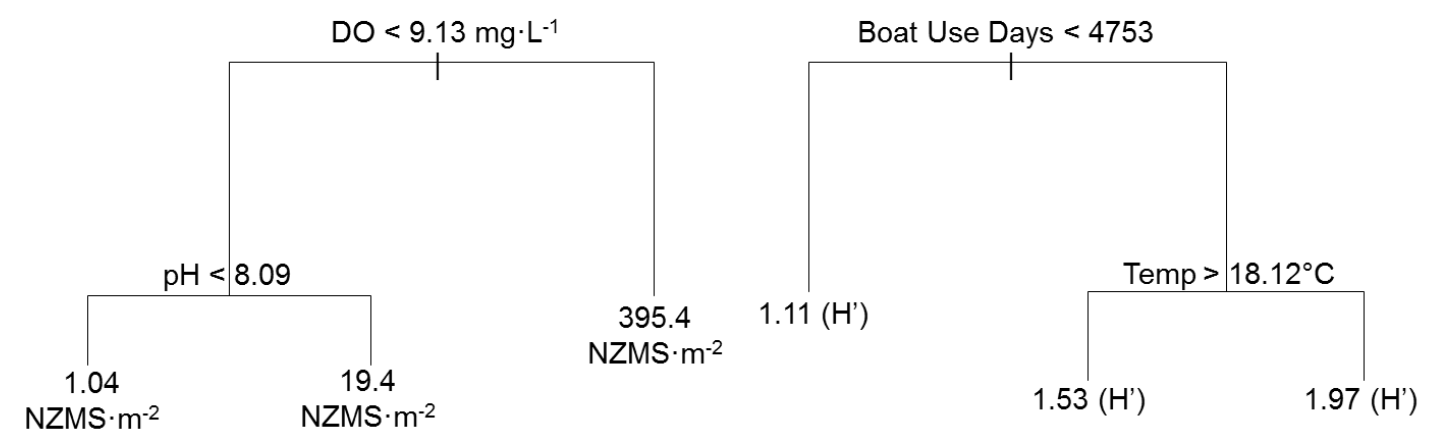

Figure 3.7. Regression trees predicting which variables in all sampling sites influence (a) New Zealand mud snails (NZMS) density and (b) Shannon-Weiner diversity (H') and which variables in just freshwater sites influence (c) New Zealand mud snails (NZMS) density and (d) Shannon-Weiner diversity (H'). DO = dissolved oxygen, Temp $=$ surface water temperature. Less than $(<)$ independent variable values - the response variables are to the right branch. Greater than $(>)$ independent variable values - the response variables are to the left branch. 


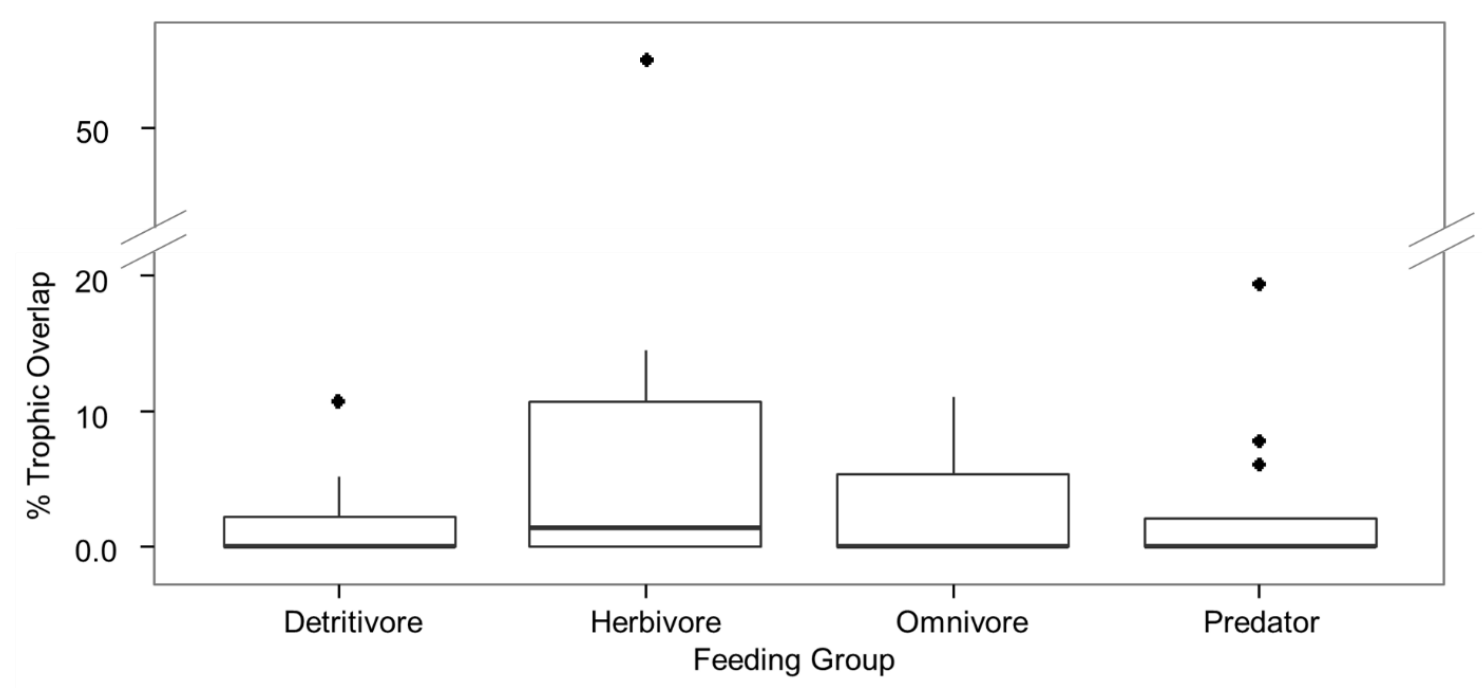

Figure 3.8. Box plots depicting the percentage of trophic overlap between New Zealand mud snails (NZMS) feeding range and specific feeding group feeding ranges. The thick, bold line of each box represents the median percentage of overlap between NZMS feeding ranges and the particular feeding group's feeding range. The lower reach of the box represents the lower quartile and the upper reach of the box represents the upper quartile of the overlap. The whiskers of the boxplots represent variability outside the upper and lower quartile within the $5^{\text {th }}$ and $95^{\text {th }}$ percentile range, with the black dots representing outliers ( $>95^{\text {th }}$ percentile). A y-axis break was created between $\sim 20$ and $\sim 40$ percent overlap. 

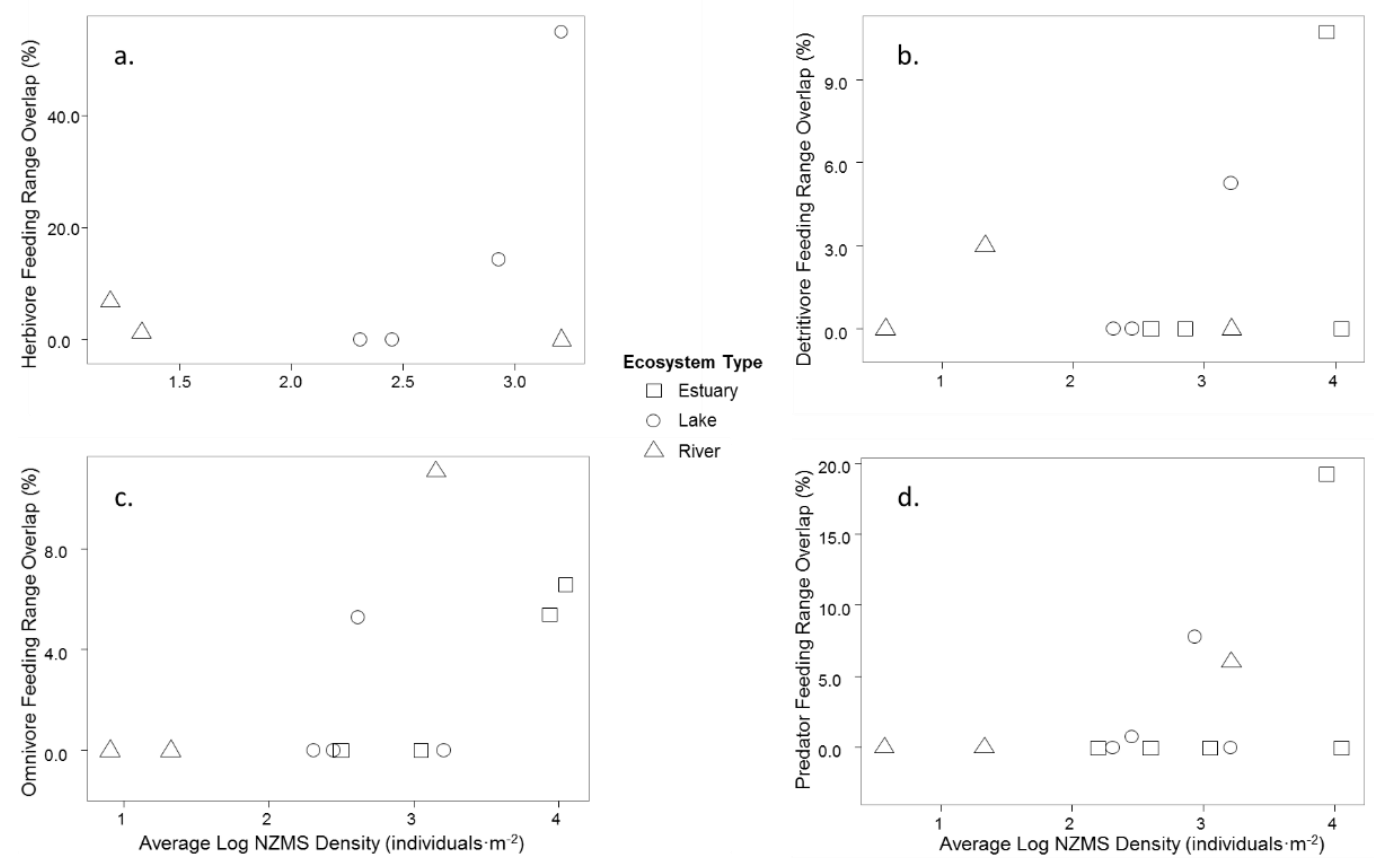

Figure 3.9. Correlations between feeding range overlap (percentage of NZMS range overlapping other feeding group's range) of specific macroinvertebrate feeding groups (a. herbivores, b. detritivores, c. omnivores, d. predators) and log-transformed New Zealand mud snails (NZMS) densities. Convex hulls were created to measure feeding range using the stable isotope signatures $\left(\delta^{15} \mathrm{~N}\right.$ and $\left.\delta^{13} \mathrm{C}\right)$ of taxon and then the hulls were measured for total area. Each point represents the amount of overlap of convex hulls between NZMS feeding range and another feeding group's feeding range at the same sampling location. The location's ecosystem is represented by a circle (lake), triangle (river), and square (estuary). No herbivores were sampled from the estuaries thus only feeding range overlaps and NZMS densities from lakes and rivers are present in the correlation. 


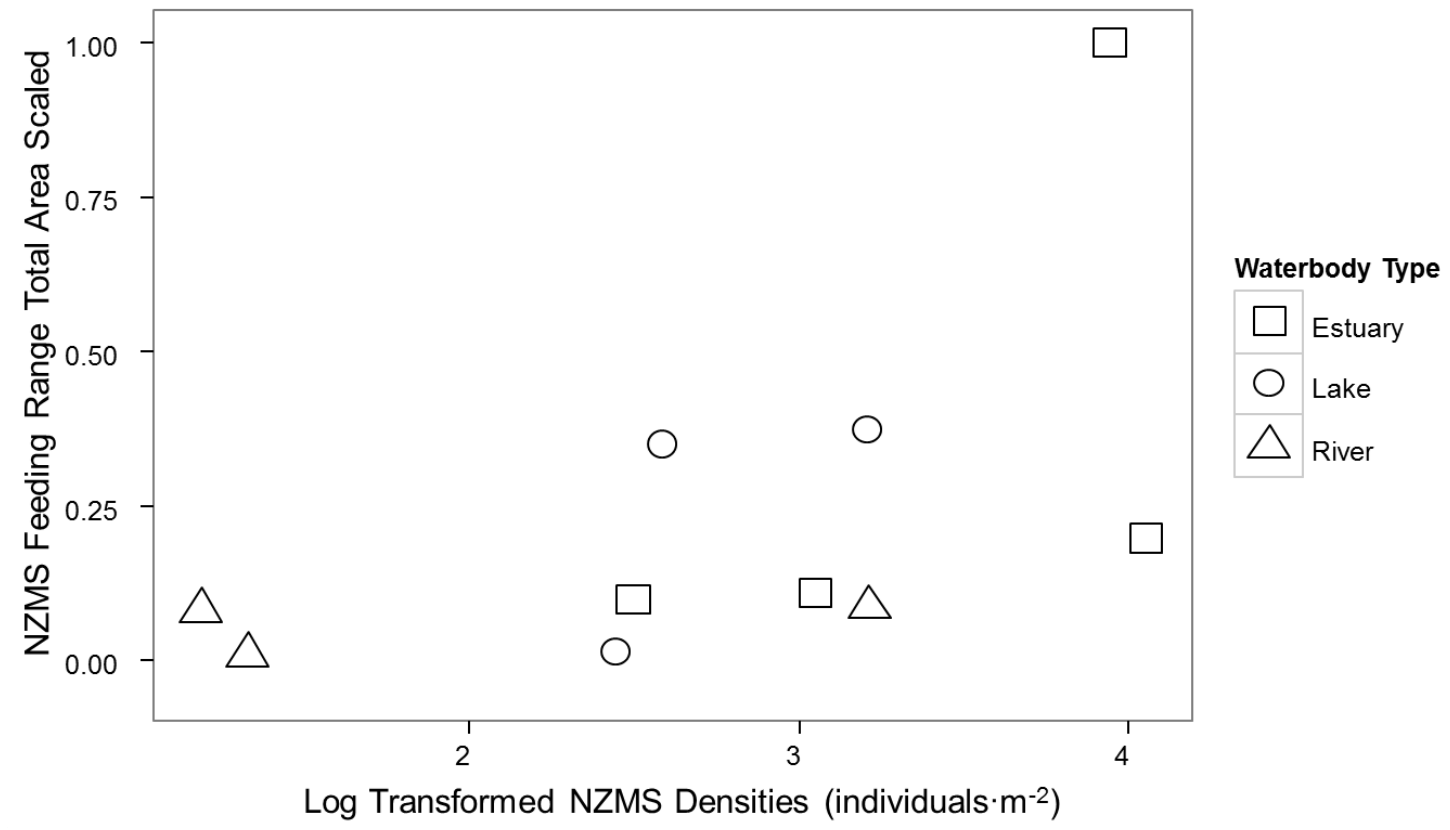

Figure 3.10. Correlation between feeding range (total area of convex hulls, max-scaled) of New Zealand mud snails (NZMS) and $\log _{10}$-transformed NZMS densities. Convex hulls were created to measure feeding range using the stable isotope signatures $\left(\delta^{15} \mathrm{~N}\right.$ and $\delta^{13} \mathrm{C}$ ) of NZMS and then the hulls were measured for total area. Each point represents an individual convex hull area from a certain location in an identified ecosystem represented by a circle (lake), triangle (river), and square (estuary). 


\section{Chapter 4: Conclusions and Future Work}

The invasion of a species is often conceptualized as a multi-stage process which encourages ecologists to conceive factors that might permit a species to pass from one stage to the next and therefore guide management (Catford et al. 2009). Proper management involves risk analysis for an ecosystem, which requires information on the invasive species, vulnerability of habitats to invasion, information on what stage the invasion is in (transportation and introduction, establishment, or spread), and the ecological and economic costs associated with containing (or failing to contain) harmful species (Stohlgren and Schnase 2006, Lodge et al. 2006). My thesis investigates multiple stages of aquatic invasions and has contributed to a better understanding of proactive and preventative management plans, as well as the management for a specific aquatic invasive species (AIS), the New Zealand mud snail (Potamopyrgus antipodarum; NZMS), which is at various phases of establishment and spread.

\section{Transportation and Introduction of Aquatic Invasive Species}

Non-native species introductions and rapid dispersal are often exacerbated by a variety of human-influenced drivers of global change including overland movement of boaters between waterbodies (Buchan and Padilla 1999, Kolar and Lodge 2002). By obtaining boaters' knowledge of AIS, laws and regulations, and proper boat cleaning procedures through human subjects surveys, managers can adapt the current AIS policies and move forward in future management plans concerning AIS transport and introduction. I found that there was a startling disconnect between what boaters say they will do and how they actually behave in regard to using a public boat wash station 
(Chapter 2), and thus management should focus on educational outreach concerning the benefits of boat wash stations and the destructiveness of AIS. Educational outreach is practical and has been shown to be a useful long-term management tool and effective at reducing AIS spread (Rothlisberger et al. 2010, Larson et al. 2011). However, outreach alone will not likely reduce invasive species introductions. A sustainable invasive species management plan should include behavioral factors such as identifying vectors (like overland boater movement), economic factors such as securing efficient funding, and social and political factors such as educational outreach and expanding policies to a regional scale (Larson et al. 2011).

The majority of boaters were familiar with Oregon's state laws and regulations regarding AIS (Chapter 2). The primary objective of Oregon's AIS Prevention Program is to keep Oregon waters free of invasive species. Similarly, Idaho passed House Bill 213 in 2009 to provide additional yearly fees to water vessels, which will be deposited into Idaho's invasive species fund helping to combat the spread and establishment of AIS (Idaho States Department of Agriculture 2009), and in 2014 Washington passed Senate Bill 6040 providing enhanced response to invasion and more stringent enforcement (Washington Invasive Species Council 2014). All of these individual state policies are necessary to address invasive species at smaller jurisdictional scales; however, coordinated regional policies may be more essential as a result of invasive species spread without regard to human-created borders (Peters and Lodge 2009). Land-scape level approaches are increasingly recognized as critically important for effective management of future spread (Drury and Rothlisberger 2008, Vander Zanden and Olden 2008). 


\section{Establishment and Spread}

Management for established and spreading invasive species is much more costly economically and ecologically than the prevention of invasive species (Pimentel et al. 2005, Stohlgren and Schnase 2006). If an invasive species is successfully introduced, the next step in invasion is establishment and spread. New Zealand mud snails are a unique AIS with their ability to successfully establish in a variety of very different aquatic environments, including the lakes, rivers, and estuaries sampled in this study, at a wide range of densities. I determined that there were three major mechanisms that likely influenced the population density as well as the establishment and spread of NZMS and their influence on the community the most: NZMS population dynamics, biotic controls, and abiotic and human-mediated controls (Chapter 3).

NZMS densities tend to boom and bust seasonally with typically greater densities in warmer months (Kerans et al. 2005, Moore et al. 2012), therefore managing established and spreading populations should be adaptable with the season. Attempting to eliminate NZMS from a system can be very difficult considering their high tolerances to abiotic factors (Jacobsen and Forbes 1997, Dybdahl and Kane 2005, Alonso and CastroDíez 2008), but if eradication is to be attempted, waiting for the population to bust should be in the management plan. Meanwhile when populations are high, the appropriate management should be containing NZMS and limiting spread.

The results of this study showed a trend of higher NZMS density in communities with lower diversity when comparing across all ecosystems (Chapter 3). Low species richness and diversity have been shown to provide less competition for establishing species and a wider range of unoccupied niches (Wolff 1998, Leppäkoski and Olenin 2000, Paavola et al. 2005). Similarly, relatively harsh abiotic conditions like high specific 
conductance, fluctuations in salinity, and drastic changes in water level found in estuaries can create niche space and have been observed to make a system vulnerable to NZMS establishment (Herbst et al. 2008). The containment of NZMS should therefore target systems with high NZMS densities and especially those near systems with the potential for NZMS establishment.

\section{Prevention}

The Tenmile Lake boat wash station aims to prevent outside AIS from entering the lake, contain present invasive species, provide a safe and effective tool for boat flushing, and increase public awareness. Understanding the influence of distinct invasive species is important for reactive mitigation, but by managing vectors rather than managing specific invasive species, a more effective proactive approach can be developed to control the introduction of invasive species (Leung et al. 2006, Peters and Lodge 2009, Rothlisberger et al. 2010). Additionally, much of the estimated cost associated with the economic damages inflicted by invasive species is controlling the density and spread of already established invasive species (Pimentel et al. 2005, Stohlgren and Schnase 2006). Because it is more effective economically and ecologically to target invasive species in the early stages of invasion, preventative management is essential. To capitalize the most on these preventative measures, vector management should not be site- or state-specific but instead it needs to be strengthened by regional policies.

In many systems it is too late for preventative management and the only management options are more costly restoration and mitigation. However, much can be learned about systems with established invasive populations and this knowledge can 
contribute to preventative measures taken in outside systems. The NZMS food web study found that estuarine systems were the most conducive to high NZMS densities in Oregon possibly due to the available niche space in a disturbance controlled estuary (Chapter 3). The management focus for a system with established NZMS densities does not actually have to differ much from those without NZMS. Management should still focus primarily on controlling vectors of spread rather than the specific characteristics of NZMS. However, knowledge about a specific invader never hurts. Vander Zanden and Olden (2008) determined that knowledge of the basic biology of a specific invasive species and identifying sites vulnerable to the invader may improve the allocation of management efforts and funds.

\section{Conclusion}

The focus for NZMS management should be on controlling their vectors of transportation and introduction. NZMS are small and can tolerate harsh abiotic conditions so cleaning, draining, and drying a boat between waterbodies is essential in limiting NZMS introductions. Therefore, educational outreach becomes necessary in order to increase awareness from those potentially transporting NZMS (like boaters). Along with more effective educational outreach campaigns, regions need to adopt management policies that cross state borders. The management of New Zealand mud snails may not be able to eliminate their densities in the Pacific Northwest, but management can substantial slow down the invasive spread by identifying systems most threatened and focusing on the vectors of transport and introduction. 


\section{References}

Aiken, S.G., Newroth, P.R., and Wile, I. 1979. The biology of Canadian weeds.: 34. Myriophyllum spicatum L. Can. J. Plant Sci. 59(1): 201-215. doi:10.4141/cjps79-028.

Alonso, A., and Castro-Díez, P. 2008. What explains the invading success of the aquatic mud snail Potamopyrgus antipodarum (Hydrobiidae, Mollusca)? Hydrobiologia 614(1): 107-116. doi:10.1007/s10750-008-9529-3.

Anton Hough, R., and Wetzel, R.G. 1977. Photosynthetic pathways of some aquatic plants. Aquat. Bot. 3: 297-313. doi:10.1016/0304-3770(77)90035-3.

Barbour, M.T., Gerritsen, J., Snyder, B.D., and Stribling, J.B. 1999. Rapid bioassessment protocols for use in streams and wadeable rivers: Periphyton, benthic macroinvertebrates, and fish, Second Editon. EPA 841-B-99-002.

Beekey, M.A., McCabe, D.J., and Marsden, J.E. 2004. Zebra mussel colonisation of soft sediments facilitates invertebrate communities. Freshw. Biol. 49(5): 535-545. doi:10.1111/j.1365-2427.2004.01207.x.

Bersine, K., Brenneis, V.E.F., Draheim, R.C., Rub, A.M.W., Zamon, J.E., Litton, R.K., Hinton, S.A., Sytsma, M.D., Cordell, J.R., and Chapman, J.W. 2008. Distribution of the invasive New Zealand mudsnail (Potamopyrgus antipodarum) in the Columbia River Estuary and its first recorded occurrence in the diet of juvenile Chinook salmon (Oncorhynchus tshawytscha). Biol. Invasions 10(8): 1381-1388. doi:10.1007/s10530-007-9213-y.

Bially, A., and Macisaac, H.J. 2000. Fouling mussels (Dreissena spp.) colonize soft sediments in Lake Erie and facilitate benthic invertebrates. Freshw. Biol. 43(1): 85-97. doi:10.1046/j.1365-2427.2000.00526.x.

Blackwood, M.A. 2007. Standard operating procedure for the benthic macroinvertebrate laboratory. Central Plains Center for BioAssessment, Kansas Biological Survey, University of Kansas.

Bobeldyk, A.M., Bossenbroek, J.M., Evans-White, M.A., Lodge, D.M., and Lamberti, G.A. 2005. Secondary spread of zebra mussels (Dreissena polymorpha) in coupled lake-stream systems. Ecoscience 12(3): 339-346. doi:10.2980/i11956860-12-3-339.1.

Bowler, P.A. 1991. The rapid spread of the freshwater hydrobiidae snail Potamopyrgus antipodarum (Gray) in the Middle Snake River, southern Idaho. In Proceedings of the Desert Fisheries Council. pp. 173-182.

Brenneis, V.E.F., Sih, A., and De Rivera, C.E. 2010. Coexistence in the intertidal: interactions between the non-indigenous New Zealand mud snail Potamopyrgus antipodarum and the native estuarine isopod Gnorimosphaeroma insulare. Oikos 119(11): 1755-1764. doi:10.1111/j.1600-0706.2010.18471.x.

Brenneis, V.E.F., Sih, A., and Rivera, C.E. de. 2011. Integration of an invasive consumer into an estuarine food web: direct and indirect effects of the New Zealand mud snail. Oecologia 167(1): 169-179. doi:10.1007/s00442-011-1962-8.

Bruhl, J., and Wilson, K. 2007. Towards a comprehensive survey of C3 and C4 photosynthetic pathways in Cyperaceae. Aliso J. Syst. Evol. Bot. 23(1): 99-148. doi:10.5642/aliso.20072301.11. 
Buchan, L.A.J., and Padilla, D.K. 1999. Estimating the probability of long-distance overland dispersal of invading aquatic species. Ecol. Appl. 9(1): 254-265. doi:10.1890/1051-0761(1999)009[0254:ETPOLD]2.0.CO;2.

Byers, J.E. 2000. Competition between two estuarine snails: implications for invasions of exotic species. Ecology 81(5): 1225-1239. doi:10.1890/00129658(2000)081[1225:CBTESI]2.0.CO;2.

Cabana, G., and Rasmussen, J.B. 1996. Comparison of aquatic food chains using nitrogen isotopes. Proc. Natl. Acad. Sci. 93(20): 10844-10847. [accessed 20 October 2014].

Carlsson, N.O.L., Brönmark, C., and Hansson, L.-A. 2004. Invading herbivory: the golden apple snail alters ecosystem functioning in asian wetlands. Ecology 85(6): 1575-1580. doi:10.1890/03-3146.

Catford, J.A., Jansson, R., and Nilsson, C. 2009. Reducing redundancy in invasion ecology by integrating hypotheses into a single theoretical framework. Divers. Distrib. 15(1): 22-40. doi:10.1111/j.1472-4642.2008.00521.x.

Caton, L.W. 1991. Improved subsampling methods for the EPA "rapid bioassessment" benthic protocols. North Am. Benthol. Soc. Bull. 8: 317-319.

Chabrerie, O., Poudevigne, I., Bureau, F., Vinceslas-Akpa, M., Nebbache, S., Aubert, M., Bourcier, A., and Alard, D. 2001. Biodiversity and ecosystem functions in wetlands: A case study in the estuary of the Seine River, France. Estuaries 24(6): 1088-1096. doi:10.2307/1353020.

Chan, S., Lam, J., and Siemens, T. 2014. Survey of Oregon boaters on regulatory and outreach strategies for aquatic invasive species in Oregon. Sea Grant Extension, IRB Project, Oregon State University, Corvallis, Oregon.

Connell, J.H. 1978. Diversity in tropical rain forests and coral reefs. Science 199(4335): 1302-1310. doi:0036-807517810324-1302\$02.0010.

Cornwell, W.K., Schwilk, D.W., and Ackerly, D.D. 2006. A trait-based test for habitat filtering: convex hull volume. Ecology 87(6): 1465-1471. doi:10.1890/00129658(2006)87[1465:ATTFHF]2.0.CO;2.

Crooks, J.A., Chang, A.L., and Ruiz, G.M. 2011. Aquatic pollution increases the relative success of invasive species. Biol. Invasions 13(1): 165-176. doi:10.1007/s10530010-9799-3.

Curtis, P.S., Balduman, L.M., Drake, B.G., and Whigham, D.F. 1990. Elevated atmospheric $\mathrm{CO} 2$ effects on belowground processes in $\mathrm{C} 3$ and $\mathrm{C} 4$ estuarine marsh communities. Ecology 71(5): 2001-2006. doi:10.2307/1937608.

Degroote, D., and Kennedy, R.A. 1977. Photosynthesis in Elodea canadensis Michx fourcarbon acid synthesis. Plant Physiol. 59(6): 1133-1135. doi:10.1104/pp.59.6.1133.

Dick, J.T.A., Gallagher, K., Avlijas, S., Clarke, H.C., Lewis, S.E., Leung, S., Minchin, D., Caffrey, J., Alexander, M.E., Maguire, C., Harrod, C., Reid, N., Haddaway, N.R., Farnsworth, K.D., Penk, M., and Ricciardi, A. 2012. Ecological impacts of an invasive predator explained and predicted by comparative functional responses. Biol. Invasions 15(4): 837-846. doi:10.1007/s 10530-012-0332-8.

Dorgelo, J. 1987. Density fluctuations in populations (1982-1986) and biological observations of Potamopyrgus Jenkinsi in two trophically differing lakes. Hydrobiol. Bull. 21(1): 95-110. doi:10.1007/BF02255459. 
Drury, K.L.S., and Rothlisberger, J.D. 2008. Offense and defense in landscape-level invasion control. Oikos 117(2): 182-190. doi:10.1111/j.2007.0030-1299.16081.x.

Dybdahl, M.F., and Kane, S.L. 2005. Adaptation vs. phenotypic plasticity in the success of a clonal invader. Ecology 86(6): 1592-1601. doi:10.1890/04-0898.

Dybdahl, M.F., and Lively, C.M. 1995. Diverse, endemic and polyphyletic clones in mixed populations of a freshwater snail (Potamopyrgus antipodarum). J. Evol. Biol. 8(3): 385-398. doi:10.1046/j.1420-9101.1995.8030385.x.

Elton, C.S. 1927. Animal ecology. Sedgwick and Jackson, London.

Endresen, Ø., Lee Behrens, H., Brynestad, S., Bjørn Andersen, A., and Skjong, R. 2004. Challenges in global ballast water management. Mar. Pollut. Bull. 48(7-8): 615623. doi:10.1016/j.marpolbul.2004.01.016.

Feminella, J.W., and Hawkins, C.P. 1995. Interactions between stream herbivores and periphyton: A quantitative analysis of past experiments. J. North Am. Benthol. Soc. 14(4): 465-509. doi:10.2307/1467536.

Frost-Christensen, H., and Sand-Jensen, K. 1995. Comparative kinetics of photosynthesis in floating and submerged Potamogeton leaves. Aquat. Bot. 51(1-2): 121-134. doi:10.1016/0304-3770(95)00455-9.

Fry, B. 2006. Stable isotope ecology. Springer Science+Business Media, LLC, New York, NY.

Gotelli, N.J., and Ellison, A.M. 2004. A primer of ecological statistics. Sinauer Associates, Sunderland, Massachusetts.

Grigorovich, I.A., Colautti, R.I., Mills, E.L., Holeck, K., Ballert, A.G., and MacIsaac, H.J. 2003. Ballast-mediated animal introductions in the Laurentian Great Lakes: Retrospective and prospective analyses. Can. J. Fish. Aquat. Sci. 60(6): 740-756. doi:10.1139/f03-053.

Hall, R.O., Dybdahl, M.F., and VanderLoop, M.C. 2006. Extremely high secondary production of introduced snails in rivers. Ecol. Appl. 16(3): 1121-1131. doi:10.1890/1051-0761(2006)016[1121:EHSPOI]2.0.CO;2.

Hall, R.O., Tank, J.L., and Dybdahl, M.F. 2003. Exotic snails dominate nitrogen and carbon cycling in a highly productive stream. Front. Ecol. Environ. 1(8): 407411. doi:10.1890/1540-9295(2003)001[0407:ESDNAC]2.0.CO;2.

Hawkins, C.P., and Furnish, J.K. 1987. Are snails important competitors in stream ecosystems? Oikos 49(2): 209-220. doi:10.2307/3566028.

Herbst, D.B., Bogan, M.T., and Lusardi, R.A. 2008. Low specific conductivity limits growth and survival of the New Zealand mud snail from the Upper Owens River, California. West. North Am. Nat. 68(3): 324-333. doi:10.3398/15270904(2008)68[324:LSCLGA]2.0.CO;2.

Herbst, D.B., Silldorff, E.L., and Cooper, S.D. 2009. The influence of introduced trout on the benthic communities of paired headwater streams in the Sierra Nevada of California. Freshw. Biol. 54(6): 1324-1342. doi:10.1111/j.13652427.2009.02187.x.

Hill, J.M., Jones, R.W., Hill, M.P., and Weyl, O.L.F. 2015. Comparisons of isotopic niche widths of some invasive and indigenous fauna in a South African river. Freshw. Biol.: 1-10. doi:10.1111/fwb.12542.

Hobbs, R.J., and Huenneke, L.F. 1992. Disturbance, diversity, and invasion: implications for conservation. In Ecosystem Management. Springer New York. pp. 164-180. 
Available from http://link.springer.com/chapter/10.1007/978-1-4612-4018-1_16 [accessed 27 January 2016].

Hoy, M., Boese, B.L., Taylor, L., Reusser, D., and Rodriguez, R. 2012. Salinity adaptation of the invasive New Zealand mud snail (Potamopyrgus antipodarum) in the Columbia River Estuary (Pacific Northwest, USA): Physiological and molecular studies. Aquat. Ecol. 46(2): 249-260. doi:10.1007/s10452-012-9396-x.

Idaho State Department of Agriculture. 2014. Idaho invasive species watercraft inspection program 5 year review 2009-2013. ISDA, Idaho. Available from http://www.agri.idaho.gov/AGRI/Categories/Environment/InvasiveSpeciesCounci 1/documents/DataReviewFINAL011514.pdf [accessed 13 February 2016].

Idaho States Department of Agriculture. 2009. Idaho state department of agriculture annual report 2009: Legislation. Available from http://www.agri.idaho.gov/Categories/AboutISDA/Documents/annual_reports/An nualReport2009.pdf [accessed 5 March 2015].

Jacobsen, R., and Forbes, V.E. 1997. Clonal variation in life-history traits and feeding rates in the gastropod, Potamopyrgus antipodarum: Performance across a salinity gradient. Funct. Ecol. 11(2): 260-267. doi:10.1046/j.1365-2435.1997.00082.x.

Johnson, L.E., Ricciardi, A., and Carlton, J.T. 2001. Overland dispersal of aquatic invasive species: A risk assessment of transient recreational boating. Ecol. Appl. 11(6): 1789-1799. doi:10.1890/1051-0761(2001)011[1789:ODOAIS]2.0.CO;2.

Kareiva, P. 2008. Ominous trends in nature recreation. Proc. Natl. Acad. Sci. 105(8): 2757-2758. doi:10.1073/pnas.0800474105.

Keeley, J.E. 1981. Isoetes howellii: A submerged aquatic CAM plant? Am. J. Bot. 68(3): 420-424. doi:10.2307/2442779.

Kerans, B.L., Dybdahl, M.F., Gangloff, M.M., and Jannot, J.E. 2005. Potamopyrgus antipodarum: Distribution, density, and effects on native macroinvertebrate assemblages in the Greater Yellowstone ecosystem. J. North Am. Benthol. Soc. 24(1): 123-138. doi:10.2307/4095703.

Kinlan, B.P., and Gaines, S.D. 2003. Propagule dispersal in marine and terrestrial environments: A community perspective. Ecology 84(8): 2007-2020. doi:10.1890/01-0622.

Kittelson, P.M., and Boyd, M.J. 1997. Mechanisms of expansion for an introduced species of cordgrass, Spartina densiflora, in Humboldt Bay, California. Estuaries 20(4): 770-778. doi: $10.2307 / 1352250$.

Kolar, C.S., and Lodge, D.M. 2001. Progress in invasion biology: Predicting invaders. Trends Ecol. Evol. 16(4): 199-204. doi:10.1016/S0169-5347(01)02101-2.

Kolar, C.S., and Lodge, D.M. 2002. Ecological predictions and risk assessment for alien fishes in North America. Science 298(5596): 1233-1236. doi:10.1126/science.1075753.

Larson, D.L., Phillips-Mao, L., Quiram, G., Sharpe, L., Stark, R., Sugita, S., and Weiler, A. 2011. A framework for sustainable invasive species management: Environmental, social, and economic objectives. J. Environ. Manage. 92(1): 1422. doi:10.1016/j.jenvman.2010.08.025.

Larson, E.R., Olden, J.D., and Usio, N. 2010. Decoupled conservatism of Grinnellian and Eltonian niches in invasive arthropod. Ecosphere 1(6). doi:10.1890/ES1000053.1. 
Layman, C.A., Arrington, D.A., Montaña, C.G., and Post, D.M. 2007. Can stable isotope ratios provide for community-wide measures of trophic structure? Ecology 88(1): 42-48. doi:10.1890/0012-9658(2007)88[42:CSIRPF]2.0.CO;2.

Leppäkoski, E., and Olenin, S. 2000. Non-native species and rates of spread: Lessons from the brackish Baltic Sea. Biol. Invasions 2(2): 151-163. doi:10.1023/A:1010052809567.

Leung, B., Bossenbroek, J.M., and Lodge, D.M. 2006. Boats, pathways, and aquatic biological invasions: Estimating dispersal potential with gravity models. Biol. Invasions 8(2): 241-254. doi:10.1007/s10530-004-5573-8.

Leung, B., and Mandrak, N.E. 2007. The risk of establishment of aquatic invasive species: Joining invasibility and propagule pressure. Proc. R. Soc. B Biol. Sci. 274(1625): 2603-2609. doi:10.1098/rspb.2007.0841.

Levine, J.M. 2000. Species diversity and biological invasions: Relating local process to community pattern. Science 288(5467): 852-854. doi:10.1126/science.288.5467.852.

Liu, X.Q., and Wang, R.Z. 2006. Photosynthetic pathway and morphological functional types in the vegetation from North-Beijing agro-pastoral ecotone, China. Photosynthetica 44(3): 365-386. doi:10.1007/s11099-006-0038-1.

Lodge, D.M., Williams, S., MacIsaac, H.J., Hayes, K.R., Leung, B., Reichard, S., Mack, R.N., Moyle, P.B., Smith, M., Andow, D.A., Carlton, J.T., and McMichael, A. 2006. Biological invasions: Recommendations for U.S. policy and management. Ecol. Appl. 16(6): 2035-2054. doi:10.1890/10510761(2006)016[2035:BIRFUP]2.0.CO;2.

Longstreth, D.J. 1989. Photosynthesis and photorespiration in freshwater emergent and floating plants. Aquat. Bot. 34(1-3): 287-299. doi:10.1016/0304-3770(89)900600.

Loo, S.E., Keller, R.P., and Leung, B. 2007a. Freshwater invasions: Using historical data to analyse spread. Divers. Distrib. 13(1): 23-32. doi:10.1111/j.13669516.2006.00313.x.

Loo, S.E., Nally, R.M., and Lake, P.S. 2007b. Forecasting New Zealand mudsnail invasion range: Model comparisons using native and invaded ranges. Ecol. Appl. 17(1): 181-189. doi:10.2307/40061986.

Mack, M.C., and D'Antonio, C.M. 1998. Impacts of biological invasions on disturbance regimes. Trends Ecol. Evol. 13(5): 195-198. doi:10.1016/S0169-5347(97)01286$\mathrm{X}$.

McCarter, N.H. 1986. Food and energy in the diet of brown and rainbow trout from Lake Benmore, New Zealand. N. Z. J. Mar. Freshw. Res. 20(4): 551-559. doi:10.1080/00288330.1986.9516175.

McCutchan, J.H., Lewis, W.M., Kendall, C., and McGrath, C.C. 2003. Variation in trophic shift for stable isotope ratios of carbon, nitrogen, and sulfur. Oikos 102(2): 378-390. doi:10.1034/j.1600-0706.2003.12098.x.

McMahon, R.F. 2011. Quagga mussel (Dreissena rotriformis bugensis) population structure during the early invasion of lakes Mead and Mohave January-March 2007. Aquat. Invasions 6(2): 131-140. doi:10.3391/ai.2011.6.2.02. 
Merritt, R.W., Cummins, K.W., and Berg, M.B. 2008. An introduction to the aquatic insects of North America. In Fourth. Kendall Hunt Publishing Company, Dubuque, Iowa.

Minckley, T.A., Clementz, M.T., Brunelle, A., and Klopfenstein, G.A. 2009. Isotopic analysis of wetland development in the American Southwest. The Holocene 19(5): 737-745. doi:10.1177/0959683609105297.

Mooney, H.A., and Cleland, E.E. 2001. The evolutionary impact of invasive species. Proc. Natl. Acad. Sci. 98(10): 5446-5451. doi:10.1073/pnas.091093398.

Moore, J.W., Herbst, D.B., Heady, W.N., and Stephanie M. Carlson. 2012. Stream community and ecosystem responses to the boom and bust of an invading snail. Biol. Invasions 14(11): 2435-2446. doi:10.1007/s10530-012-0240-y.

ODEQ. 2004a. Mode of operations manual. Oregon Department of Environmental Quality. Available from http://www.deq.state.or.us/lab/techrpts/docs/DEQ03LAB0036SOP.pdf [accessed 3 December 2015].

Olden, J.D., Lawler, J.J., and Poff, N.L. 2008. Machine learning methods without tears: A primer for ecologists. Q. Rev. Biol. 83(2): 171-193. doi:10.1086/587826.

Olden, J.D., LeRoy Poff, N., Douglas, M.R., Douglas, M.E., and Fausch, K.D. 2004. Ecological and evolutionary consequences of biotic homogenization. Trends Ecol. Evol. 19(1): 18-24. doi:10.1016/j.tree.2003.09.010.

Oregon State Marine Board. 2009. Boating in Oregon: Triennial survey results - 2008. Oregon State University Survey Research Center. Available from www.boatoregon.com.

Paavola, M., Olenin, S., and Leppäkoski, E. 2005. Are invasive species most successful in habitats of low native species richness across European brackish water seas? Estuar. Coast. Shelf Sci. 64(4): 738-750. doi:10.1016/j.ecss.2005.03.021.

Padilla, D.K., and Williams, S.L. 2004. Beyond ballast water: Aquarium and ornamental trades as sources of invasive species in aquatic ecosystems. Front. Ecol. Environ. 2(3): 131-138. doi:10.1890/1540-9295(2004)002[0131:BBWAAO]2.0.CO;2.

Pagano, A.M., and Titus, J.E. 2004. Submersed macrophyte growth at low pH: Contrasting responses of three species to dissolved inorganic carbon enrichment and sediment type. Aquat. Bot. 79(1): 65-74. doi:10.1016/j.aquabot.2004.01.004.

Pergams, O.R.W., and Zaradic, P.A. 2008. Evidence for a fundamental and pervasive shift away from nature-based recreation. Proc. Natl. Acad. Sci. 105(7): 22952300. doi:10.1073/pnas.0709893105.

Peters, J.A., and Lodge, D.M. 2009. Invasive species policy at the regional level: A multiple weak links problem. Fisheries 34(8): 373-380. doi:10.1577/1548-844634.8.373.

Pimentel, D., Zuniga, R., and Morrison, D. 2005. Update on the environmental and economic costs associated with alien-invasive species in the United States. Ecol. Econ. 52(3): 273-288. doi:10.1016/j.ecolecon.2004.10.002.

Poff, N.L., Olden, J.D., Vieira, N.K.M., Finn, D.S., Simmons, M.P., and Kondratieff, B.C. 2006. Functional trait niches of North American lotic insects: Traits-based ecological applications in light of phylogenetic relationships. J. North Am. Benthol. Soc. 25(4): 730-755. doi:10.1899/08873593(2006)025[0730:FTNONA]2.0.CO;2. 
Post, D.M. 2002. Using stable isotopes to estimate trophic position: models, methods, and assumptions. Ecology 83(3): 703-718. doi:10.1890/00129658(2002)083[0703:USITET]2.0.CO;2.

Reesman, M., Boatner, R., and Dolphin, G. 2012. Oregon's aquatic invasive species prevention program: 2012 program report. Oregon Department of Fish and Wildlife. Available from http://www.dfw.state.or.us/conservationstrategy/invasive_species/docs/AISPP_20 12_Annual_Report_Final.pdf [accessed 5 June 2014].

Richards, D.C., Cazier, L.D., and Lester, G.T. 2001. Spatial distribution of three snail species, including the invader Potamopyrgus antipodarum, in a freshwater spring. West. North Am. Nat. 61(3): 375-380.

Richards, D.C., O'Connell, P., and Shinn, D.C. 2004. Simple control method to limit the spread of the New Zealand mudsnail Potamopyrgus antipodarum. North Am. J. Fish. Manag. 24(1): 114-117. doi:10.1577/M02-133.

Rodda, G.H., Fritts, T.H., and Chiszar, D. 1997. The disappearance of Guam's wildlife. BioScience 47(9): 565-574. doi:10.2307/1313163.

Rodriguez, L.F. 2006. Can invasive species facilitate native species? Evidence of how, when, and why these impacts occur. Biol. Invasions 8(4): 927-939. doi:10.1007/s10530-005-5103-3.

Rothlisberger, J.D., Chadderton, W.L., McNulty, J., and Lodge, D.M. 2010. Aquatic invasive species transport via trailered boats: What is being moved, who is moving it, and what can be done. Fisheries 35(3): 121-132. doi:10.1577/15488446-35.3.121.

Ryan, R.L. 2005. Exploring the effects of environmental experience on attachment to urban natural areas. Environ. Behav. 37(1): 3-42. doi:10.1177/0013916504264147.

Sage, R.F., Christin, P.-A., and Edwards, E.J. 2011. The C4 plant lineages of planet Earth. J. Exp. Bot. 62(9): 3155-3169. doi:10.1093/jxb/err048.

Sakai, A.K., Allendorf, F.W., Holt, J.S., Lodge, D.M., Molofsky, J., With, K.A., Baughman, S., Cabin, R.J., Cohen, J.E., Ellstrand, N.C., McCauley, D.E., O’Neil, P., Parker, I.M., Thompson, J.N., and Weller, S.G. 2001. The population biology of invasive species. Annu. Rev. Ecol. Syst. 32: 305-332.

Schreiber, E.S.G., Lake, P.S., and Quinn, G.P. 2002. Facilitation of native stream fauna by an invading species? Experimental investigations of the interaction of the snail, Potamopyrgus antipodarum (Hydrobiidae) with native benthic fauna. Biol. Invasions 4(3): 317-325. doi:10.1023/A:1020925022843.

Smith, D. 2001. Pennak's freshwater invertebrates of the United States. In Fourth. John Wiley \& Sons, Inc., New York.

Smith, L.D., Wonham, M.J., McCann, L.D., Ruiz, G.M., Hines, A.H., and Carlton, J.T. 1999. Invasion pressure to a ballast-flooded estuary and an assessment of inoculant survival. Biol. Invasions 1(1): 67-87. doi:10.1023/A:1010094527218.

Soberón, J. 2007. Grinnellian and Eltonian niches and geographic distributions of species. Ecol. Lett. 10(12): 1115-1123. doi:10.1111/j.1461-0248.2007.01107.x.

Stewart-Koster, B., Olden, J.D., and Johnson, P.T.J. 2015. Integrating landscape connectivity and habitat suitability to guide offensive and defensive invasive species management. J. Appl. Ecol.: n/a-n/a. doi:10.1111/1365-2664.12395. 
Stohlgren, T.J., and Schnase, J.L. 2006. Risk analysis for biological hazards: What we need to know about invasive species. Risk Anal. 26(1): 163-173. doi:10.1111/j.1539-6924.2006.00707.x.

Strecker, A.L., Arnott, S.E., Yan, N.D., and Girard, R. 2006. Variation in the response of crustacean zooplankton species richness and composition to the invasive predator Bythotrephes longimanus. Can. J. Fish. Aquat. Sci. 63(9): 2126-2136. doi:10.1139/f06-105.

Strecker, A.L., Campbell, P.M., and Olden, J.D. 2011. The aquarium trade as an invasion pathway in the Pacific Northwest. Fisheries 36(2): 74-85. doi:10.1577/03632415.2011.10389070.

Stribling, J.M., and Cornwell, J.C. 1997. Identification of important primary producers in a Chesapeake Bay tidal creek system using stable isotopes of carbon and sulfur. Estuaries 20(1): 77-85. doi:10.2307/1352721.

Thorp, J.H., and Covich, A.P. 2010. Ecology and classification of North American freshwater invertebrates. Elsevier Inc., San Diego, CA.

Tilt, J.H., Kearney, A.R., and Bradley, G. 2007. Understanding rural character: Cognitive and visual perceptions. Landsc. Urban Plan. 81(1-2): 14-26. doi:10.1016/j.landurbplan.2006.09.007.

Townsend, C.R., Scarsbrook, M.R., and Dolédec, S. 1997. The intermediate disturbance hypothesis, refugia, and biodiversity in streams. Limnol. Oceanogr. 42(5): 938949. doi:10.4319/1o.1997.42.5.0938.

UC Davis Stable Isotope Facility. 2013. Carbon (13C) and nitrogen (15N) sample preparation. Available from http://stableisotopefacility.ucdavis.edu/13cand15nsamplepreparation.html [accessed 30 September 2013].

USGS. 2015. USGS nonindigenous aquatic species (NAS) reporting and sighting - New Zealand mudsnail. Government. Available from http://nas.er.usgs.gov/viewer/omap.aspx?SpeciesID=1008 [accessed 11 December 2015].

Vander Zanden, M.J., and Olden, J.D. 2008. A management framework for preventing the secondary spread of aquatic invasive species. Can. J. Fish. Aquat. Sci. 65(7): 1512-1522. doi:10.1139/F08-099.

Vander Zanden, M.J., and Rasmussen, J.B. 1999. Primary consumer $\delta 13 \mathrm{C}$ and $\delta 15 \mathrm{~N}$ and the trophic position of aquatic consumers. Ecology 80(4): 1395-1404. doi:10.1890/0012-9658(1999)080[1395:PCCANA]2.0.CO;2.

Van, T.K., Haller, W.T., and Bowes, G. 1976. Comparison of the photosynthetic characteristics of three submersed aquatic plants. Plant Physiol. 58(6): 761-768. doi:10.1104/pp.58.6.761.

Ventura, M., and Jeppesen, E. 2009. Effects of fixation on freshwater invertebrate carbon and nitrogen isotope composition and its arithmetic correction. Hydrobiologia 632(1): 297-308. doi:10.1007/s10750-009-9852-3.

Vinson, M.R., and Baker, M.A. 2008. Poor growth of rainbow trout fed New Zealand mud snails Potamopyrgus antipodarum. North Am. J. Fish. Manag. 28(3): 701709. doi:10.1577/M06-039.1.

Voshell, J., and Reese, J. 2002. A guide to common freshwater invertebrates of North America. The McDonald \& Woodward Publishing Co., Granville, Ohio. 
Wallace, C. 1992. Parthenogenesis, sex and chromosomes in Molluscan Stud. 58(2): 93-107. doi:10.1093/mollus/58.2.93.

Potamopyrgus. J.

Washington Invasive Species Council. 2014. Washington invasive species council: Annual report to the legislature. Available from http://www.invasivespecies.wa.gov/documents/2014-Annual-Report.pdf [accessed 5 March 2015].

Washington Invasive Species Council. 2015. Washington invasive species council: 2015 annual report to the legislature. Washington State Recreation and Conservation Office, Washington. Available from http://www.invasivespecies.wa.gov/documents/2015Annual_Report.pdf [accessed 13 February 2016].

Wilcove, D.S., Rothstein, D., Dubow, J., Phillips, A., and Losos, E. 1998. Quantifying threats to imperiled species in the United States. BioScience 48(8): 607-615. doi: $10.2307 / 1313420$.

Wolff, W.J. 1998. Exotic invaders of the meso-oligohaline zone of estuaries in the Netherlands: Why are there so many? Helgoländer Meeresunters. 52(3-4): 393400. doi:10.1007/BF02908913.

Xu, J., Zhang, X., Ye, N., Zheng, Z., Mou, S., Dong, M., Xu, D., and Miao, J. 2013. Activities of principal photosynthetic enzymes in green macroalga Ulva linza: Functional implication of C4 pathway in CO2 assimilation. Sci. China Life Sci. 56(6): 571-580. doi:10.1007/s11427-013-4489-x.

Zaranko, D.T., Farara, D.G., and Thompson, F.G. 1997. Another exotic mollusc in the Laurentian Great Lakes: The New Zealand native Potamopyrgus antipodarum (Gray 1843) (Gastropoda, Hydrobiidae). Can. J. Fish. Aquat. Sci. 54(4): 809-814. doi:10.1139/f96-343. 


\section{Appendix A: Informed consent}

The informed consent form given to all boaters prior to participating in the Tenmile Lake boater survey. Participants were also encouraged to contact via post mail or phone if they had any questions or concerns about their participation in this study.

\section{胥 Portland State}

Department of Environmental Science and Management

Post Office Box 751

Portland, Oregon 97207-0751
503-725-4982 tel 503-725-9040 fax

You are invited to participate in a research study conducted by Professor Angela Strecker from Portland State University, Department of Environmental Science and Management. These researchers hope to learn about boater behavior and attitudes on aquatic invasive species. You were selected as a possible participant in this study because you are a boater here at Tenmile Lake.

If you decide to participate, you will be asked to verbally answer questions. The first part of the survey will last approximately 10 minutes. If you agree to answer the more indepth questions, this second part of the survey will last approximately 15 minutes. While participating in this study, it is possible that you will feel some embarrassment or discomfort, at which point the interviewer will disregard your responses or will terminate the interview. You may not receive any direct benefit from taking part in this study, but the study may help to increase knowledge which may help others in the future. To encourage participation, we will enter your name in a draw for a $\$ 50$ gift certificate from a local vendor.

Any information that is obtained in connection with this study and that can be linked to you or identify you will be kept private and will not be shared. This information will be kept private by storage at Portland State University in a password-protected computer file. Paper copies will be kept in a locked filing cabinet.

Your participation is voluntary. You do not have to take part in this study and you may withdraw from this study at any time.

If you have questions or concerns about your participation in this study, contact Angela Strecker (strecker@pdx.edu, 503-725-2427) at PO Box 751, Portland State University, Portland OR 97201. If you have concerns about your rights as a research subject, please contact Human Subjects Research Review Committee, Research and Strategic Partnerships, PO Box 751, Portland State University, Portland OR 97201 (hsrrc@lists.pdx.edu, 1-877-480-4400).

Please indicate to the researcher that you have read and understand the above information and agree to take part in this study. The researcher will provide you with a copy of this form for your own records. 


\section{Appendix B: Survey questions pre-boat wash}

Boater survey questions from the 2012 pre-boat wash installation field season. The boater surveys included a three step process: Step 1 an observational survey, Step 2 a short form boater survey, and Step 3 an in-depth boater survey.

\section{Step 1: Observational Survey (to be filled out by researcher)}

1. Coming from in state/out of state? If out of state, name:

2. Kind of boat (motorized, non-motorized, canoe, fishing):

3. Details about the day (fishing tournament, etc):

4. Did the boat launch clean (no vegetation or invertebrates)?

5. Did the boat leave clean?

If not, what was on it (vegetation, invertebrates)?

6. Was there any effort to remove the fouling organisms?

Drain bilge/live well?

\section{Step 2: Short Form Boater Survey (to be filled out by researcher)}

1. When was the last time your boat was in the water?

2. What waterbody did you and your boat come from?

What waterbody are you visiting next?

How many waterbodies have you visited in the last month?

3. Do you know about the invasive species prevention program permit? yes no

a. Have you ever been asked to show your permit? yes no

4. Are you aware of the phrase "clean, drain, dry"? yes no

a. Have you done this before? always sometimes never

b. Do you know which parts of the boat might be susceptible to invasive species attachment? yes no

5. Have you ever been through a boat inspection station?
a. Oregon
b. other: 
6. Would you use a boat wash station at a boat ramp? ___ yes __ no

a. If no, what would it take for you to change your behavior?

7. Are you aware of a state law that prohibits launching a boat that has invasive species on it?

yes no

8. Have you ever backflushed your motor in a lake after boating in salt water? always __ sometimes never

a. Do you know anyone who has? ___ yes __ no

9. Are you aware of the state regulations regarding the use and movement of baitfish?

yes no

a. What about crayfish? ___ yes __ no

10. Do you know how to report a suspected invasive species? ___ yes ___ no

a. Would you be able recognize or name an invasive species? ___ yes no

11. What types of activities do you engage in with your boat (e.g., sailing, fishing, recreation)?

12. Did you see any signage regarding invasive species when you arrived at the lake?

yes _ no

Left the lake? __ yes __ no

\section{Step 3: In-Depth Boater Survey (to be filled out by researcher)}

1. How do invasive species affect you and your activities?

a. Do they change your experience at the lake?

2. How important are invasive species as an issue in Oregon?

very somewhat not at all 
3. Where did you see or hear the information regarding aquatic invasive species?

4. If you do not wash your boat (clean, drain, dry), what would motivate you to do so?

5. What invasive species are you aware of?

6. Have you heard of Hydrilla? Eurasian watermilfoil? Brazilian elodea? 


\section{Appendix C: Survey questions post-boat wash}

Boater survey questions from the 2013 post-boat wash installation field season. The postboat wash survey is identical to the 2012 pre-boat wash survey with the addition of question 7 in the "Step 1: Observation Survey" (bold) and a change in question 6 in the "Step 2: Boater Survey" from "Would you use a boat wash station at Tenmile Lake?" (2012) to "Do you use the boat wash station here at Tenmile Lake?" (bold).

\section{Step 1: Observational Survey (to be filled out by researcher)}

1. Coming from in state/out of state? If out of state, name:

2. Kind of boat (motorized, non-motorized, canoe, fishing):

3. Details about the day (fishing tournament, etc):

4. Did the boat launch clean (no vegetation or invertebrates)?

5. Did the boat leave clean?

If not, what was on it (vegetation, invertebrates)?

6. Was there any effort to remove the fouling organisms?

Drain bilge/live well?

7. Did the boater use the boat wash station?

If yes, was the station staffed by a volunteer at the time?

\section{Step 2: Short Form Boater Survey (to be filled out by researcher)}

1. When was the last time your boat was in the water?

2. What waterbody did you and your boat come from?

What waterbody are you visiting next?

How many waterbodies have you visited in the last month?

3. Do you know about the invasive species prevention program permit? yes no

a. Have you ever been asked to show your permit? yes no

4. Are you aware of the phrase "clean, drain, dry"? yes no

a. Have you done this before? always sometimes never 
b. Do you know which parts of the boat might be susceptible to invasive species attachment? yes no

5. Have you ever been through a boat inspection station?
a. Oregon
b. other:

6. Do you use the boat wash station here at Tenmile Lake? yes no

a. If no, what would it take for you to change your behavior?

7. Are you aware of a state law that prohibits launching a boat that has invasive species on it?

yes no

8. Have you ever backflushed your motor in a lake after boating in salt water? always sometimes never

b. Do you know anyone who has? yes no

9. Are you aware of the state regulations regarding the use and movement of baitfish?

yes no

b. What about crayfish? yes no

10. Do you know how to report a suspected invasive species? yes no

a. Would you be able to visually recognize or name an invasive species? yes no

Name:

11. What types of activities do you engage in with your boat (e.g., sailing, fishing, recreation)?

12. Did you see any signage regarding invasive species when you arrived at the lake? yes no

Left the lake? yes no

\section{Step 3: In-Depth Boater Survey (to be filled out by researcher)}

1. How do invasive species affect you and your activities? 
a. Do they change your experience at the lake?

2. How important are invasive species as an issue in Oregon?

very ___ somewhat not at all

3. Where did you see or hear the information regarding aquatic invasive species?

4. If you do not wash your boat (clean, drain, dry), what would motivate you to do so?

5. What invasive species are you aware of?

6. Have you heard of Hydrilla? Eurasian watermilfoil? Brazilian elodea? 


\section{Appendix D: Waterbodies visited by boaters}

Table D1: All of the waterbodies last visited by surveyed boaters at Tenmile Lake during the 2012 and 2013 field seasons. The percentage is the number of boaters surveyed who last came from that waterbody. Waterbodies outside of Oregon are labeled with the state abbreviation.

\begin{tabular}{|c|c|c|c|c|c|c|c|}
\hline $\begin{array}{l}\text { Waterbody } \\
\text { Boat Came } \\
\text { From }\end{array}$ & Tenmile & $\begin{array}{l}\text { Siltcoos } \\
\text { Lake }\end{array}$ & Eel Lake & $\begin{array}{l}\text { Woahink } \\
\text { Lake }\end{array}$ & Loon Lake & $\begin{array}{l}\text { Umpqua } \\
\text { River }\end{array}$ & $\begin{array}{l}\text { Tahkenitch } \\
\text { Lake }\end{array}$ \\
\hline 2012 & $34.7 \%$ & $8.0 \%$ & $7.0 \%$ & $5.5 \%$ & $5.5 \%$ & $5.0 \%$ & $4.0 \%$ \\
\hline 2013 & $21.0 \%$ & $7.0 \%$ & $11.0 \%$ & $6.5 \%$ & $4.0 \%$ & $6.5 \%$ & $5.0 \%$ \\
\hline $\begin{array}{l}\text { Waterbody } \\
\text { Boat Came } \\
\text { From }\end{array}$ & $\begin{array}{l}\text { Smith } \\
\text { River }\end{array}$ & Coos Bay & $\begin{array}{l}\text { Fern } \\
\text { Ridge } \\
\text { Lake }\end{array}$ & $\begin{array}{l}\text { Klamath } \\
\text { Lake }\end{array}$ & $\begin{array}{l}\text { Lake } \\
\text { Shasta } \\
\text { (CA) }\end{array}$ & $\begin{array}{l}\text { Wincheste } \\
\text { r Bay }\end{array}$ & $\begin{array}{l}\text { Detroit } \\
\text { Lake }\end{array}$ \\
\hline 2012 & $2.5 \%$ & $2.0 \%$ & $2.0 \%$ & $2.0 \%$ & $1.5 \%$ & $1.5 \%$ & $1.0 \%$ \\
\hline 2013 & $0.5 \%$ & $3.0 \%$ & $1.0 \%$ & $2.0 \%$ & $0.5 \%$ & $4.0 \%$ & $1.5 \%$ \\
\hline $\begin{array}{l}\text { Waterbody } \\
\text { Boat Came } \\
\text { From }\end{array}$ & $\begin{array}{l}\text { Diamond } \\
\text { Lake }\end{array}$ & $\begin{array}{l}\text { Mercer } \\
\text { Lake }\end{array}$ & $\begin{array}{l}\text { Siuslaw } \\
\text { River }\end{array}$ & $\begin{array}{l}\text { Snake } \\
\text { River (ID) }\end{array}$ & $\begin{array}{l}\text { Willamett } \\
\text { e River }\end{array}$ & $\begin{array}{l}\text { Crane } \\
\text { Prairie }\end{array}$ & $\begin{array}{l}\text { Columbia } \\
\text { River }\end{array}$ \\
\hline 2012 & $1.0 \%$ & $1.0 \%$ & $1.0 \%$ & $1.0 \%$ & $1.0 \%$ & $0.5 \%$ & $0.5 \%$ \\
\hline 2013 & $1.5 \%$ & $2.5 \%$ & $1.0 \%$ & $0.0 \%$ & $0.5 \%$ & $1.0 \%$ & $0.5 \%$ \\
\hline $\begin{array}{l}\text { Waterbody } \\
\text { Boat Came } \\
\text { From }\end{array}$ & $\begin{array}{l}\text { Haystack } \\
\text { Reservoir }\end{array}$ & $\begin{array}{l}\text { Green } \\
\text { Peter } \\
\text { Lake }\end{array}$ & $\begin{array}{l}\text { Howard } \\
\text { Prairie }\end{array}$ & $\begin{array}{l}\text { Coquille } \\
\text { River }\end{array}$ & $\begin{array}{l}\text { Munsel } \\
\text { Lake }\end{array}$ & $\begin{array}{l}\text { Dorena } \\
\text { Lake }\end{array}$ & $\begin{array}{l}\text { Sutton } \\
\text { Lake }\end{array}$ \\
\hline 2012 & $0.5 \%$ & $0.5 \%$ & $0.5 \%$ & $0.0 \%$ & $0.0 \%$ & $0.0 \%$ & $0.0 \%$ \\
\hline 2013 & $2.0 \%$ & $1.5 \%$ & $1.0 \%$ & $3.0 \%$ & $2.0 \%$ & $2.0 \%$ & $1.0 \%$ \\
\hline $\begin{array}{l}\text { Waterbody } \\
\text { Boat Came } \\
\text { From }\end{array}$ & $\begin{array}{l}\text { Dexter } \\
\text { Lake }\end{array}$ & $\begin{array}{l}\text { Rogue } \\
\text { River }\end{array}$ & $\begin{array}{l}\text { Lost } \\
\text { Creek } \\
\text { Lake }\end{array}$ & Alsea Bay & $\begin{array}{l}\text { Deschutes } \\
\text { River }\end{array}$ & $\begin{array}{l}\text { Mayfield } \\
\text { Lake } \\
\text { (WA) }\end{array}$ & Suttle Lake \\
\hline 2012 & $0.0 \%$ & $0.0 \%$ & $0.0 \%$ & $0.5 \%$ & $0.0 \%$ & $0.0 \%$ & $0.0 \%$ \\
\hline 2013 & $1.0 \%$ & $1.0 \%$ & $1.0 \%$ & $0.5 \%$ & $0.5 \%$ & $0.5 \%$ & $0.5 \%$ \\
\hline $\begin{array}{l}\text { Waterbody } \\
\text { Boat Came } \\
\text { From }\end{array}$ & $\begin{array}{l}\text { Floras } \\
\text { Lake }\end{array}$ & $\begin{array}{l}\text { Paddock } \\
\text { Valley } \\
\text { (ID) }\end{array}$ & $\begin{array}{l}\text { Wickiup } \\
\text { Reservoir }\end{array}$ & $\begin{array}{l}\text { Flathead } \\
\text { Lake } \\
\text { (MT) }\end{array}$ & $\begin{array}{l}\text { Meiss } \\
\text { Lake (CA) }\end{array}$ & $\begin{array}{l}\text { Mackenzie } \\
\text { River }\end{array}$ & $\begin{array}{l}\text { Riffe Lake } \\
\text { (WA) }\end{array}$ \\
\hline 2012 & $0.0 \%$ & $0.0 \%$ & $0.0 \%$ & $0.5 \%$ & $0.05 \%$ & $0.5 \%$ & $0.5 \%$ \\
\hline
\end{tabular}




\begin{tabular}{|l|l|l|l|l|l|l|l|}
\hline 2013 & $\mathbf{0 . 5 \%}$ & $\mathbf{0 . 5 \%}$ & $\mathbf{0 . 5 \%}$ & $\mathbf{0 . 0 \%}$ & $\mathbf{0 . 0 \%}$ & $\mathbf{0 . 0 \%}$ & $\mathbf{0 . 0 \%}$ \\
\hline $\begin{array}{l}\text { Waterbody } \\
\text { Boat Came } \\
\text { From }\end{array}$ & $\begin{array}{l}\text { Siletz } \\
\text { River }\end{array}$ & $\begin{array}{l}\text { Silver } \\
\text { Lake } \\
\text { (WA) }\end{array}$ & $\begin{array}{l}\text { Timothy } \\
\text { Lake }\end{array}$ & $\begin{array}{l}\text { Garibaldi } \\
\text { Bay }\end{array}$ & & \\
\hline 2012 & $\mathbf{0 . 5 \%}$ & $\mathbf{0 . 5 \%}$ & $\mathbf{0 . 5 \%}$ & $\mathbf{0 . 5 \%}$ & & & \\
\hline 2013 & $\mathbf{0 . 0 \%}$ & $\mathbf{0 . 0 \%}$ & $\mathbf{0 . 0 \%}$ & $\mathbf{0 . 0 \%}$ & & & \\
\hline
\end{tabular}




\section{Appendix E: Raw data of survey answers}

Raw data of boater survey answers from the 2012 pre-boat wash field season and the 2013 post-boat wash field season with sample size. All questions are italicized and questions in bold are from the 2013 field season only.

\section{Step 1: Observational Survey (to be filled out by researcher)}

1. Coming from in statelout of state? If out of state, name:

$2012(\mathrm{n}=199)$ : Oregon=176, California $=13$, Washington $=5$, Idaho=3, Arizona $=2$ $2013(\mathrm{n}=200)$ : Oregon=185, California $=5$, Arizona $=4$, Washington=4, Idaho=1, Nevada $=1$

2. Kind of boat (motorized, non-motorized, canoe, fishing):

2012 ( $n=199)$ : Motorized Fishing=151, Motorized Recreation=31, Motorized Luxury=7, Canoe $=3$, Sail Boat $=3$, Jet Skis $=1$

2013 ( $\mathrm{n}=200$ ): Motorized Fishing=146, Motorized Recreation=40, Motorized Luxury=5, Canoe $=5$, Sail Boat $=3$, Jet Skis $=2$, Kayak $=2$

3. Details about the day (fishing tournament, etc):

$2012(n=199):$ No Tournament $=118$, Tenmile Open $=21$, Smaller Tournaments $=60$

2013 ( $\mathrm{n}=200)$ : No Tournament=146, Tenmile Open=33, Smaller Tournaments=21,

4. Did the boat launch clean (no vegetation or invertebrates)?

2012 ( $\mathrm{n}=199):$ Yes=75, No/Vegetation attached=2, Did not see boat launch=122

$2013(\mathrm{n}=200):$ Yes $=84$, No/Vegetation attached=3, Did not see boat launch=113

5. Did the boat leave clean?

If not, what was on it (vegetation, invertebrates)?

$2012(\mathrm{n}=199):$ Yes $=172$, No/Vegetation=20, No Invertebrates=5, No/Both Invertebrates and Vegetation $=2$

2013 ( $\mathrm{n}=200)$ : Yes=176, No/Vegetation=22, No Invertebrates=1, No/Both Invertebrates and Vegetation $=1$

6. Was there any effort to remove the fouling organisms? 
$2012(\mathrm{n}=199)$ : Yes, Nothing to Remove=68, Removed Fouling Organism=54, No, but Clean $=50, \mathrm{No}=23$, Yes, Did Not Get All Organisms $=4$

2013 ( $\mathrm{n}=200)$ : Yes, Nothing to Remove=71, Removed Fouling Organism=68, No, but Clean $=37, \mathrm{No}=21$, Yes, Did Not Get it All $=3$

Drain bilge/live well?

$2012(\mathrm{n}=199): \mathrm{Yes}=53, \mathrm{No}=79, \mathrm{~N} / \mathrm{A}=67$

$2013(n=200): Y e s=124, \mathrm{No}=39, \mathrm{~N} / \mathrm{A}=37$

8. Did the boater use the boat wash station?

2013 ( $\mathrm{n}=200)$ : Yes, Leaving Lake=63, Yes, Entering and Leaving Lake=6, $\mathrm{No}=131$

If yes, was the station staffed by a volunteer at the time?

2013 (n=0): *Boat wash station was never staffed during the 2013 field season

\section{Step 2: Boater Survey (to be filled out by researcher)}

1. When was the last time your boat was in the water?

$2012(\mathrm{n}=199): 1$ Day= 30, 2-6 Days $=52,7-14$ Days $=74,15-31$ Days $=23,32-364$

Days $=16,365+$ Days $=4$

$2013(\mathrm{n}=200): 1$ Day=36, 2-6 Days=75, 7-14 Days=66, 15-31 Days=19, 32-364 Days=3, $365+$ Days $=1$

2. What waterbody did you and your boat come from?

2012 ( $\mathrm{n}=199)$ : See Appendix D

2013 ( $\mathrm{n}=200)$ : See Appendix D

What waterbody are you visiting next?

2012 (n=199): Don't Know=17, Umpqua River=15, Tenmile Lake=71, Non-descript Bay=3, Woahink Lake=13, Eel Lake=12, Loon Lake=9, Coos Bay=8, Siltcoos Lake=7, Tahkenitch Lake=7, Siuslaw River $=4$, Fern Ridge Lake=3, Willamette River=3, Lake Shasta=3, Hagg Lake=2, Silutz Lake=2, Lake Washington=2, Detroit Lake=1, Klamath Lake=1, Winchester Bay=1, Coos River=1, Deschutes River=1, Diamond Lake=1, Alsea River=1, Haystack Reservoir=1, Mackenzie River=1, Smith River=1, Snake River=1, Suttle Lake=1, Sutton Lake=1, Charelston Bay=1, Foster Reservoir=1, Green Peter=1, Howard Prairie $=1$, Timothy Lake $=1$

2013 ( $\mathrm{n}=200$ ): Don't Know=19, Alsea Bay=1, Coos Bay=2, Coos River=1, Coquille River=3, Crane Prairie Reservoir=1, Detroit Lake=2, Devils Lake=1, Dorena Lake=4, 
East Lake =1, Eel Lake=17, Emigrant Lake=1, Fern Ridge=4, Howard Prairie=1, Klamath=3, Lake Billy Chinook=1, Loon Lake=3, Lost Creek Lake=2, Rogue River=2, Siltcoos=18, Siuslaw=7, Smith River=5, Suttle Lake=1, Sutton Lake=3, Tahlenitch Lake=12, Tenmile Lake=57, Umpqua River $=7$, Willamette River=1, Willow Lake=1, Winchester Bay $=5$, Woahink Lake $=13$, Yamhill River $=1$

How many waterbodies have you visited in the last month?

$2012(n=199): 1$ waterbody $=50,2=61,3=53,4=20,5=9,6=6$

$2013(n=200): 1$ waterbody $=19,2=47,3=62,4=39,5=20,6=9,7=3,10=1$

3. Do you know about the invasive species prevention program permit? yes no

$2012(\mathrm{n}=199):$ Yes $=140, \mathrm{No}=59$

$2013(n=200): Y e s=144, \mathrm{No}=56$

a. Have you ever been asked to show your permit? yes

$2012(\mathrm{n}=199): \mathrm{Yes}=22, \mathrm{No}=177$

$2013(\mathrm{n}=200): \mathrm{Yes}=54, \mathrm{No}=146$

4. Are you aware of the phrase "clean, drain, dry"? yes no

$2012(\mathrm{n}=199): \mathrm{Yes}=126, \mathrm{No}=73$

$2013(\mathrm{n}=200): \mathrm{Yes}=132, \mathrm{No}=68$

a. Have you done this before? always sometimes never $2012(\mathrm{n}=199):$ Yes/Always $=89$, Yes/Sometimes $=37$, Yes/Never $=0$, No/Always $=25$, No/Sometimes $=44, \mathrm{No} / \mathrm{Never}=4$

$2013(\mathrm{n}=200):$ Yes/Always $=118$, Yes/Sometimes $=14$, Yes/Never=0, No/Always=35, No/Sometimes $=32$, No/Never $=1$

b. Do you know which parts of the boat might be susceptible to invasive species attachment? yes no

$2012(\mathrm{n}=199): \mathrm{Yes}=191, \mathrm{No}=8$

$2013(n=200): Y e s=186, \mathrm{No}=14$

5. Have you ever been through a boat inspection station?

a. Oregon

b. other:

2012 ( $\mathrm{n}=199): \mathrm{No}=152, \mathrm{Yes} /$ Arizona=1, Yes/California=17, Yes/Lake Tahoe=1, Yes/Nevada $=1$, Yes/Oregon $=27$ 
2013 ( $\mathrm{n}=200): \mathrm{No}=146$, Yes/Arizona=3, Yes/California=7, Yes/California and Oregon=2, Yes/Oregon=38, Yes/Washington=4

6. Would you use a boat wash station at a boat ramp? yes no

$2012(\mathrm{n}=199): \mathrm{Yes}=160, \mathrm{No}=39$

a. If no, what would it take for you to change your behavior?

$2012(\mathrm{n}=48 *)$ : Cleans at Home/Better Equipment=22, Station Inconvenient/Too Long to Wait $=8$, Boated More Often=4, If Going from One Waterbody to Another=10, If Station was Enforced=2, Had a Better Boat=2

*9 surveyed boaters claimed they would use the boat wash station only if it had better equipment than their home boat wash equipment

7. Do you use the boat wash station here at Tenmile Lake? yes _ no $2013(\mathrm{n}=200): \mathrm{Yes}=78, \mathrm{No}=122$

a. If no, what would it take for you to change your behavior?

2013 ( $\mathrm{n}=126 *$ ): Cleans at Home/Better Equipment=39, Station Inconvenient/Too Long to Wait $=35$, Boated More Often=16, If Going from One Waterbody to Another=16, If Station was Enforced=2, Had a Better Boat=6, If the Station Had Heated Water=11

*4 surveyed boaters who use the boat wash station only use it if they are going to a different waterbody next.

8. Are you aware of a state law that prohibits launching a boat that has invasive species on it?

yes _ no

$2012(\mathrm{n}=199):$ Yes $=138, \mathrm{No}=61$

$2013(\mathrm{n}=200): \mathrm{Yes}=109, \mathrm{No}=91$

9. Have you ever backflushed your motor in a lake after boating in salt water?

always sometimes never

$2012(\mathrm{n}=199)$ : Always $=1$, Sometimes $=19$, Never $=179$

$2013(\mathrm{n}=200)$ : Always $=2$, Sometimes $=7$, Never $=191$

a. Do you know anyone who has? yes no

$2012(\mathrm{n}=199):$ Yes $=73, \mathrm{No}=126$

$2013(\mathrm{n}=200): \mathrm{Yes}=64, \mathrm{No}=136$ 
10. Are you aware of the state regulations regarding the use and movement of baitfish?

a. yes __ no

$2012(\mathrm{n}=199): \mathrm{Yes}=126, \mathrm{No}=73$

$2013(\mathrm{n}=200):$ Yes $=163, \mathrm{No}=37$

b. What about crayfish? __yes __ no

$2012(\mathrm{n}=199):$ Yes $=119, \mathrm{No}=80$

$2013(\mathrm{n}=200):$ Yes $=124, \mathrm{No}=76$

11. Do you know how to report a suspected invasive species? yes _ no

$2012(\mathrm{n}=199):$ Yes $=89, \mathrm{No}=110$

$2013(\mathrm{n}=200): \mathrm{Yes}=84, \mathrm{No}=116$

a. Would you be able to visually recognize or name an invasive species? yes no

$2012(\mathrm{n}=199): \mathrm{Yes}=148, \mathrm{No}=51$

$2013(\mathrm{n}=200):$ Yes $=154, \mathrm{No}=46$

Name:

$2012(\mathrm{n}=148 *)$ : Zebra mussel=89, New Zealand mud snail=29, hydrilla=28, green $c r a b=16$, trout species $=16$, Brazilian elodea $=27$, quagga mussel $=12$, yellow perch $=12$, Eurasian watermilfoil $=11$, rusty crayfish $=11$, northern pike $=10$, white flowered lilypads (odorata) $=9$, shad $=8$, catfish and bullheads $=3$, bass $=3$, swollen bladderwort $=3$, nutria $=2$, Asian freshwater clams $=1$, carp $=1$, bluegill $=1$, parrot feather $=1$, softshell clam $=2$, terrestrial vegetation $=17$, terrestrial faun $=7$

$2013(\mathrm{n}=154 *)$ : Zebra mussel=118, New Zealand mud snail $=34$, hydrilla $=20$, green $\mathrm{crab}=7$, trout species $=26$, Brazilian elodea $=13$, quagga mussel $=19$, yellow perch $=13$, Eurasian watermilfoil $=13$, rusty crayfish $=13$, northern pike $=6$, white flowered lilypads (odorata) $=4$, $\operatorname{shad}=14$, bass $=10$, nutria $=2$, Asian freshwater clams $=1$, carp $=5$, bluegill $=1$, parrot feather $=5$, snakehead fish $=4$, reed canary grass $=5$, round goby $=2$, terrestrial vegetation $=30$, terrestrial fauna $=16$

*Surveyed boaters named one or more species

12. What types of activities do you engage in with your boat (e.g., sailing, fishing, recreation)?

$2012(\mathrm{n}=199)$ : Fishing $=103$, Recreation $=40$, Recreation $\&$ Fishing $=24$, Leisure $=23$, Transportation $=6$, Sailing $=3$ 
2013 ( $\mathrm{n}=200)$ : Fishing $=128$, Recreation=30, Recreation \& Fishing=22, Leisure=15, Transportation $=2$, Sailing $=3$

13. Did you see any signage regarding invasive species when you arrived at the lake? yes __ no

$2012(\mathrm{n}=199): \mathrm{Yes}=50, \mathrm{No}=149$

$2013(\mathrm{n}=200): \mathrm{Yes}=63, \mathrm{No}=137$

Left the lake? yes _ no

$2012(\mathrm{n}=199):$ Yes $=11, \mathrm{No}=188$

$2013(\mathrm{n}=200):$ Yes $=9, \mathrm{No}=191$

\section{Step 3: In-Depth Boater Survey (to be filled out by researcher)}

1. How do invasive species affect you and your activities?

$2012(\mathrm{n}=69)$ : Avoid areas that may have invasives $=5$, More aware of negative impacts $=17$, inhibits exercise $=1$, Invasive species don't affect my activities $=9$, More permits and checkpoints $=8$, more rules and regulations to follow $=8$, Take better care of boat and equipment $=22$, Invasives have benefitted $m e=2$

$2013(\mathrm{n}=57)$ : Avoid areas that may have invasives $=12$, More aware of negative impacts $=5$, Invasive species don't affect my activities $=10$, More rules and regulations to follow $=8$, Take better care of boat and equipment $=21$, Invasives have benefitted me $=1$

a. Do they change your experience at the lake?

$2012(\mathrm{n}=68)$ : Yes $/$ Avoid areas $=5$, Fishing is worse $=4$, Less Enjoyable $=9, \mathrm{No}=50$, 2013 ( $\mathrm{n}=57)$ : Yes/ Avoid areas=7, Fishing is worse=7, Less Enjoyable=5, No=37, Better fishing $=1$

2. How important are invasive species as an issue in Oregon?

very somewhat not at all

$2012(\mathrm{n}=69)$ : Very $=47$, Somewhat $=22$, Not at All $=0$

$2013(\mathrm{n}=57)$ : Very $=30$, Somewhat $=27$, Not at All $=0$

3. Where did you see or hear the information regarding aquatic invasive species?

$2012\left(\mathrm{n}=69^{*}\right)$ : Education=6, Signage $=21$, Word of Mouth=21, News=36, ODFW Newsletter $=5$, Internet $=8$, No Info seen $=3$

$2013\left(\mathrm{n}=58^{*}\right)$ : Education=4, Signage $=20$, Word of Mouth=22, News=20, ODFW Newsletter $=5$, Internet $=12$, Books $=3$, Permit $=1$ 
*Some surveyed boaters provided multiple sources

4. If you do not wash your boat (clean, drain, dry), what would motivate you to do so?

$2012(\mathrm{n}=68)$ : Boating more often=4, If cleaning was quicker and easier=2, A boat wash station $=7$, Washes boat $=55$

2013 ( $\mathrm{n}=57)$ : Boating more often $=3$, Boating in multiple waterbodies $=3$, A nicer boat $=3$, More boat wash stations $=2$, Washes boat $=46$

5. What invasive species are you aware of?

2012 ( $\mathrm{n}=69)$ : Answers included to the answers from question 11 in Step 2 of the survey. 2013 ( $\mathrm{n}=57)$ : Answers included to the answers from question 11 in Step 2 of the survey.

6. Have you heard of Hydrilla? Eurasian watermilfoil? Brazilian elodea?

2012 (n=69): Hydrilla/Yes=27, Hydrilla/No=41, Eurasian watermilfoil/Yes=18, Eurasian watermilfoil $/ \mathrm{No}=50$, Brazilian elodea $/ \mathrm{Yes}=13$, Brazilian elodea $/ \mathrm{No}=55$,

2013 (n=57): Hydrilla/Yes=17, Hydrilla/No=40, Eurasian watermilfoil/Yes=15, Eurasian watermilfoil $/ \mathrm{No}=42$, Brazilian elodea/Yes $=7$, Brazilian elodea $/ \mathrm{No}=50$, 
Appendix F: Boat ramp signage

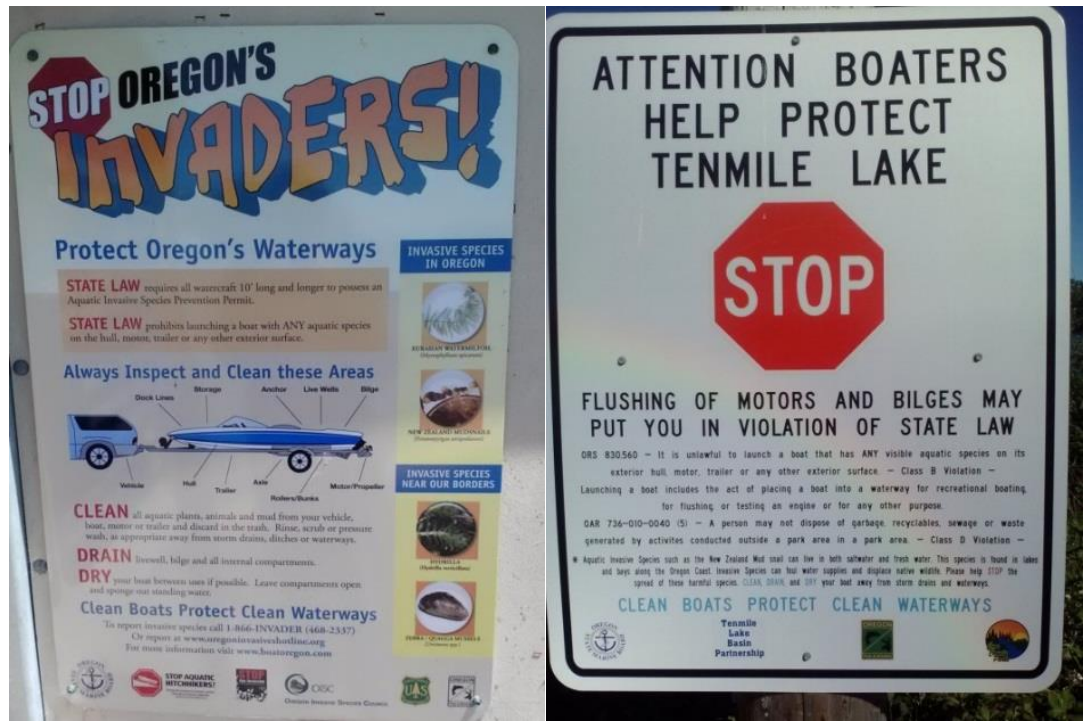

Figure F1: Signs at Tenmile Lake boat ramp instructing visitors on invasive species and proper boat cleaning procedure (left) and warning against back-flushing motors (right). The back-flushing sign (right) was installed in between the 2012 and 2013 field season. Photos were taken by Sam Cimino in the 2013 (post-boat wash) field season.

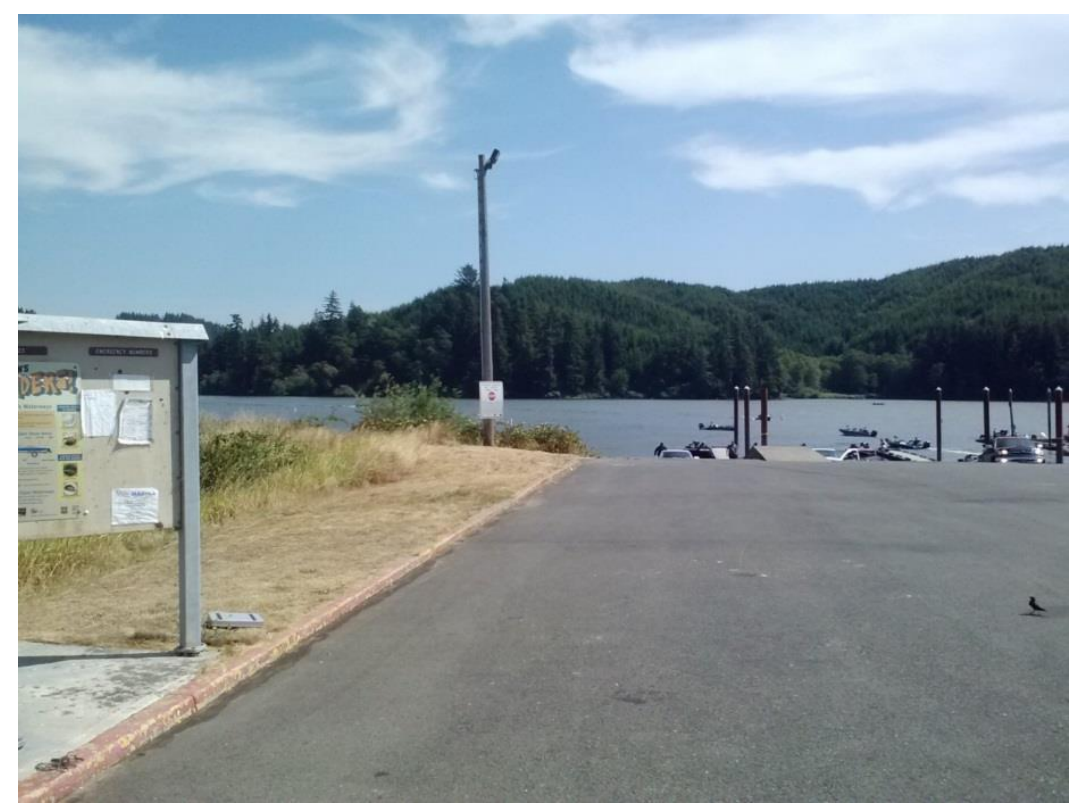

Figure F2: Tenmile Lake public boat ramp with the "Aquatic Invaders" sign (far left) approximately 30 meters distance from the boat ramp and the "Warning of BackFlushing" sign (near boat ramp). Photo was taken during the 2013 field season (Sam Cimino). 


\section{Appendix G: Sampling method}

Appendix $G$ includes a conceptual diagram on proper quantitative macroinvertebrate sampling protocol of the riverine and lake ecosystems. The conceptual diagram was created by Valance Brenneis to assist with future sampling procedure.

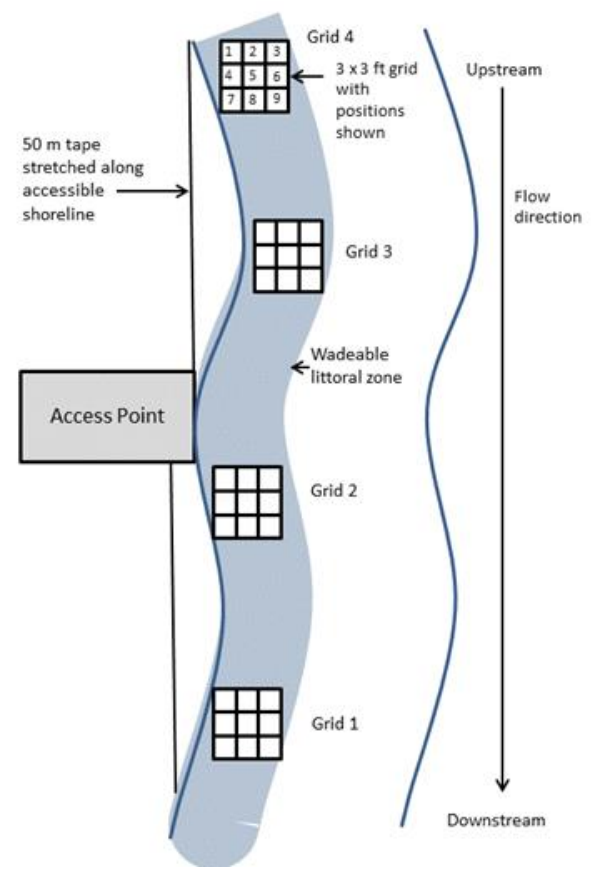

Figure G1. Placement of imaginary grids for collection of eight $1 \mathrm{ft}^{2}$ samples substrate for benthic invertebrate collection. Figure created by Valance Brenneis. 


\section{Appendix H: River data}

Appendix $\mathrm{H}$ includes the data that influenced addressing both upstream and downstream sites of river systems to be treated as independent replicates. Similarly, these riverine sites sampled from 2006-2008 and from 2012-2013 were also deemed independent of each other.

Table H1. Differences in downstream (DS) and upstream (US) reaches of the sampled rivers. Data was collected by Valance Brenneis and analysis was performed by Valance Brenneis and Sam Cimino.

\begin{tabular}{lrrl}
\hline Site & Distance from Mouth $(\mathbf{k m})$ & Elevation $(\mathbf{m})$ & Substrate \\
\hline Deschutes DS & 0.32 & 70 & Silt/Bedrock \\
Deschutes US & 32.3 & 260 & Gravel/Bedrock \\
John Day DS & 4.72 & 170 & Gravel \\
John Day US & 24.8 & 400 & Gravel \\
Siuslaw DS & 15 & Silt \\
Siuslaw US & 6.52 & 75 & Bedrock \\
Umpqua DS & 28.0 & 5 & Silt/Sand \\
Umpqua US & 14.6 & 25 & Bedrock \\
\hline
\end{tabular}




\section{Appendix I: Stable isotope maps}

Appendix I includes graphs of the stable isotope signatures of the sampled taxa at the lake and estuary sites collected in the summer of 2013. Color required to fully understand food webs.

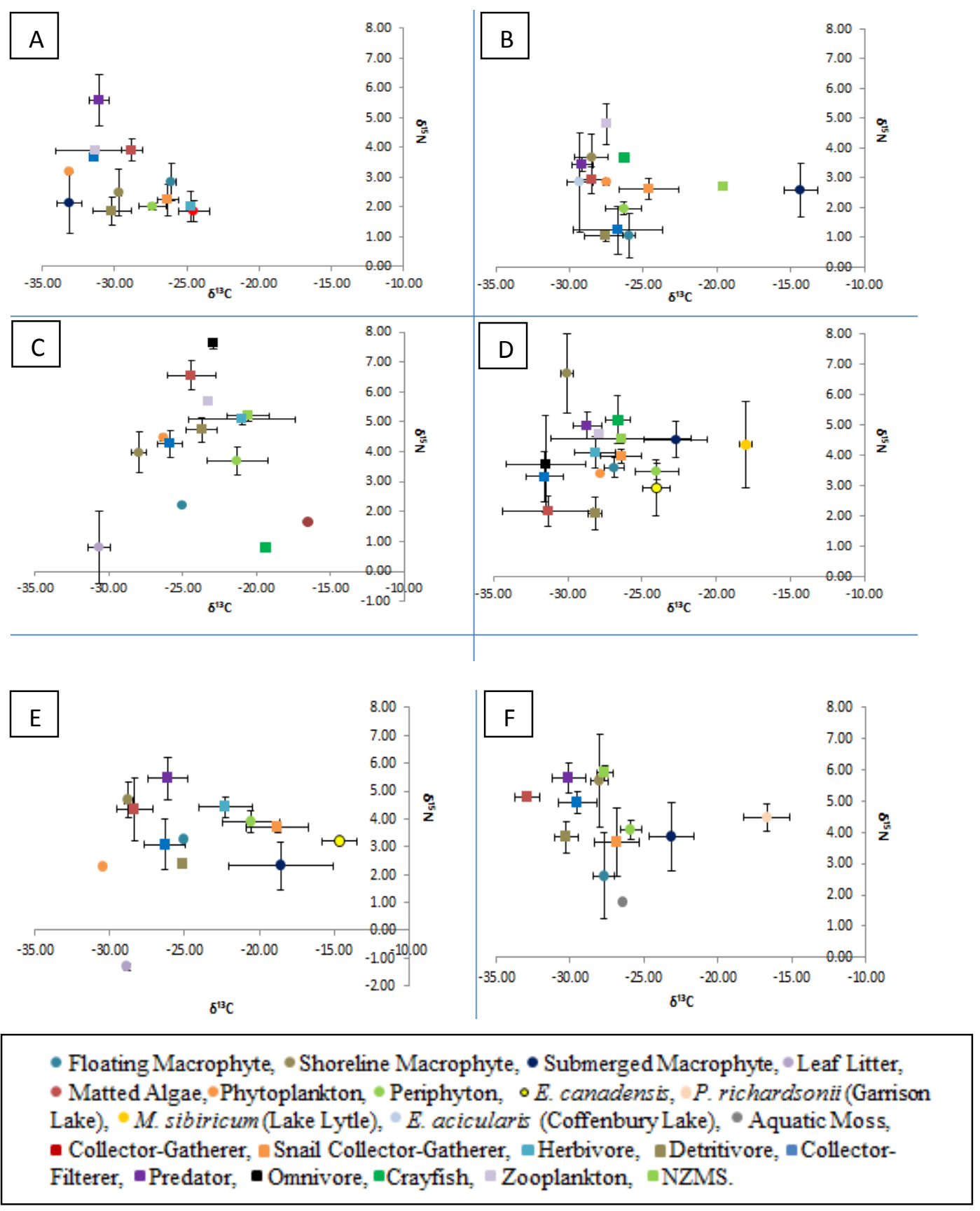

Figure I1. A. Cullaby Lake, B. Coffenbury Lake, C. Devils Lake (Lincoln Co.), D. Lake Lytle, E. Mercer Lake, and F. Garrison Lake. Average stable isotope signatures of the benthic food webs with standard error bars for $\delta^{13} \mathrm{C}$ and $\delta^{15} \mathrm{~N}$. Horizontal error bars represent a range in $\delta^{13} \mathrm{C}$ indicating a range in consumer diet. Vertical error bars represent a range in $\delta^{15} \mathrm{~N}$ indicating a range in trophic position. 


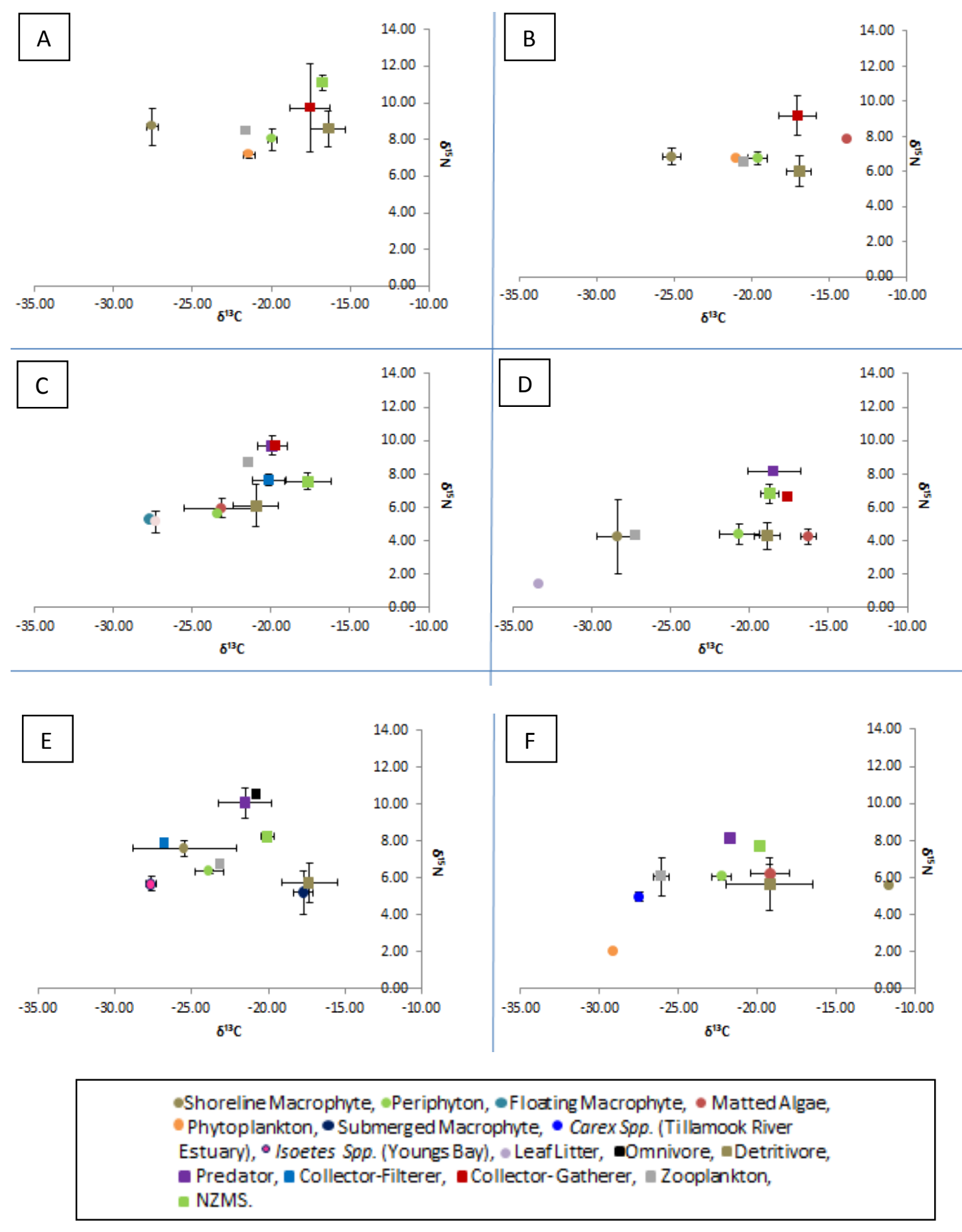

Figure I2. A. Rogue River Estuary, B. Coquille River Estuary, C. Yaquina River Estuary, D. Nestucca River Estuary, E. Columbia River Estuary at Youngs Bay, and F. Tillamook River Estuary at Memaloose Point. Average stable isotope signatures of the benthic food webs with standard error bars for $\delta^{13} \mathrm{C}$ and $\delta^{15} \mathrm{~N}$. 


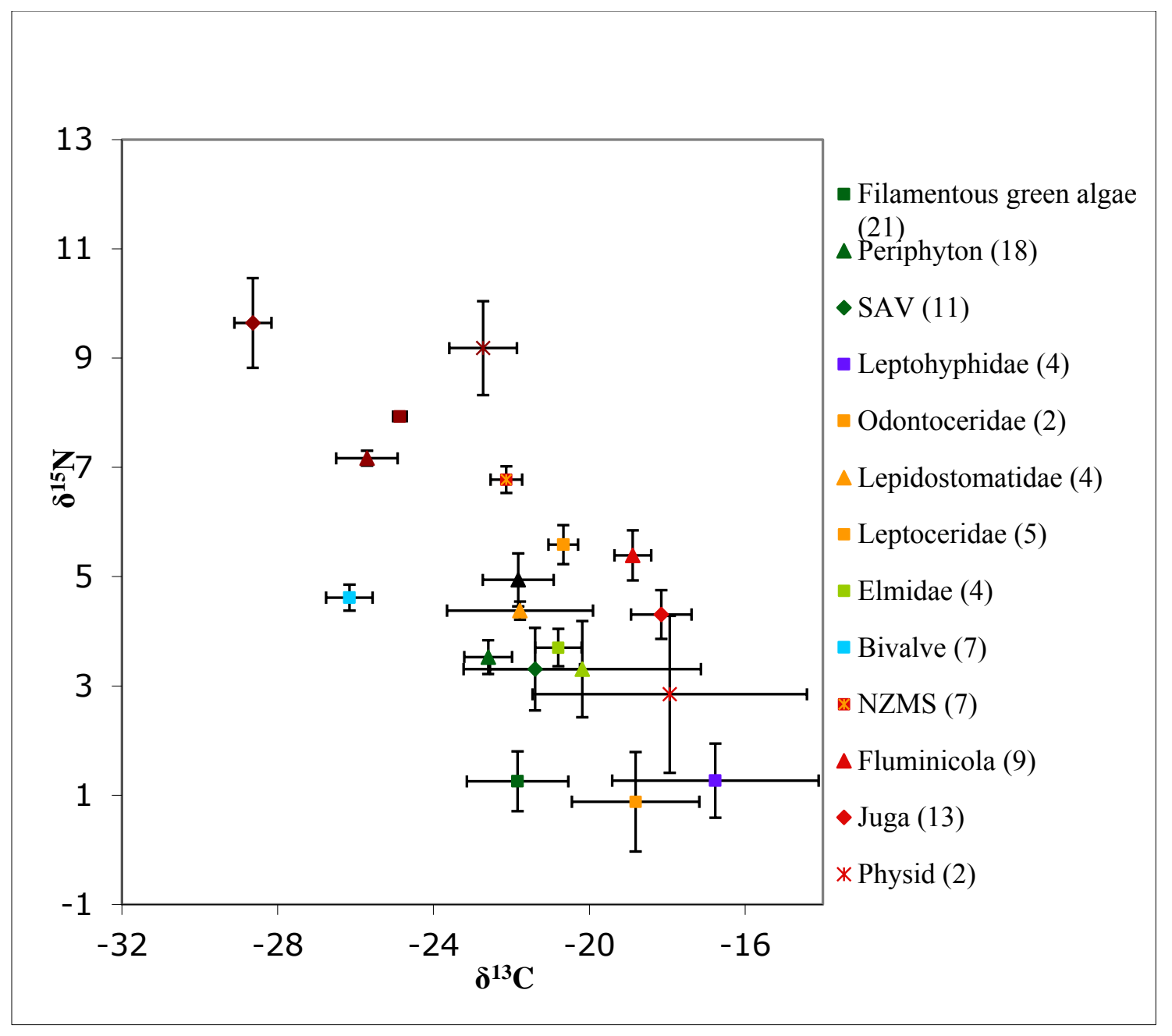

Figure I3. Umpqua River and Siuslaw River upstream and downstream stable isotope samples. The figure was produced and samples were collected by Dr. Valance Brenneis. The number in parentheses indicates the number of samples analyzed for stable isotopes. 


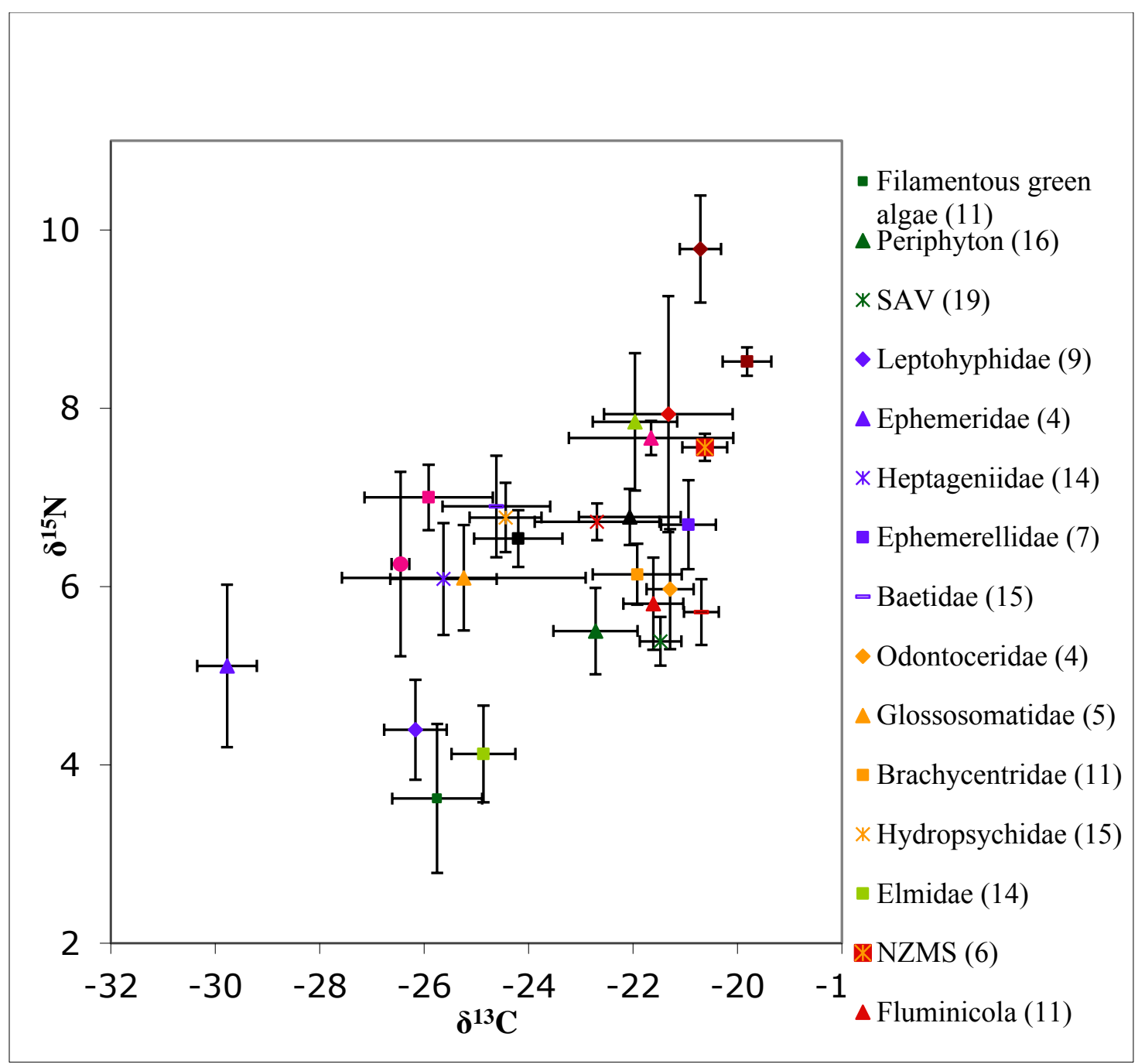

Figure I4. Deschutes River and John Day River upstream and downstream stable isotope samples. The figure was produced and samples were collected by Dr. Valance Brenneis. The number in parentheses indicates the number of samples analyzed for stable isotopes. 


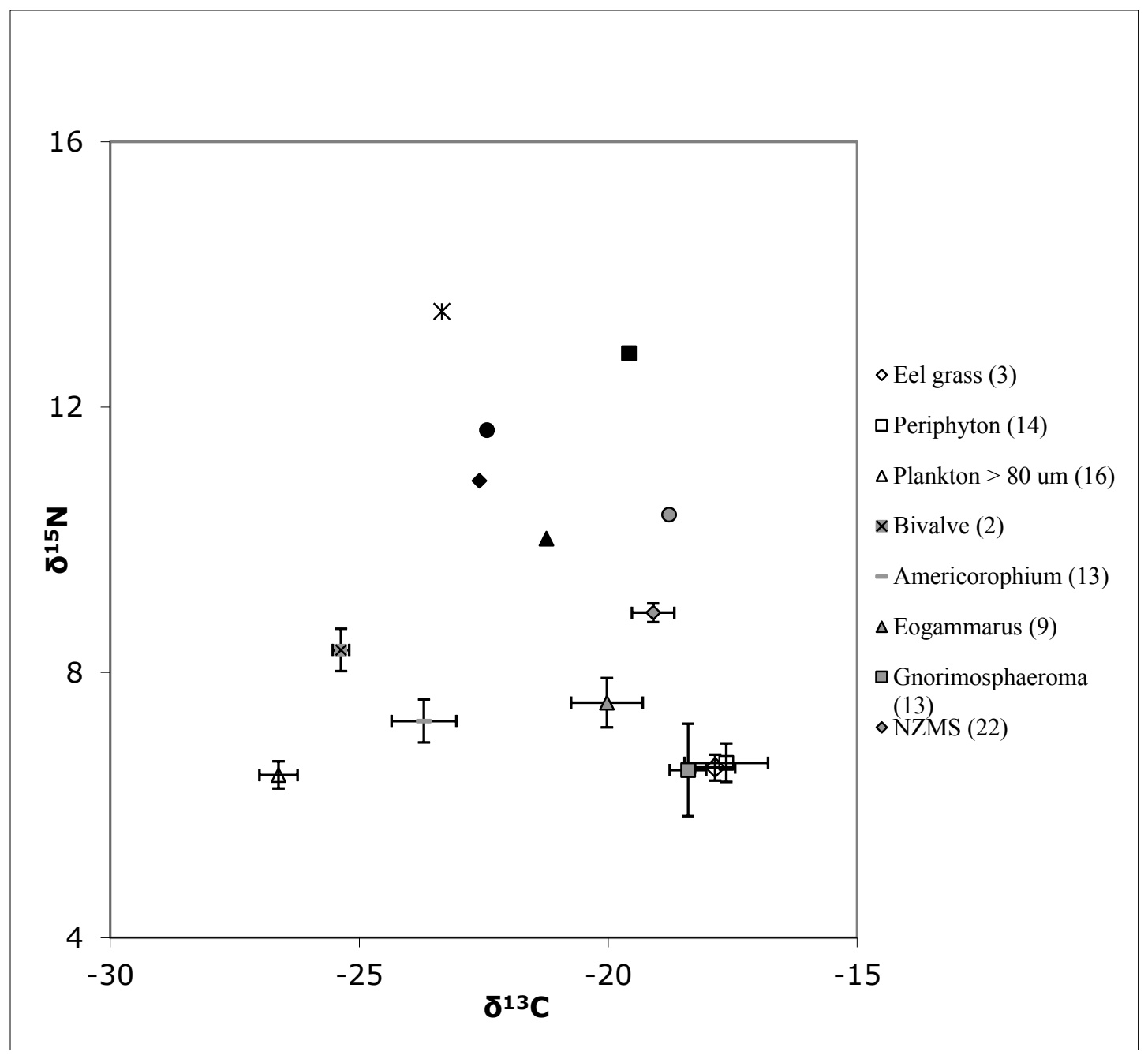

Figure I5. Columbia River Estuary at Youngs Bay stable isotope samples. The figure was produced and samples were collected by Dr. Valance Brenneis. The number in parentheses indicates the number of samples analyzed for stable isotopes. 


\section{Appendix J: Convex hulls depicting feeding ranges}

Appendix $\mathrm{J}$ includes all of the convex hulls depicting the feeding ranges of NZMS and a specific feeding group (herbivore [J1], detritivore [J2], omnivore [J3], and predator [J4]) at each sampling site with enough individuals with stable isotope signatures $(3+)$ to create a convex hull and observe feeding range overlap.
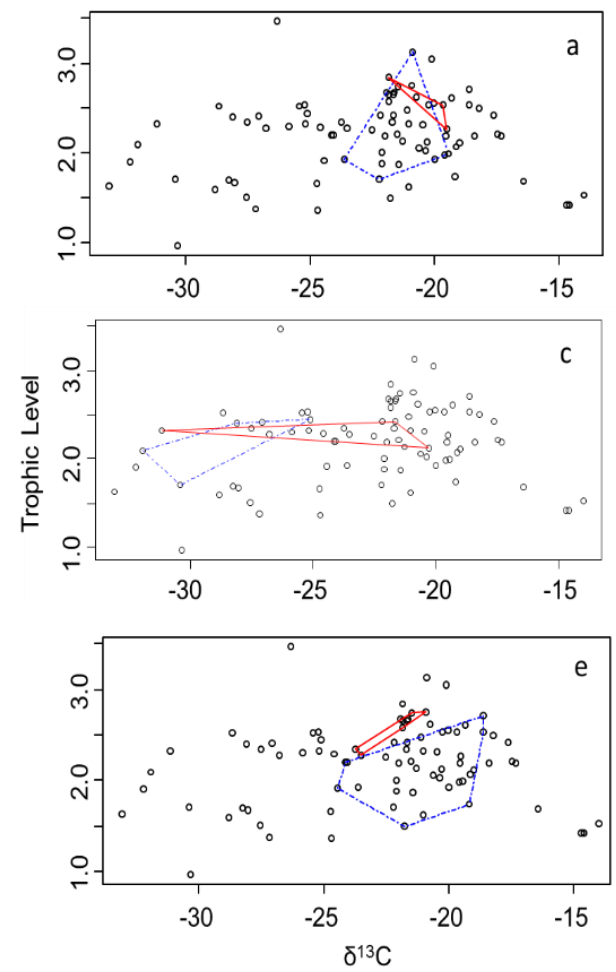
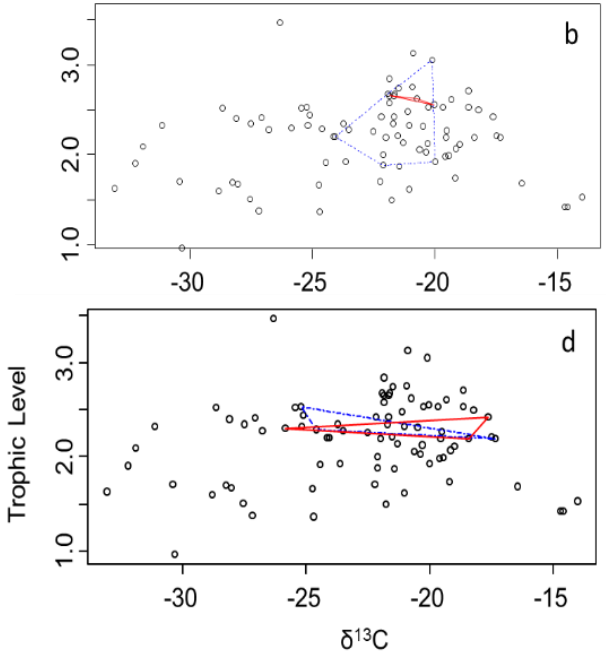

Figure J1. a. Deschutes River downstream, b. Deschutes River upstream, c. Lake Lytle, d. Devils Lake (Lincoln Co.), and e. Umpqua River downstream, stable isotope signatures of the benthic invertebrates with convex hulls depicting the feeding ranges of herbivores (dashed-blue polygons) and NZMS (solid-red polygons). 

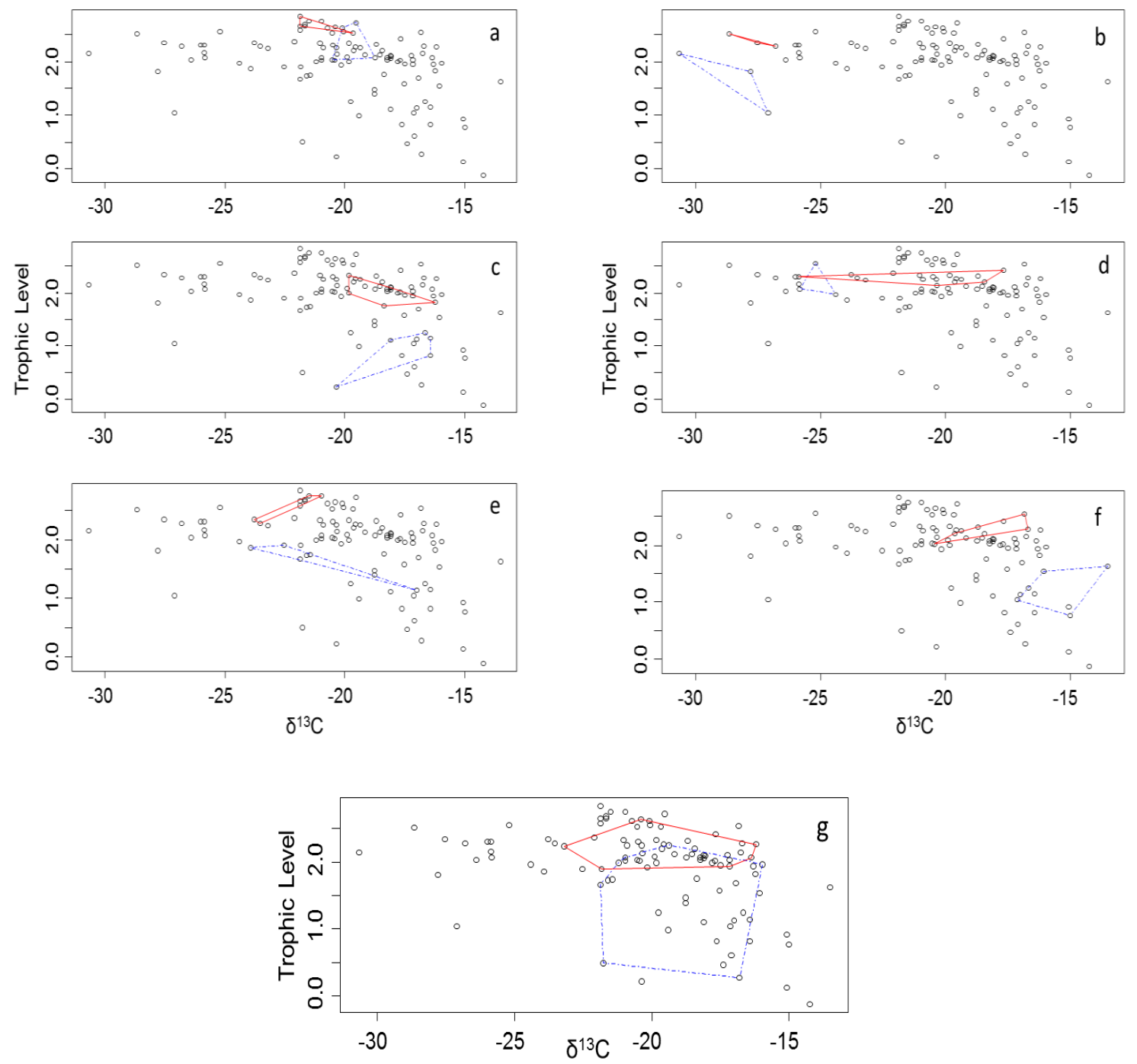

Figure J2. a. Deschutes River upstream, b. Garrison Lake, c. Nestucca Estuary, d. Devils Lake (Lincoln Co.), e. Umpqua River downstream, f. Rogue Estuary, and g. Youngs Bay stable isotope signatures of the benthic invertebrates with convex hulls depicting the feeding ranges of detritivores (dashed-blue polygons) and NZMS (solid-red polygons). 

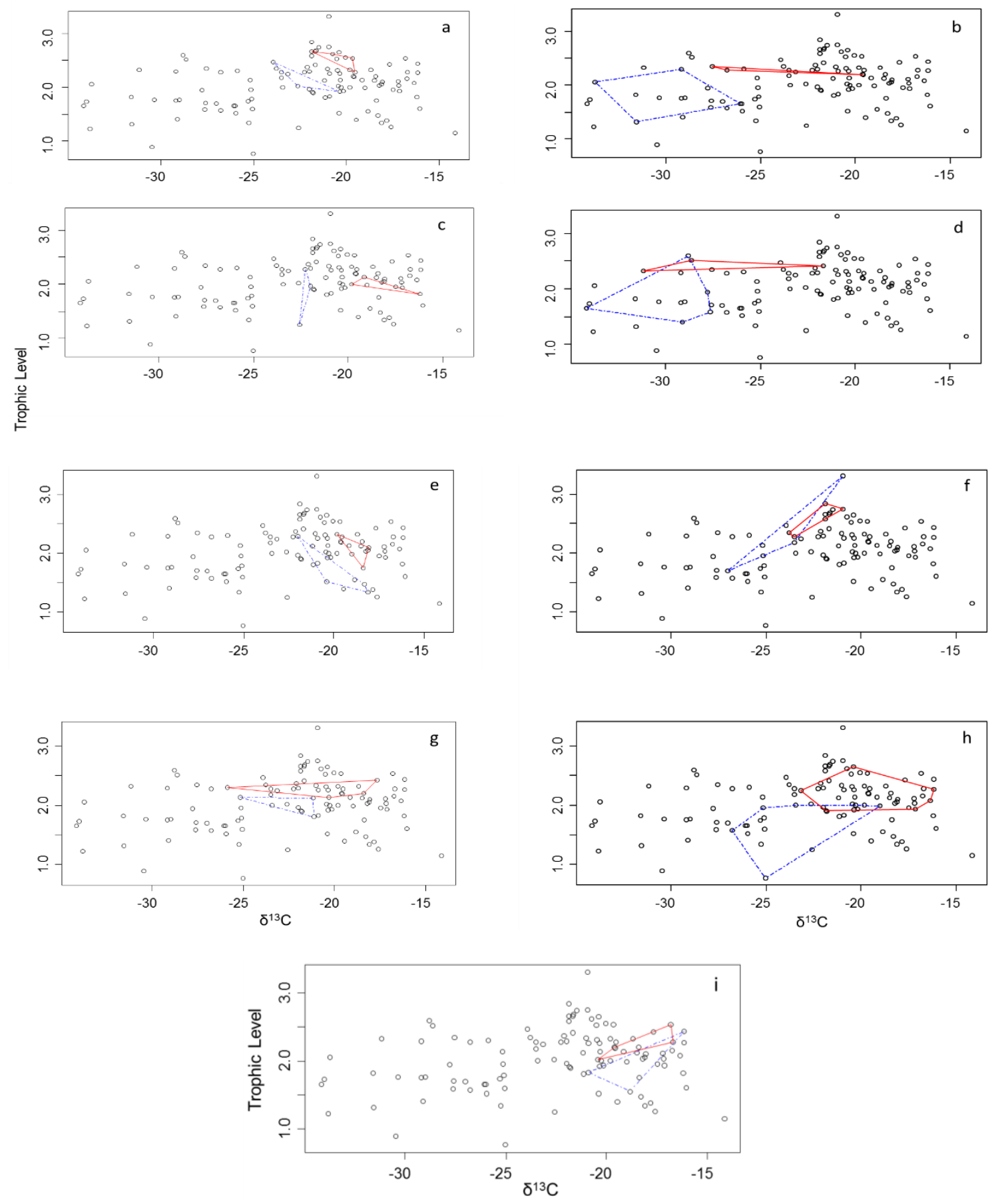

Figure J3. a. Deschutes River downstream, b. Coffenbury Lake, c. Yaquina Estuary, d. Lake Lytle, e. Nestucca Estuary, f. Umpqua River downstream, g. Devils Lake (Lincoln Co.), h. Youngs Bay, and i. Rogue Estuary stable isotope signatures of the benthic invertebrates with convex hulls depicting the feeding ranges of omnivores (dashed-blue polygons) and NZMS (solid-red polygons). 

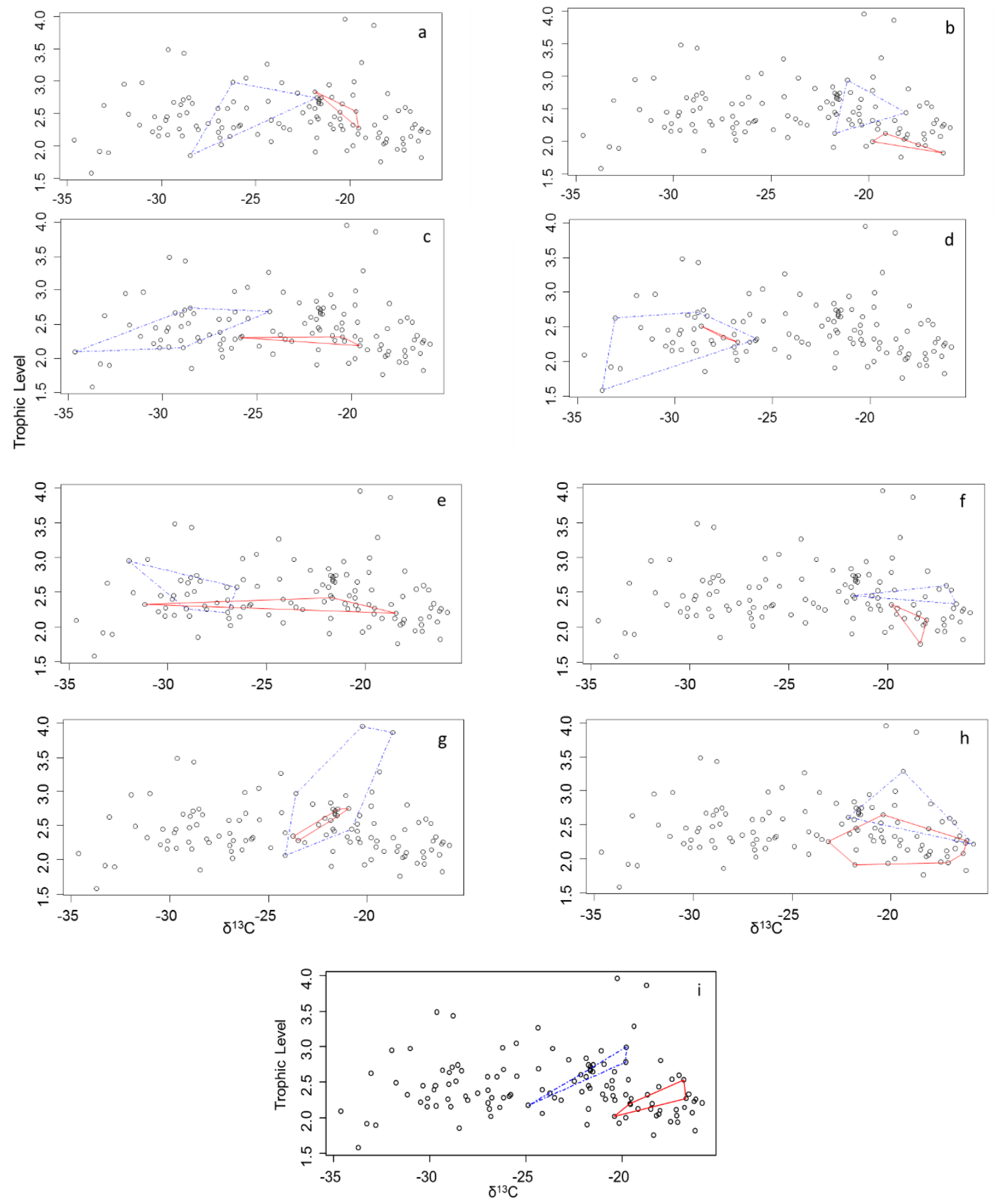

Figure J4. a. Deschutes River downstream, b. Tillamook Estuary, c. Devils Lake (Lincoln Co.), d. Garrison Lake, e. Lake Lytle, f. Nestucca Estuary, g. Umpqua River downstream, h. Youngs Bay, and i. Rogue Estuary stable isotope signatures of the benthic invertebrates with convex hulls depicting the feeding ranges of predators (dashed-blue polygons) and NZMS (solid-red polygons). 


\section{Appendix K: NZMS densities}

Appendix K includes the densities of NZMS at a particular location per square meter with an included standard error.

Table K1. The average densities and standard error (SE) of New Zealand mud snails per square meter at each sampling location. Each location was sampled for densities at five different sites. Freshwater River data 2006-2008 and 2012-2013 and Youngs Bay data from 2006-2008 and 2012 was collected and analyzed by Valance Brenneis.

\begin{tabular}{|c|c|c|c|}
\hline Ecosystem & Location/Year & $\begin{array}{l}\text { Average Density } \\
\left(\text { Individuals } \cdot \mathbf{m}^{-2}\right)\end{array}$ & SE \\
\hline \multirow[t]{6}{*}{ Freshwater Lakes } & Coffenbury/2013 & 204.01 & 196.04 \\
\hline & Cullaby/2013 & 0.00 & 0.00 \\
\hline & Lytle/2013 & 474.34 & 242.76 \\
\hline & Devils/2103 & $1,611.79$ & 442.89 \\
\hline & Mercer/2013 & 0.00 & 0.00 \\
\hline & Garrison/2013 & 280.75 & 189.38 \\
\hline \multirow[t]{8}{*}{ Brackish Estuaries } & Youngs Bay/ 2013 & $12,829.91$ & $2,682.31$ \\
\hline & Tillamook/2013 & 157.43 & 65.87 \\
\hline & Nestucca/2013 & $1,116.88$ & 375.97 \\
\hline & Yaquina/2013 & 391.47 & 179.27 \\
\hline & Coquille/2013 & 0.00 & 0.00 \\
\hline & Rogue/2013 & $9,984.65$ & $4,505.50$ \\
\hline & Youngs Bay/2006-2008 & $8,706.9$ & $2,987.64$ \\
\hline & Youngs Bay/2012 & $10,454.34$ & 463.47 \\
\hline \multirow[t]{16}{*}{ Freshwater Rivers } & Deschutes DS/2006 & 2.69 & 2.26 \\
\hline & Deschutes DS/2012 & 0.34 & 0.34 \\
\hline & Deschutes US/2006-2008 & 20.32 & 13.19 \\
\hline & Deschutes US/2012 & 53.57 & 51.23 \\
\hline & John Day DS/2006 & 0.00 & 0.00 \\
\hline & John Day DS/2012 & 0.00 & 0.00 \\
\hline & John Day US/2006 & 0.00 & 0.00 \\
\hline & John Day US/2012 & 0.00 & 0.00 \\
\hline & Siuslaw DS/2006 & 0.00 & 0.00 \\
\hline & Siuslaw DS/2012-2013 & 97.80 & 6.41 \\
\hline & Siuslaw US/2006 & 0.00 & 0.00 \\
\hline & Siuslaw US/2012 & 0.00 & 0.00 \\
\hline & Umpqua DS/2006-2008 & $1,730.03$ & 915.21 \\
\hline & Umpqua DS/2012-2013 & 31.76 & 11.77 \\
\hline & Umpqua US/2006 & 0.00 & 0.00 \\
\hline & Umpqua US/2012 & 0.00 & 0.00 \\
\hline
\end{tabular}

